\title{
Interaction between \\ entomopathogenic bacteria and their hosts
}

\author{
Dissertation \\ zur Erlangung des Doktorgrades \\ der Naturwissenschaften
}

vorgelegt beim Fachbereich für Biowissenschaften (15)

der Johann Wolfgang Goethe-Universität

in Frankfurt am Main

von

Helena Vural geb.: Eresmann

Frankfurt am Main 2021

D30 

vom Fachbereich für Biowissenschaften (15) der

Johann Wolfgang Goethe-Universität als Dissertation angenommen.

Dekan: Prof. Dr. Sven Klimpel

Gutachter: Prof. Dr. Helge B. Bode

Zweitgutachter: Prof. Dr. Ralf Heermann

Datum der Disputation: 


\section{Table of contents}

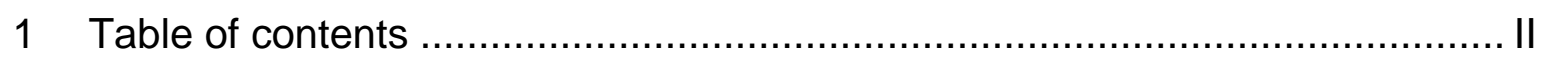

2 Table of abbreviations .................................................................. IV

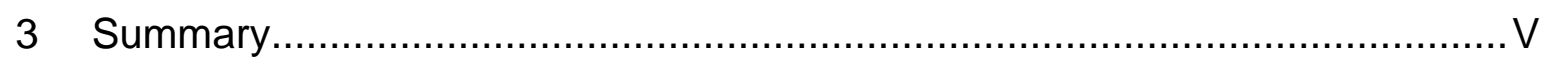

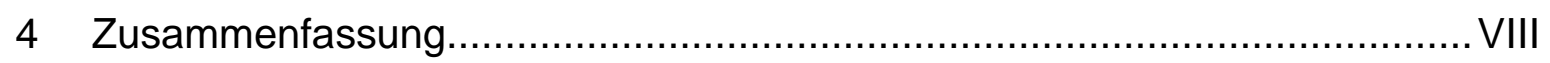

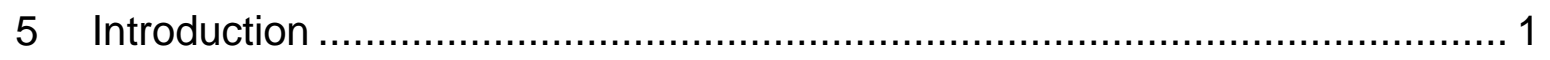

5.1 Drug development from nature: specialized metabolites ...................... 1

5.2 The tritrophic relationship between bacteria, nematode and insect: the life cycle of Heterorhabditis and Steinernema ............................................. 2

5.3 Photorhabdus and Xenorhabdus kill the insect ................................. 4

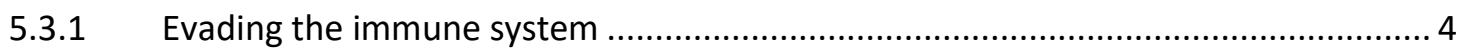

5.3.2 Killing the insect prey and protecting it from competition ...................................... 6

5.4 Photorhabdus and Xenorhabdus support nematode development........... 9

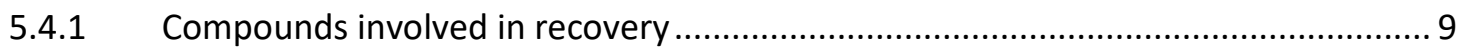

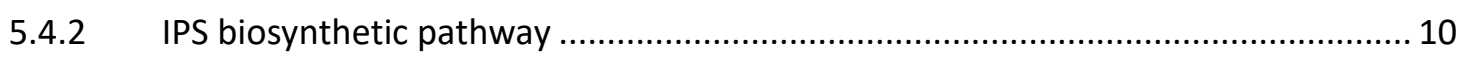

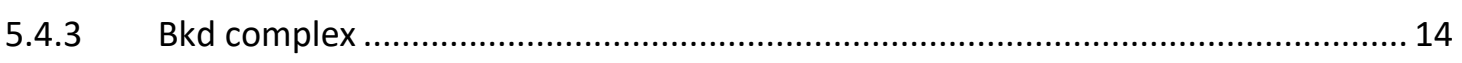

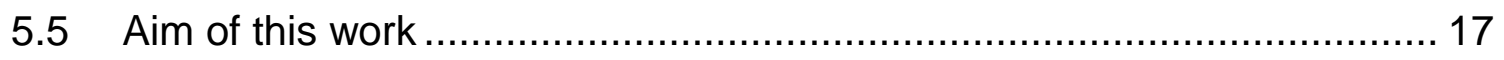

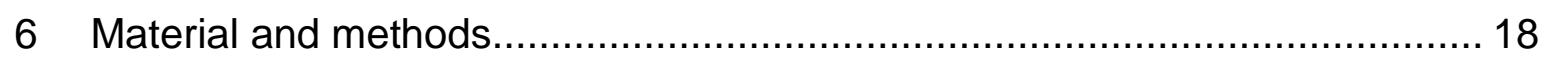

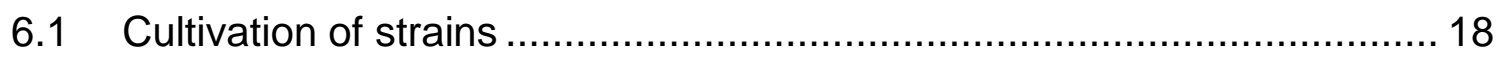

6.2 Isotope labelling and reverse feeding ........................................ 18

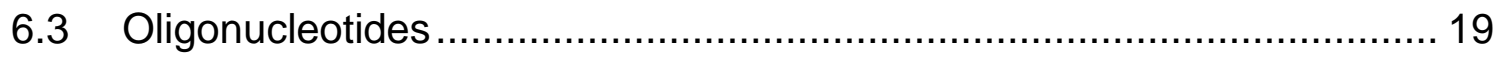

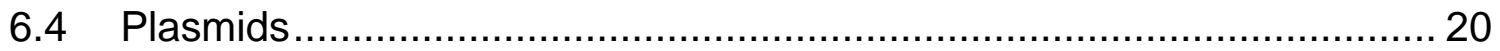

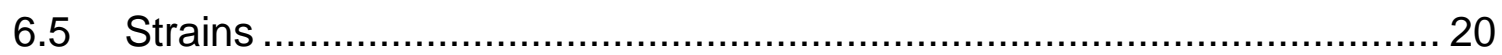

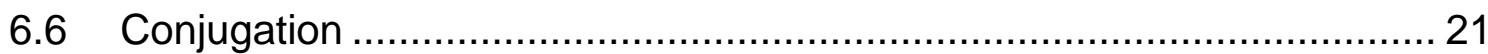

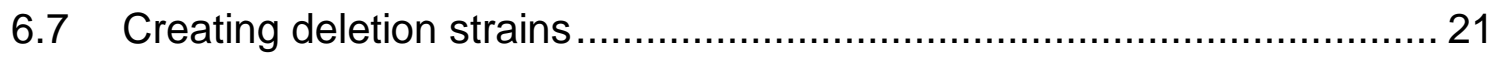

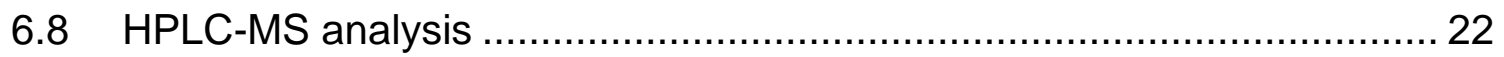

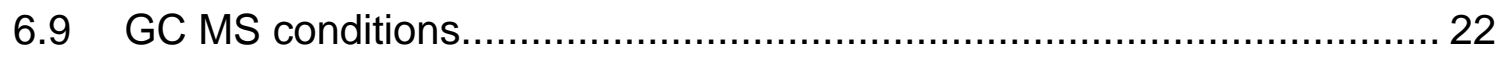


6.10 Extracting lipids from bacteria ................................................. 23

$6.11 \quad$ Nematode bioassay ............................................................ 24

6.12 Scanning electron microscopy (SEM) ………............................. 26

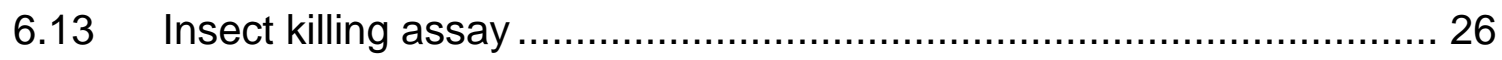

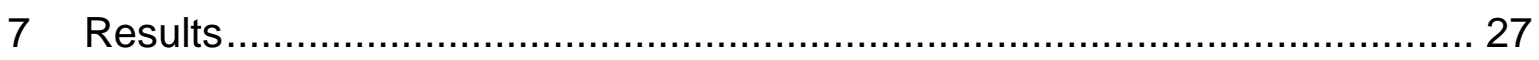

7.1 The influence of isopropyl stilbene towards nematode development ......27

7.1.1 Nematode bioassay: Finding the right strain for negative control ......................... 27

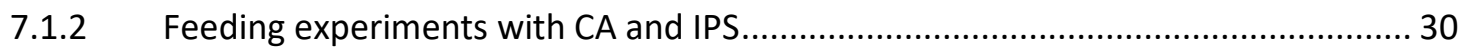

7.2 Branched-chain fatty acids are essential for IJ development ................. 32

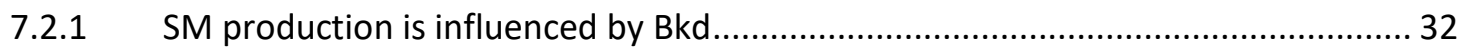

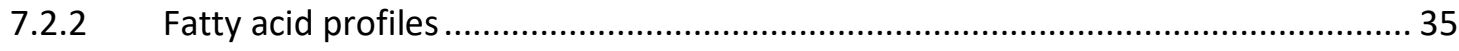

7.3 Epoxy stilbene derivatives with unknown function................................ 43

7.3.1 HPLC-MS based characterisation of unknown EPS adducts .................................... 43

7.3.2 Insect extracts reveal another unknown EPS derivatives ....................................... 54

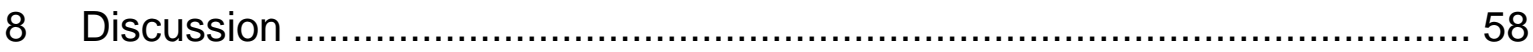

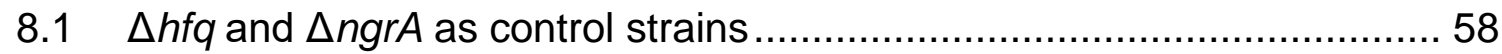

8.2 The influence of stilbenes and derivatives towards nematode development 60

8.3 Branched-chain fatty acids are essential for IJ development .................63

8.3.1 The hidden effect of cod liver oil towards NG-IJ development ...............................63

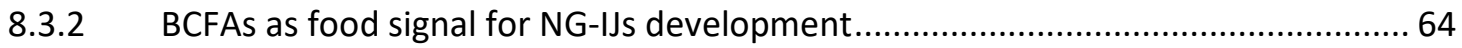

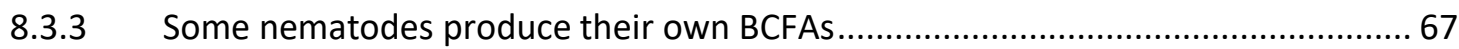

8.4 New epoxy stilbene derivatives with unknown function .......................... 68

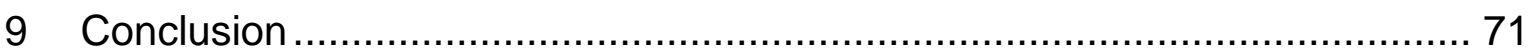

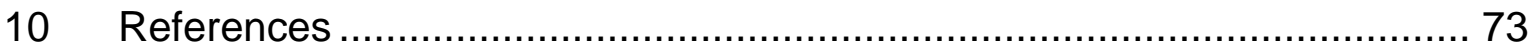

11 Danksagung ……................................ Fehler! Textmarke nicht definiert.

12 Curriculum vitae..................................... Fehler! Textmarke nicht definiert. 


\section{Table of abbreviations}

\begin{tabular}{l|l} 
ACP & acyl carrier protein \\
BCFA & branched-chain fatty acid \\
Bkd & branched-chain keto acid dehydrogenase \\
BPC & base peak chromatogram \\
CA & cinnamic acid \\
CHD & cyclohexanedione \\
CIP & crystalline inclusion protein \\
CoA & coenzyme A \\
DAR & dialkylresorcinol \\
EIC & extracted ion chromatogram \\
EPS & epoxy stilbene \\
FA & Fatty acid \\
FAD & flavin adenine dinucleotide \\
FAME & fatty acid methyl ester \\
GC & gas chromatography \\
HPLC & high performance liquid chromatography \\
IJ & infective juvenile \\
IPS & isopropyl stilbene \\
LB & lysogeny broth \\
MS & mass spectrometry \\
NG-IJ & next generation infective juvenile \\
NRPS & non-ribosomal peptide synthetase \\
PCP & peptide carrier protein \\
PCR & Polymerase chain reaction \\
Pdh & pyruvate dehydrogenase \\
PKS & polyketide synthase \\
PPTase & phosphopantetheinyl transferase \\
RTX & repeats-in-toxin \\
SM & specialized metabolite \\
TC & toxin complex \\
&
\end{tabular}




\section{Summary}

Photorhabdus and Xenorhabdus are Gram-negative, entomopathogenic bacteria, living in endosymbiosis with the soil-dwelling nematode of the genera Steinernema and Heterorhabditis. The life cycle of these nematodes consists of non-feeding infective juvenile (IJ) stage, which actively searches for insects in the soil. After penetrating the insect prey, Photorhabdus and Xenorhabdus bacteria are released from the nematode gut. The bacteria proliferate and produce toxins to kill the insect. Photorhabdus and Xenorhabdus support nematode development throughout the life cycle and to get rid of food competitors by providing a wide variety of specialized metabolites (SMs). However, little is known about which SMs function as so called "food signals" to trigger the development process.

The IJs develop into adult, self-fertilizing hermaphrodites in a process called recovery, while feeding on cadaver and bacterial biomass. Heterorhabditis and Steinernema proceed to breed until nutrients are exhausted. Next generation IJs (NG-IJs) develop and leave the cadaver to search for another insect prey.

Photorhabdus and Xenorhabdus can be cultivated in defined medium under laboratory conditions. By placing IJs on a plate containing their respective bacterial symbiont, the complete life cycle of the nematodes can be observed in vitro. The in vitro nematode bioassay was used as a tool to investigate the development of the nematode.

The aim of this study was to find the food signals responsible for nematode development. Different Photorhabdus deletion strains unable to produce one or several SMs were co-cultivated with nematodes in the nematode bioassay. Subsequently, two aspects of the life cycle were investigated: recovery and NG-IJ development.

As isopropyl stilbene (IPS) is postulated to function as a food signal to support nematode recovery, it was used as a starting point for investigations. This study was focused on the biosynthetic pathway of IPS, including intermediates, side products and derivatives to investigate which one is in fact responsible for supporting nematode development. 
The biosynthesis of IPS requires two precursors, phenylalanine and leucine (Figure 5). The first topic was focused on the phenylalanine derived pathway. Photorhabdus laumondii deletion mutants, defective in intermediate steps of this pathway, were created. The deletion of the genes coding for the phenylalanine ammonium lyase $(s t / A)$, converting phenylalanine into cinnamic acid (CA), the coenzyme $A(C \circ A)$ ligase $(s t / B)$ and the operon coding for a ketosynthase and aromatase $(s t / C D E)$, were used. These strains were used for nematode bioassay including complementation of mutant phenotypes by feeding experiments. Recovery of nematodes grown on the deletion strains was always lower than recovery of nematodes grown on wild type bacteria. Feeding IPS to a deletion strain did not restore wild type level nematode recovery, thus IPS cannot be the food signal. Instead, the food signal must be another compound derived from this part of biosynthetic pathway. Lumiquinone and 2,5-dihydrostilbene are suggested to function as food signals and need to be investigated in future work.

The second part of this study was focused on the leucine derived pathway, which involved the Bkd complex forming the iso-branched part of IPS. A deletion of bkd was created and phenotypically analysed, subsequently performed with the nematode bioassay. Not only IPS but also other branched SMs, like photopyrones and phurealipids are synthetised by the Bkd complex. Deletions strains defective in producing photopyrones and phurealipids were also performed in nematode bioassays to investigate effects of these SMs individually. Branched SMs did not have an impact on nematode development, but nematodes grown on the $\triangle b k d A B C$ strain showed a reduced nematode recovery and almost diminished NG-IJs development. As the Bkd complex also produces branched chain fatty acids (BCFAs), feeding experiments were performed with lipid extracts of wild type and mutant strain. All lipid extracts improved recovery, but only wild type lipids could complement NG-IJ development. This strongly indicates that BCFAs play an important role in NG-IJ development, which needs to be proven with purified BCFA feeding. This is an interesting finding, which could improve nematode production for biocontrol agent usage.

The role of IPS derived to epoxy stilbene (EPS) for nematode development, was another focus in the nematode life cycle. Recently it was demonstrated that EPS 
does not support nematode development. However, EPS forms adducts with amino acids. In my thesis, novel adducts containing the amino acid phenylalanine or a tetrapeptide were characterized. Another adduct, most likely being an EPS dimer, was also characterized. The biological role of such adducts was discussed to be potentially important for insect weakening and the structure of the novel compounds need to be structure elucidated and tested for bioactivity. 


\section{Zusammenfassung}

Die insektenpathogenen Bakterien der Gattungen Photorhabdus und Xenorhabdus leben als Darmbakterien in Symbiose mit Nematoden der Gattungen Heterorhabditis bzw. Steinernema. Die Nematoden leben in einer Dauerform, die als infektiöse Juvenilen (infective juveniles: IJs) bezeichnet wird. In der Erde suchen IJs aktiv nach Insektenlarven, die sie befallen können. Sobald eine geeignete Beute gefunden wurde, dringen die IJs durch Körperöffnungen der Larve ein und entlassen ihre symbiontischen Darmbakterien in die Hämolymphe der Insektenlarve. Photorhabdus und Xenorhabdus vermehren sich und produzieren Toxine, die das Insekt töten und das Gewebe zersetzen. Außerdem produzieren die Bakterien ein breites Spektrum an speziellen Metaboliten (specialized metabolites: SMs), um den Kadaver vor Fressfeinden zu schützen und um die Nematoden bei ihrer Entwicklung zu unterstützen. Sowohl Heterorhabditis als auch Steinernema sind nicht in der Lage ohne Anwesenheit ihres bakteriellen Symbionten den Entwicklungszyklus der Nematoden zu durchlaufen.

Der Entwicklungszyklus der Nematoden besteht aus vier Juvenilen Stadien (J1-J4) und einem eierlegenden, adulten Stadium. Die IJs stellen ein gesondertes J3 Stadium dar. Diese beginnen, sich im zersetzten Insekt zu J4 und anschließend zum adulten Stadium zu entwickeln. Dieser Prozess, in dem die IJs ihre Dauerform verlassen und sich zu entwickeln beginnen, wird „Recovery“ genannt. Bei Heterorhabditis besteht das adulte Stadium aus Hermaphroditen, während bei Steinernema männliche und weibliche Adulte entstehen. Nach Kopulation werden Eier gelegt, aus denen J1 Nematoden schlüpfen, die wieder den Zyklus bis zum Adulten durchlaufen. Sobald die Nahrungsquelle im Insekt erschöpft ist, entstehen neue IJs, die den Kadaver verlassen, um nach neuen Insekten zu suchen.

Photorhabdus und Xenorhabdus lassen sich problemlos im Labor im herkömmlichen Nähmedium bei $30^{\circ} \mathrm{C}$, unabhängig vom Symbionten, anzüchten. In diesem Nährmedium produzieren sie ebenfalls SMs, die deutlich leichter zu extrahieren sind als in der natürlichen Umgebung. Dadurch wurde es bereits ermöglicht eine breite Palette an SMs aufzuklären und den entsprechenden Gencluster zuzuordnen. Dennoch gibt es noch einige kryptische Gencluster, bei 
denen das Produkt ungeklärt geblieben ist, vermutlich weil die natürliche Umgebung Signalmoleküle oder Vorstufen zur Synthese enthält, die im künstlichen Medium fehlen. Selbst wenn die Struktur genau bestimmt werden kann, ist die Bestimmung der natürlichen Funktion der SMs, ebenfalls wegen der fehlenden natürlichen Umgebung, schwierig.

Das Verständnis der natürlichen Funktion hat jedoch einen enormen Mehrwert für das potenzielle Nutzen dieser SMs. Bioaktive SMs können als Antibiotika oder Antimykotika dienen, toxische SMs können als Pestizide eingesetzt werden. Dadurch könnte man gegebenenfalls dem wachsenden Problem der ResistenzEntwicklung gegenüber bereits bestehenden Medikamenten und Pestiziden begegnen. Es gibt für Letzteres allerdings noch einen anderen Lösungsansatz: ergänzend oder sogar anstelle von Pestiziden setzt man biologische Schädlingsbekämpfungsmittel gegen Insekten in der Landwirtschaft ein. Die Nematoden Gattungen Heterorhabditis und Steinernema eignen sich hervorragend dafür, da sie sich bereits natürlicherweise von Insekten ernähren und diese aktiv suchen. Sie sind selbstregulierend, da sie sich selbstständig vermehren und nach Erschöpfung der Nahrungsquelle von allein aussterben.

Verschiedene Spezies beider Gattungen werden bereits in der Landwirtschaft eingesetzt. Hierfür werden sie in großen Fermentern, die Nährstoffe und den bakteriellen Symbionten enthalten, kultiviert. Die Bakterien produzieren alles, was die Nematoden zum Vermehren brauchen. Allerdings ist die Industrie an einer Verbesserung der Kultivierung interessiert, um mehr Ausbeute an IJ Nematoden zu bekommen. Bisher wurde versucht die Zielsetzung zu erreichen, indem man dem Medium des Fermenters verschiedene vermeintliche Nährstoffe zuführte und beobachtete ob sich die Ausbeute verbesserte, nach dem Prinzip Versuch und Irrtum (,trial and error"). Diese Vorgehensweise ist sehr zeit- und kostenaufwendig. Ein besseres Verständnis über den Nematodenzyklus und darüber welches „Nahrungsmittelsignal“ (,food signal“) von seinem bakteriellen Symbionten benötigt wird, um sich optimal entwickeln und vermehren zu können, ist eine viel rationalere Methode. Das Nahrungsmittelsignal kann dann nämlich zusätzlich als Komponente zum Fermenter Medium dazugegeben werden, um die Ausbeute an IJs zu optimieren. 
$\mathrm{Da}$ es jedoch schwierig ist, die Entwicklung der Nematoden im Inneren des Insektes einzusehen, wurde ein in vitro Nematoden Entwicklungstest etabliert, um die natürliche Umgebung von Bakterium und Nematode unter Laborbedingungen nachzuahmen. Auf einer Petrischale wird ein Medium verwendet, das ähnliche Nährstoffe aufweisen soll wie ein Insekt. Zunächst werden die Photorhabdus und Xenorhabdus Bakterien auf dem Medium gezüchtet und anschließend die IJ Nematoden darauf platziert. Auf dieser Platte entwickeln sich die IJs wie sie es im Insekt tun würden. Platziert man die Petrischale in eine noch größere Petrischale, die Wasser enthält, kann man sogar den Ausbruch von neuen IJs beobachten. Diese springen dann in das Wasser, wo sie gezählt werden können.

Um herauszufinden welche bakteriellen SMs eine unterstützende Funktion haben, ist es notwendig Deletionsmutanten der Bakterien herzustellen, um diese mit dem in vitro Nematoden Entwicklungstest auf die Fähigkeit zur Unterstützung der Nematodenentwicklung zu testen. Der Nematodenzyklus soll qualitativ (Recovery) und quantitativ (Recovery und NG-IJs) untersucht werden. Ist die Entwicklung gestört, kann es auf den fehlenden SM der Deletionsmutante zurückgeführt werden.

In der Literatur ist Isopropylstilbene (IPS), ein SM produziert von Photorhabdus, als ein Nahrungsmittelsignal für die Nematodenentwicklung beschrieben. In dieser Arbeit soll der Biosyntheseweg von IPS genauer betrachtet werden. Hierfür sollen Photorhabdus laumondii Deletionsmutanten der einzelnen Gene, die für Enzyme der einzelnen IPS Biosyntheseschritte codieren, hergestellt werden. Ziel war es hierbei, zu untersuchen ob die Zwischenprodukte und Derivate von IPS einen Effekt auf die Entwicklung der Nematoden hat. Hierfür wurde der in vitro Nematoden Entwicklungstest genutzt.

Der Biosyntheseweg von IPS basiert auf zwei Bausteinen: Phenylalanin und Leucin. Phenylalanin wird durch die Phenylalanin Ammoniumlyase (StIA) in Zimtsäure (CA) umgewandelt, die dann durch die CoA-Ligase (StIB) als Thioester aktiviert und anschließend kettenverlängert wird. Leucin wird zunächst enzymatisch zu Keto-Isovalerinsäure transaminiert und anschließend mittels des Bkd Komplexes kettenverlängert. Beide Vorstufen schließen sich mittels Michael 
Addition und Claisen Kondensation zu einem $\mathrm{C}_{6}$-kettigen Ring zusammen, welcher abschließend enzymatisch (StICDE) aromatisiert wird.

Im ersten Abschnitt dieser Arbeit ging es um den Phenylalanin Teil des Biosyntheseweges. Deletionsmutanten von $s t / A$, st/B und $s t / C D E$ wurden in den Nematoden Entwicklungstests bezüglich des Recovery getestet. Alle Deletionen führten zu einer verringerten Nematodenentwicklung. Zusätzlich wurden die Mutanten mit IPS und CA komplementiert. Es konnte festgestellt werden, dass zwar CA, das Produkt aus StIA, die $\Delta$ stlA Mutante komplementieren konnte, IPS jedoch weder in der Lage war $\Delta s t I A$, noch $\Delta s t / B$ zu komplementieren. Es wurde daraus geschlussfolgert, dass IPS, in Widerspruch zur Literatur, nicht das Signal sein kann, das für die Nematodenentwicklung zuständig ist. Andere Derivate, wie Dihydrostilben oder Lumiquinon entstehen ebenfalls über diesen Zweig des Biosyntheseweges. Diese fallen zwar ebenfalls in den Deletionsmutanten weg, können aber nicht durch die IPS Fütterung wiederhergestellt werden. Diese Derivate sollen Augenmerk für zukünftige Projekte sein.

Im zweiten Teil wurde die Umsetzung von Leucin genauer beleuchtet. Der Bkd Komplex katalysiert den iso-verzweigten Baustein vom IPS. Jedoch wird dieser Baustein auch für andere verzweigte SMs verwendet. Folglich sollten bei einer Deletion von bkdABC auch die anderen iso-verzweigten SMs wegfallen, wie etwa Phurealipide und Photopyrone. Um dies zu bestätigen, wurde zunächst ein Profil von den produzierten SMs im $P$. laumondii Wildtyp, in der $\triangle b k d A B C$ Mutante und vergleichsweise in der $\triangle$ st/CDE Mutante, mittels Hochleistungsflüssigkeitschromatographie gekoppelt an einem Massenspektrometer (HPLC-MS), erstellt. Nach Bestätigung des Wegfallens genannter iso-verzweigter SMs, wurden Deletionsmutanten, die diese SMs nicht produzieren können, zusammen mit $\triangle b k d A B C$ Mutante ebenfalls im Nematoden Entwicklungstest getestet, um den Ursprung von eventuellen Effekten eines fehlenden Bkd Komplexes genau bestimmen zu können. Ein Effekt von Phurealipiden und Photopyronen konnte so ausgeschlossen werden.

Der Bkd Komplex wird ebenfalls dazu benötigt iso-verzweigte Fettsäuren aus den Aminosäuren Leucin, Isoleucin und Valin zu synthetisieren. Zunächst wurde ein 
Fettsäureprofil mittels Gaschromatographie gekoppelt an ein Massenspektrometer (GC-MS) erstellt. Die Abwesenheit von iso-verzweigten Fettsäuren in der $\triangle b k d A B C$ Mutante konnte so bestätigt werden.

Iso-verzweigte Fettsäuren wurden ebenfalls mit dem Nematoden Entwicklungsassay analysiert. Dies sollte erfolgen, indem die Deletionsmutante von bkdABC mit Lipiden (aus P. laumondii Wildtyp isoliert und iso-verzweigte Fettsäuren enthaltend) zugefüttert wurde, um eine potenzielle Komplementation herbeizuführen. Untersucht wurden das Recovery und die Produktionsrate von neuen IJs. Beide waren vermindert, wenn die Nematoden auf der $\triangle b k d A B C$ Mutante inkubiert wurden und konnten mit Wildtyp Lipiden komplementiert werden. Demnach wird postuliert, dass iso-verzweigte Fettsäuren eine wichtige Rolle für die Nematoden spielen müssen. Iso-verzweigte Fettsäuren können verschieden langkettig sein, daher soll für zukünftige Projekte im Detail analysiert werden, welche Fettsäuren im Einzelnen beteiligt sind. Dies würde es ermöglichen, durch eine gezielte Zugabe zum Medium im Fermenter, die Ausbeute an IJ Produktion zu verbessern.

Im dritten Abschnitt ging es um die weitere Verarbeitung von IPS und der Funktion der daraus entstehenden Derivate. Mithilfe einer Epoxidase kann IPS in Epoxystilben (EPS) umgewandelt werden. Eine Deletionsmutante der Epoxidase hat keinen negativen Effekt auf die Nematodenentwicklung, was eine unterstützende Funktion von EPS für die Nematoden ausschließen lässt. Dennoch wird im Inneren des Insektes eine große Menge von EPS gebildet. Außerdem ist es in der Lage ein Addukt mit der Aminosäure Prolin zu bilden. In dieser Arbeit soll mittels HPLC-MS herausgefunden werden, ob dieses Prolinaddukt ein einmaliges Phänomen darstellt, oder ob weitere Addukte mit Aminosäuren möglich sind. Es wurden zwei Addukte gefunden, wenn $P$. laumondii im artifiziellem Labormedium gezüchtet wurde. Durch reverse Fütterungsversuche von ${ }^{12} \mathrm{C}$-haltigen Aminosäuren in einem ${ }^{13} \mathrm{C}$-haltigen Medium, konnte in Erfahrung gebracht werden, dass das erste Addukt ein Phenylalanin beinhaltet und das zweite Addukt das Tetrapeptid Leucin-Prolin-Leucin-Prolin. Im Anschluss wurde P. laumondii in der Insektenlarve Galleria mellonella gezüchtet und es wurde ein weiteres Addukt gefunden, welches charakteristisch wie ein Dimer aussieht. Fütterungsversuche 
mit dem Vorläufermolekül CA in deuterierter Form konnten den Einbau von zwei Bausteinen bestätigen. Für zukünftige Projekte sollte die Struktur aller drei Addukte mittels kernmagnetischer Resonanz (NMR) aufgeklärt werden und die Funktion solcher Addukte genauer betrachtet werden. 



\section{Introduction}

\subsection{Drug development from nature: specialized metabolites}

Specialized metabolites (SMs) are low molecular compounds produced by a living organism. Initially the term "secondary metabolites" was introduced by Kossel in 1910 as he described them as opposed to primary metabolites which are responsible for sustaining living, growing and reproduction ${ }^{[1]}$. Since SMs have no obvious impact in live sustaining mechanisms, they were considered as "secondary". However, thanks to the improving biochemical techniques and the rise of molecular biology, growing knowledge of organismic interaction, chemical and microbial ecology expanded immensely ${ }^{[1]}$. Thus, these natural products are not of secondary importance but in fact have supporting functions for the producer, and therefore, the term "specialized metabolites" seems to be more suitable ${ }^{[2]}$.

Since the discovery of penicillin by Fleming in $1928^{[3]}$, the interest in bioactive SMs increased. Many pharmaceutical active SMs of microorganisms were found, amongst other, antibiotics, antitumor agents, immunosuppressive agents, enzyme inhibitors, antimigraine and antiparasitic agents ${ }^{[4]}$. However, the overuse of antibiotics led to a growing problem of multi drug resistant microorganisms ${ }^{[5]}$ The biological active compounds produced by microorganisms to eliminate other microorganisms competing for the same food sources, can be used as novel antibiotics, as resistance to already existing antibiotics becomes a growing problem in medicine ${ }^{[6,7]}$. Therefore, new antibiotics are needed, like the SMs produced by bacteria.

An excessive use of pesticides also led to insect pest resistance ${ }^{[8]}$. The first case of insect resistance was reported against dichlorodiphenyltrichloroethane (commercially known as DDT) ${ }^{[9]}$. Additionally, pesticides harm the environment ${ }^{[10]}$. A more efficient and targeted use is a good start, but still new pesticides need to be found. Resistance due to over usage of pesticides ${ }^{[8]}$ can be avoided by finding new pesticides. Toxic compounds produced by insect pathogenic microorganisms to kill the insect could be a promising source for finding new pesticides. 
Organic farming could bypass the pesticide resistance, as finding new pesticides would possibly only delay the problem. An example for efficient biocontrol agents are nematodes and their bacterial symbionts. Phasmarhabditis hermaphrodita carrying Moraxella osloensis is a slug pathogenic nematode and could potentially be used as a slug control agent. Steinernema and Heterorhabditis are two nematode genera, which are already used as insect control agents ${ }^{[11]}$. Steinernema and Heterorhabditis carry bacterial endosymbionts in their gut, Xenorhabdus and Photorhabdus, respectively. The symbiosis is beneficial for both partners. Bacteria use the nematode as a vector to find an insect prey, whereas the nematode takes advantage of the bacterial toxins to kill the insect ${ }^{[12]}$. Additionally, the bacteria provide a high variety of compounds supporting nematode development ${ }^{[13-15]}$ and to repel or kill food competitors ${ }^{[16,17]}$. Therefore, Photorhabdus and Xenorhabdus gained scientific interest over the years as a biocontrol agent for agriculture ${ }^{[11]}$ and as potential antibiotic ${ }^{[16,17]}$ producers and will be of special interest for this study. A better understanding on how the bacteria support their nematode and how they kill the insect should improve the use as biocontrol agent.

\subsection{The tritrophic relationship between bacteria, nematode and insect: the life cycle of Heterorhabditis and Steinernema}

The complex and unique life cycle of the Gram-negative, rod-shaped bacteria Photorhabdus and Xenorhabdus consist of symbiosis with nematodes and parasitism towards insects. Naturally, these bacteria are endosymbionts of the soil-living infective juvenile (IJ) stage nematodes from the genera Heterorhabditis and Steinernema, respectively ${ }^{[18]}$. The IJs are non-feeding with a sealed mouth and anus until they find and penetrate an insect prey. After penetration its mouth opens and mutualistic bacterial cells are regurgitated into the haemocoel[19] (Figure 11). The bacteria proliferate and kill the insect within 48 hours (for details see chapter 5.3). In a process called "recovery", the IJs start to develop into a Juvenile 4 (J4) stage followed by an adult stage (Figure 1II). The adult nematodes breed by laying eggs while feeding on the cadaver and bacterial biomass. The eggs hatch into Juvenile 1 (J1) stage nematodes and grow to become Juvenile 2 
(J2) and Juvenile 3 (J3) stage nematodes. From J3 there are two paths, either becoming $\mathrm{J} 4$ and continuing with breeding (Figure 1III) or becoming an IJ again (Figure 1IV). Usually, the life cycle continues with the breeding path approximately 2-3 times. Once nutrients are exhausted new IJs start to develop. These next generation of IJs (NG-IJs) leave the cadaver to search for a new insect host. This life cycle can be seen as a cyclic association starting and ending with the IJs stage (Figure 1) ${ }^{[20,21]}$.

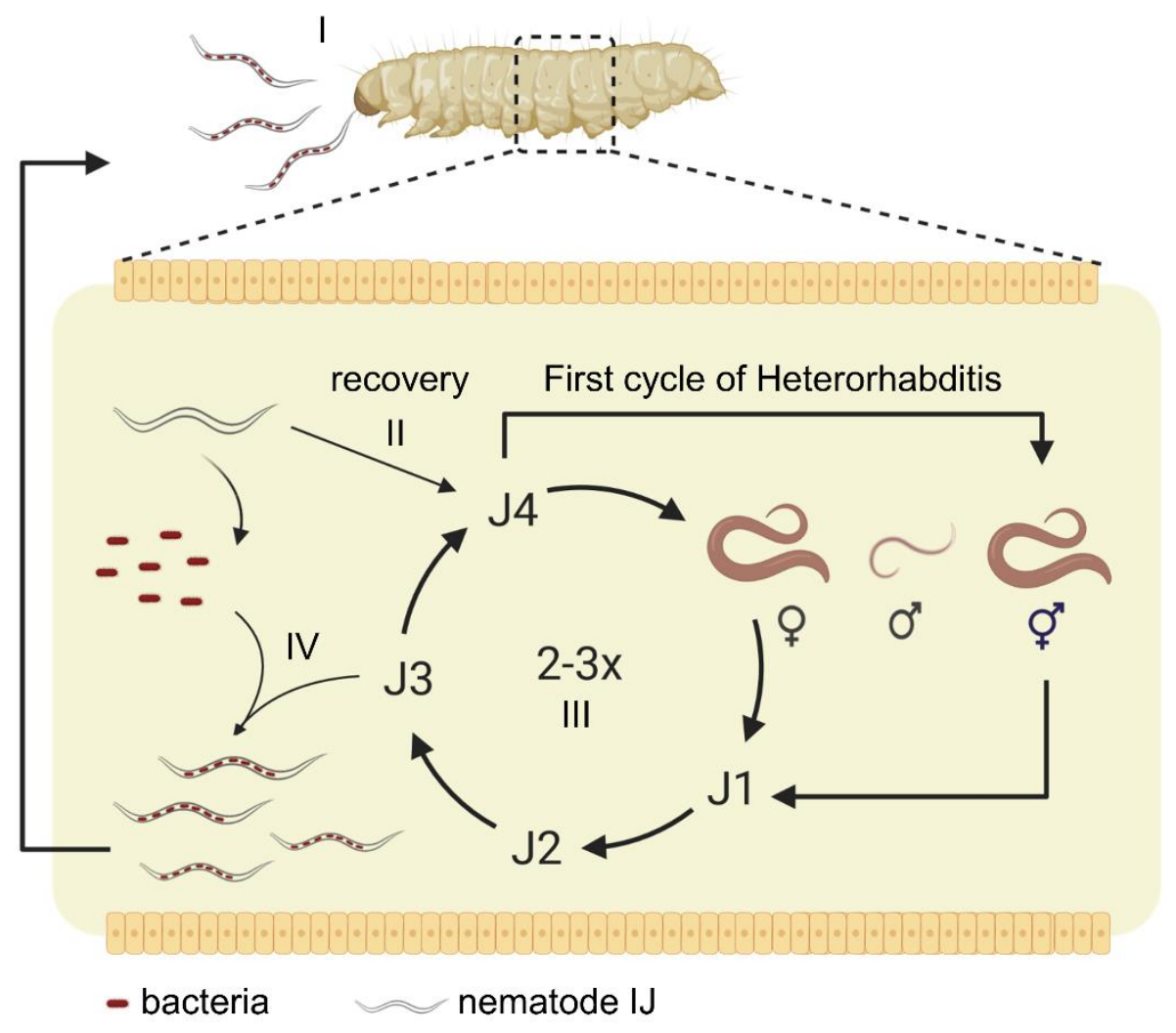

Figure 1. Photorhabdus and Xenorhabdus life cycle scheme. I) IJs live in the soil and hunt for an insect prey. II) After entering the insect's haemocoel, bacteria proliferate and produce toxins to kill the insect. Bacteria produce compounds to support nematode development and IJs start to develop into $\mathrm{J} 4$ and finally to adults, in a process called recovery. III) Nematodes breed and undergo development cycles (J1-J4 and adult stage) 2-3 times. IV) Nutrients of the insect cadaver are exhausted. NG- IJs develop from J3 and few bacteria are taken up by their symbionts. The NG-IJs exit the cadaver to find a new prey. Figure was designed with biorender.com.

While both Photorhabdus and Xenorhabdus are capable of infecting several different insect hosts, the symbiosis with the nematode is mostly speciesspecific $^{[19,22,23]}$. A convergent evolution of these species might explain their similar 
lifestyle ${ }^{[24]}$. However, there is a distinct difference in the life cycles of Heterorhabditis and Steinernema. Heterorhabditis IJs develop only into hermaphrodites and subsequently develop into females and males in the second round of the cycle. In contrast, Steinernema IJs develop directly into females and males $^{[25]}$. In theory, only one Heterorhabditis $\mathrm{IJ}$ is sufficient to proliferate inside the insect. At the same time, Steinernema needs at least one female plus one male inside one insect cadaver to continue reproduction. To achieve this, Steinernema might use pheromones to attract individuals from the other sex to invade into the same insect ${ }^{[26]}$. After successful fertilization, both Steinernema and Heterorhabditis lay eggs externally which develop into adult males or females. However, most of the eggs hatch in the uterus and consume the mother. The development of NGIJs is mainly restricted to these intrauterine hatching eggs. While adult nematodes also feed on the bacteria in the insect carcass, the symbiotic bacteria are transmitted exclusively maternal. This process is known as endotokia matricida ${ }^{[27-}$ 29].

\subsection{Photorhabdus and Xenorhabdus kill the insect}

\subsubsection{Evading the immune system}

Part of the insect immune system are pattern recognition proteins which can detect Gram-positive, Gram-negative bacteria and several fungal species. The immune response is activated by receptors that recognize microbial surface determinants, such as lipopolysaccharide (LPS) and peptidoglycan ${ }^{[30]}$. Haemocytes encapsulate the invading microorganism. The capsule is melanized using a proteolytic cascade leading to an activation of the phenoloxidase, which pigments the insect larva black. The trapped organism inside the melanized nodule is removed by circulation ${ }^{[31-33]}$.

Once penetrating the insect, both nematodes and bacteria need to overcome the immune system of the insect prey. Steinernema and Heterorhabditis prevent recognition of the insect due to special components on their epicuticle. These components include the sugars D-mannose, $\mathrm{N}$-acetyl-D-galactosamine and $\mathrm{N}$ acetyl-D-glucosamine, which prevent insect haemocyte binding to the epicuticle ${ }^{[34,35]}$. Still inside the nematode, the symbiotic bacteria are initially 
protected from the insect's immune system until they are regurgitated into the haemocoel. Photorhabdus induces the production of microbial recognition proteins by the insects fat body resulting in a triggered immune response as it was observed in the tobacco hornworm Manduca sexta[36]. The entomopathogenic bacteria interfere with the immune system directly in contrary to the defensive mechanism by surface covering of the nematode mentioned above. After a short delay, the growth of Photorhabdus becomes exponential inside the insect ${ }^{[37]}$ finally leading to sepsis indicating that Photorhabdus surpass the immune system of the insect.

Interestingly, insects infected by Photorhabdus and Xenorhabdus do not turn black, indicating that the bacteria are capable of inhibiting the phenoloxidase, which initiates the melanisation process ${ }^{[38,39]}$. Rhabduscin, a SM produced by Photorhabdus and Xenorhabdus strains, inhibits the phenoloxidase directly ${ }^{[40]}$. Also rhabdopeptides ${ }^{[41]}$ and xenortides ${ }^{[42]}$, SMs produced by Xenorhabdus, are speculated to inhibit the serine protease, involved in phenoloxidase activation cascade ${ }^{[43]}$.

Glidobactin, a Photorhabdus produced SM, is a potential proteasome inhibitor, weakening the immune system from another perspective, as it reduces the insects ability of protein degradation ${ }^{[44,45]}$. In Figure 2 all mentioned SMs capable of evading the immune system are summed up. 


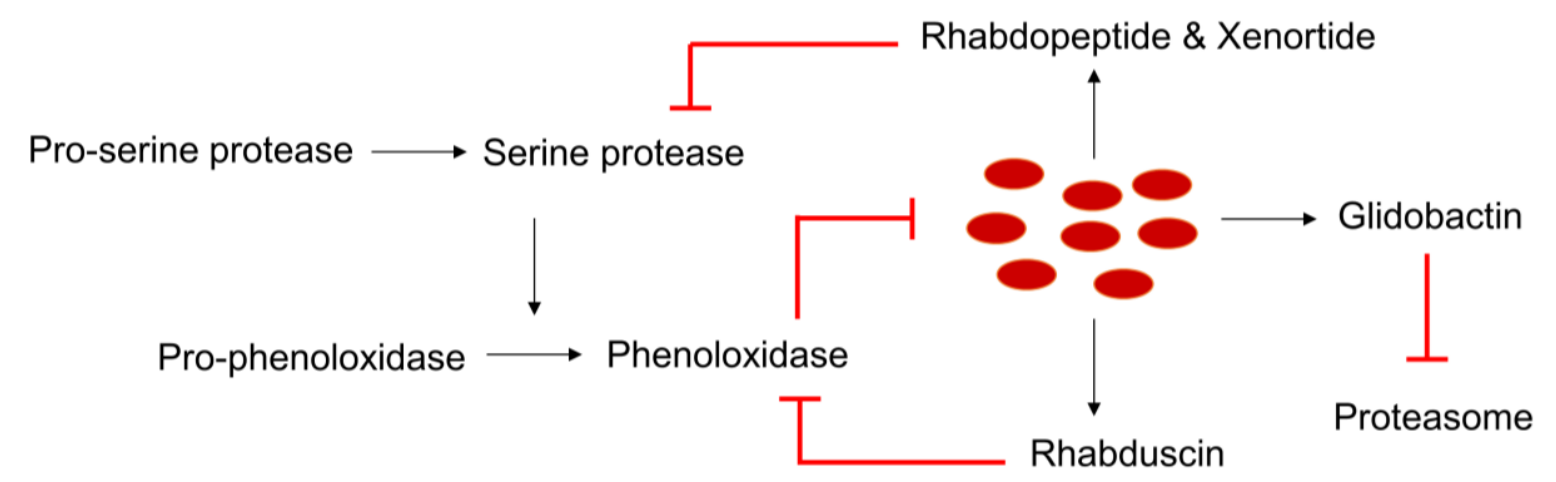

Figure 2. Scheme on how Photorhabdus and Xenorhabdus evade the immune system of the insect. Red dots symbolize Photorhabdus/Xenorhabdus bacteria. Figure adjusted from ${ }^{[43]}$.

Although evading the immune system would be enough to kill the insect via septicaemia, the bacteria also produce cytotoxic compounds that actively harm the host. Some examples of cytotoxic compounds are described in the next section.

\subsubsection{Killing the insect prey and protecting it from competition}

Besides inhibiting the immune system, the bacteria produce a variety of protein toxins and SMs to kill the insect. Photorhabdus secrets a toxin complex (Tc) protein encoded by the loci $t c a, t c b$, $t c c$, and tcd that has been characterized to be toxic towards the insect species $M$. sexta ${ }^{[8]}$. Tc toxins are composed of three subunits. TcA perforates the host membrane and injects TcB inside the cell. TcB is a carrier of TcC the actual cytotoxic component killing the cell[46,47].

An repeats-in-toxin (RTX)-like metalloprotease PrtA, is toxic towards the wax moth Galleria mellonella, by possibly playing a key role in degrading insect tissues ${ }^{[48,49]}$. Also the Pir protein produced by Photorhabdus ${ }^{[50]}$ and Xenorhabdus ${ }^{[51]}$ is cytotoxic and is responsible for destroying insect tissue ${ }^{[52]}$. Xenorhabdus uses the chaperone GroEL with chitin-binding activity to kill the insect ${ }^{[53]}$ and a fimbrial shaft protein MrxA to lyse the haemocytes of the insect ${ }^{[54]}$. Additionally, the TonB complex facilitate the uptake of siderophores killing the insect by scavenging iron from the haemocoel[55].

Cytotoxicity could also be observed for xenocyloin, which shows activity against insect hemocytes thus contributing to the overall virulence ${ }^{[56]}$. 
After successfully killing the insect, the bacteria defend the cadaver against other soil microorganisms ${ }^{[16,17]}$ and even scavengers, like other insects ${ }^{[57]}$. Several SMs with antibiotic activity have been found. Xenocoumacin I is produced by Xenorhabdus with an antibiotic ${ }^{[58]}$ and antifungal activity ${ }^{[59]}$. Fabclavine shows broad-spectrum activity against Gram-negative and Gram-positive bacteria, fungi, and other eukaryotic cells ${ }^{[60]}$. Nematophin shows more specific bioactivity against Gram-positive bacteria and some fungi species ${ }^{[61]}$. Photorhabdus photoditritide is active against Gram-positive and Gram-negative bacteria and against protozoan parasites $^{[62]}$. In Figure 3, the structures of SMs involved in insect immune system invasion and cadaver defending are listed. 


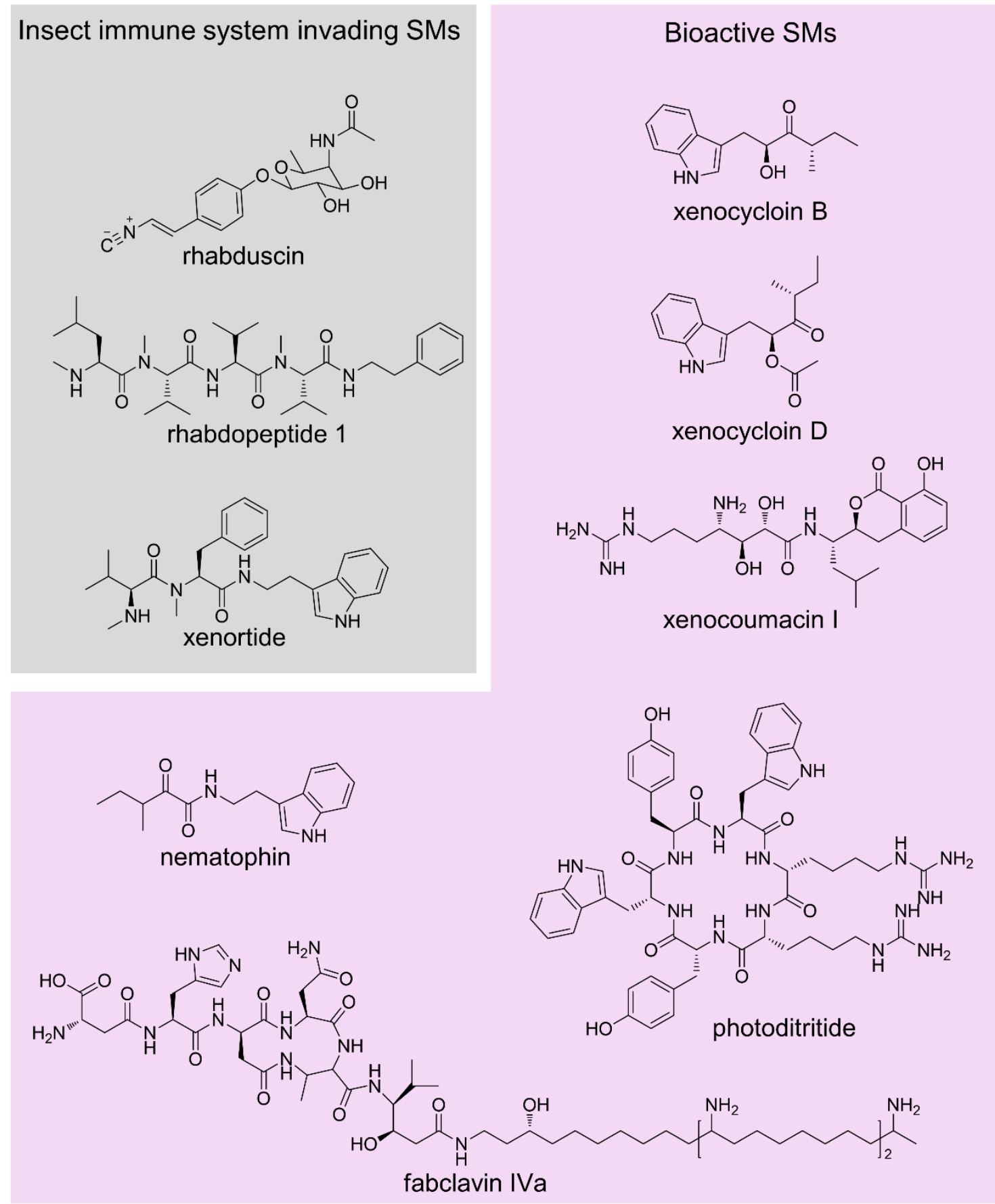

Figure 3. SMs produced by Photorhabdus and Xenorhabdus with respective function.

Isopropyl stilbene (IPS) is another Photorhabdus SM with activity against Grampositive and Gram-negative bacteria[63], antifungal[64] and even nematicidal activity ${ }^{[65]}$. IPS is also postulated to be involved in nematode recovery and will be therefore described in more detail in chapter 5.4.2. 


\subsection{Photorhabdus and Xenorhabdus support nematode development}

\subsubsection{Compounds involved in recovery}

Once Photorhabdus and Xenorhabdus have killed the insect, they use the cadaver as a food source. The IJs start to develop into $\mathrm{J} 4$ and subsequently into adult nematodes. This process is called recovery. In case of Heterorhabditis, the adult consists of hermaphrodites and the adult stage in Steinernema consists of males and females (Figure 1). In the early years of Heterorhabditis and Steinernema research, the compounds produced by the symbiotic bacteria to support nematode development and reproduction were not characterized. They were simply described as "food signal" in literature ${ }^{[66,67]}$. Since then, several attempts were made to find out which produced compound from the bacteria can function as food signals and will be explained in the following.

In previous studies it was assumed that if the bacteria reach their stationary phase in the insect carcass, they start to produce the food signals to induce the nematode cycle. One observation was the formation of crystalline inclusion proteins (CIPs) as nematode development supporting food signal. These CIPs are produced by both, Photorhabdus and Xenorhabdus and are thought to be nutritional for the nematodes[68-70]. Another finding for a nematode development supporter was the exbD gene in Photorhabdus temperata encoding for a component of the TonB complex. The TonB complex enables the uptake of siderophores. Deleting this gene reduces virulence (see chapter 5.3.2) and Heterorhabditis development. This was complemented by supplying iron, implying that $P$. temperata scavenges iron from the insect and subsequently uses it to support nematode development ${ }^{[55]}$.

SMs are produced by nonribosomal peptide synthetases (NRPS) and polyketide synthases (PKS). In NRPSs activated amino acids are covalently bound forming peptides and a great diversity of chemical modifications, such as the incorporation of D-amino acids and/or glycosylated amino acids, can be observed[71]. PKSs synthesize complex SMs using acetyl-CoA and malonyl-CoA or derivatives thereof as building blocks ${ }^{[72]}$. For both, NRPS and PKS a phosphopantetheinyl transferase 
(PPTase) is essential. It transfers a 4'-phosphopantetheinyl moiety of coenzyme A to the acyl carrier protein (ACP) domain of PKS and to the peptide carrier protein (PCP) domain of NRPS, respectively, transforming the inactive apo- into the active holo-form resulting in activation of the domain (Figure 4$)^{[73,74]}$.

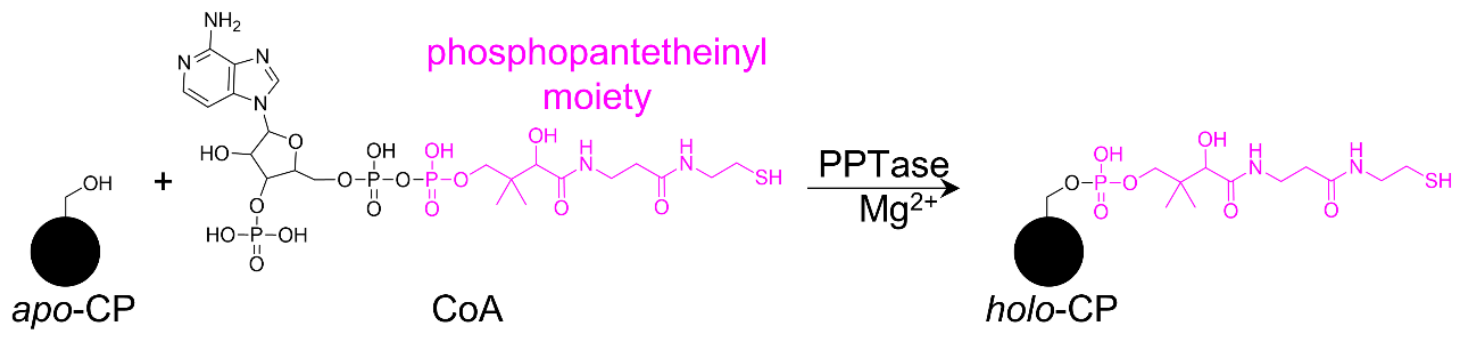

Figure 4. Transfer of phosphopantetheinyl moiety of CoA on an ACP or PCP domain for activation, catalysed by PPTase.

Consequently, the deletion of the PPTase encoding gene ngrA in Photorhabdus led to loss of most SMs. Only the red pigments anthraquinones are still produced by a PKS system which includes its own PPTase AntB for activation ${ }^{[75]}$. Nematode recovery was diminished in a $\Delta n g r A$ deletion strain underlining the important role of SMs for nematode development ${ }^{[13]}$.

Not only has the deletion of ngrA indicated that SMs are important for nematode development, but also the deletion of the posttranslational regulator encoded by $h f q$. Hfq is an RNA-binding protein connecting sRNA and mRNA. The deletion of hfoto the loss of most SMs ${ }^{[76]}$. Recovery in Heterorhabditis was not observed when associated with the $h f q$ deletion mutant as symbiont ${ }^{[76]}$.

\subsubsection{IPS biosynthetic pathway}

As it was described in the previous sections, Photorhabdus and Xenorhabdus produce a high variety of SMs, but little is known about their influence on nematode development. IPS from Photorhabdus is so far described as a major factor for nematode recovery ${ }^{[14]}$. Stilbenes are widely distributed in the plant kingdom and have been reviewed elsewhere ${ }^{[77]}$. However, IPS is a unique stilbene known to be produced exclusively in the Photorhabdus genus ${ }^{[78]}$. In plants, stilbenes have antimicrobia|[79] and nematicida|[ ${ }^{[0]}$ properties and also for IPS from Photorhabdus similar bioactivities have been described ${ }^{[81]}$. IPS also showed anti- 
inflammatory effects and is currently clinically used for the treatment of atopic dermatitis ${ }^{[82]}$.

The biosynthetic pathway of IPS can be divided into two routes, subsequently combining as one. One route starts with phenylalanine as a precursor (Figure 5, highlighted in orange) the second route starting with leucine for the iso-branched part of IPS (Figure 5, highlighted in green). For the first part the phenylalanine ammonium lyase (StIA) catalyses the non-oxidative deamination of phenylalanine to trans-cinnamic acid $(\mathrm{CA})^{[83]}$ which gets activated to its thioester cinnamoyl-CoA by the coenzyme $A(\mathrm{CoA})$ ligase (StIB). So far it is suggested that the activated cinnamoyl-precursor is elongated with malonate extender units, similar to a fatty acid-like elongation mechanism ${ }^{[14]}$. The Michael acceptor 5-phenyl-2,4pentadienoyl-ACP is then used for the subsequent reactions with the precursor molecule from the iso-branched route.

In the iso-branched route of the biosynthetic pathway leucine is transaminated to a-ketoisovaleric acid, by the action of a transaminase. The branched-chain keto acid dehydrogenase (Bkd) complex, encoded by the operon $b k d A B C$, catalyses the formation of isovaleryl- $\beta$-ketoacyl-ACP ${ }^{[14]}$. The Bkd complex will be explained in more detail in the upcoming section. Both, 5-phenyl 5-phenyl-2,4-pentadienoylACP and isovaleryl- $\beta$-ketoacyl-ACP are combined via Michael addition and Claisen condensation by the ketosynthase StID to result in a cyclohexanedione (CHD) intermediate. The CHD intermediate is further oxidized by the aromatase

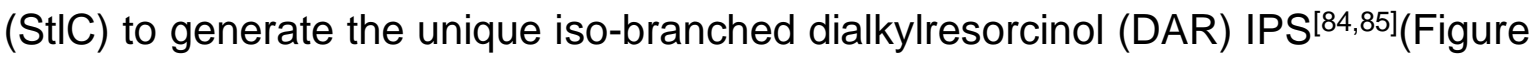
$5)$. 
<smiles>N[C@@H](Cc1ccccc1)C(=O)O</smiles>

StIA

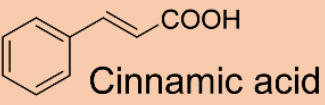

StIB<smiles>O=C(/C=C/c1ccccc1)S(=O)(=O)O</smiles><smiles>CC(C)CC(N)C(=O)O</smiles>

Transaminase<smiles>CC(CC(=O)O)C(C(=O)O)C(=O)O[Na]</smiles>

BkdAB<smiles>CC(C)CC(=O)OC(C)(C)C</smiles>

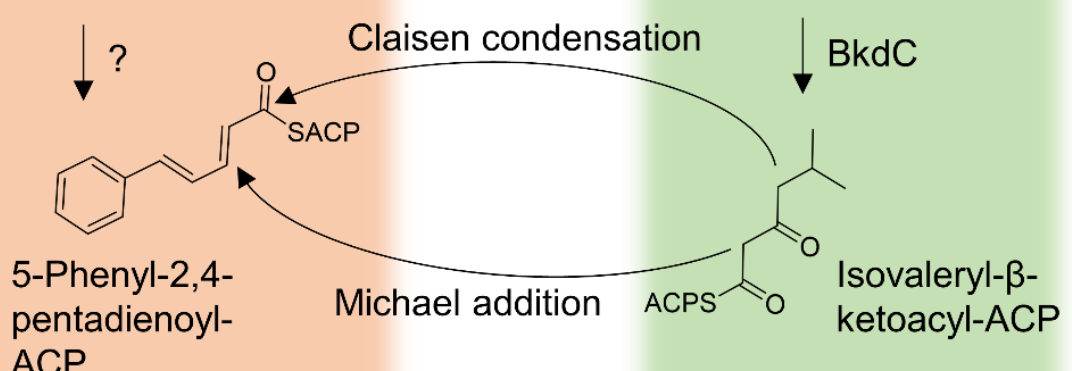<smiles>CC(C)C1C(=O)CC(/C=C/c2ccccc2)CC1=O</smiles>

StIC<smiles>CC(C)c1c(O)cc(/C=C/c2ccccc2)cc1O</smiles>

IPS

Epoxidase<smiles></smiles>

EPS

Figure 5. IPS biosynthetic pathway scheme: the phenylalanine derived pathway highlighted in orange, the iso-branched derived pathway highlighted in green. 
IPS, which so far represents the major product from the IPS pathway. Alternatively, a straight chain FA can be integrated, forming ethyl stilbene or a reduced form of IPS, 2,5-dihydrostilbene is possible (Figure 6A). Further, IPS can be converted into epoxy stilbene (EPS) by the flavin adenine dinucleotide (FAD)dependent epoxidase ${ }^{[86]}$. A low abundance of EPS in Photorhabdus may also be explained by the high reactivity of the epoxy group in EPS resulting in various side products $^{[87]}$ (Figure 6B).

A) IPS derivatives

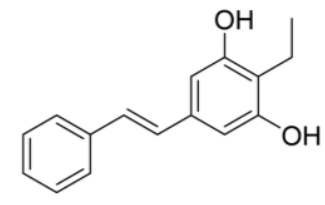

ethyl stilbene

B) EPS derivatives<smiles>CC(C)c1c(O)cc(C(O)C(O)c2ccccc2)cc1O</smiles><smiles>CC(C)c1c(O)cc(C(O)C(=O)c2ccccc2)cc1O</smiles><smiles>CC(C)c1c(O)cc(/C=C/C2=CCC=CC2)cc1O</smiles>

2,5-dihydrostilbene<smiles>COC(c1cc(O)c(C(C)C)c(O)c1)C(O)c1ccccc1</smiles>

Figure 6. Stilbene derivatives ${ }^{[87]}$ A) IPS derivatives ethyl stillbene and 2,5-dihydrostilbene. B) Reduced EPS derivatives and hydration adducts. 


\subsubsection{Bkd complex}

In general, the presence of a Bkd complex is well known for Gram-positive bacteria with the main function of producing branched chain fatty acids (BCFAs). Bacillus subtilis is a great example for a Bkd complex holder ${ }^{[8,89]}$ with a total of 96\% BCFAs ${ }^{[90]}$. In an other Gram-positive bacterium, namely Listeria monocytogenes, $90 \%$ of the produced fatty acids (FAs) are BCFAs ${ }^{[191}$. An example for Gram-negative bacterium harbouring a Bkd complex is Pseudomonas aeruginosa ${ }^{[92]}$. Bacteria like Escherichia coli, who are unable to produce BCFAs, produce unsaturated FAs instead ${ }^{[93]}$. BCFAs are incorporated in lipids, having the function of increasing membrane fluidity, similar to unsaturated FAs. Increasing fluidity is a response mechanism to cold stress ${ }^{[94,95] .}$

The Bkd complex is responsible for the biosynthesis of BCFAs from leucine, isoleucine and valine. The first enzymatic reaction is the deamination of their corresponding 2-oxo acid: a-ketoisocaproic acid, and a-ketoisovaleric acid, respectively[97]. The iso-branched precursor is the activated by CoA and subsequently elongated. The Bkd complex contains three subunits E1, E2 and E3. E1 functions as a decarboxylase/dehydrogenase, E2 as a dihydrolipoamide acyltransferase and E3 as a dihydrolipoamide dehydrogenase ${ }^{[97-99]}$ (Figure 7). 
A) $\mathrm{CO}_{2}$
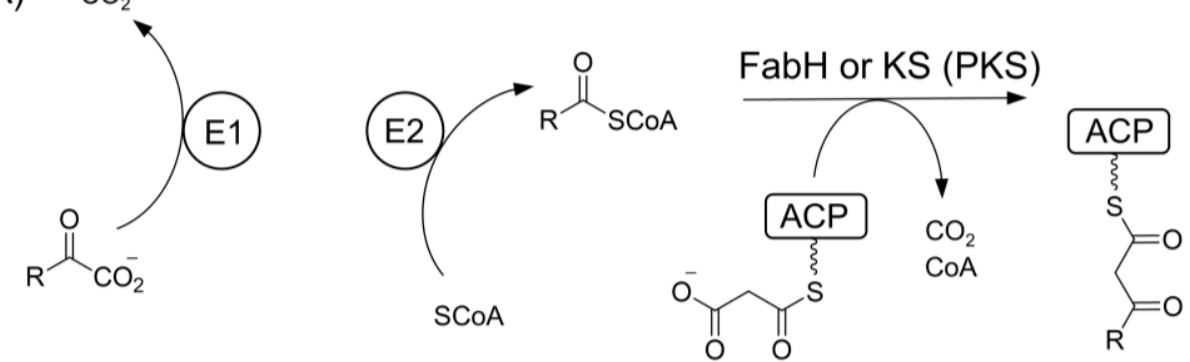

B) $\quad \mathrm{CO}_{2}$
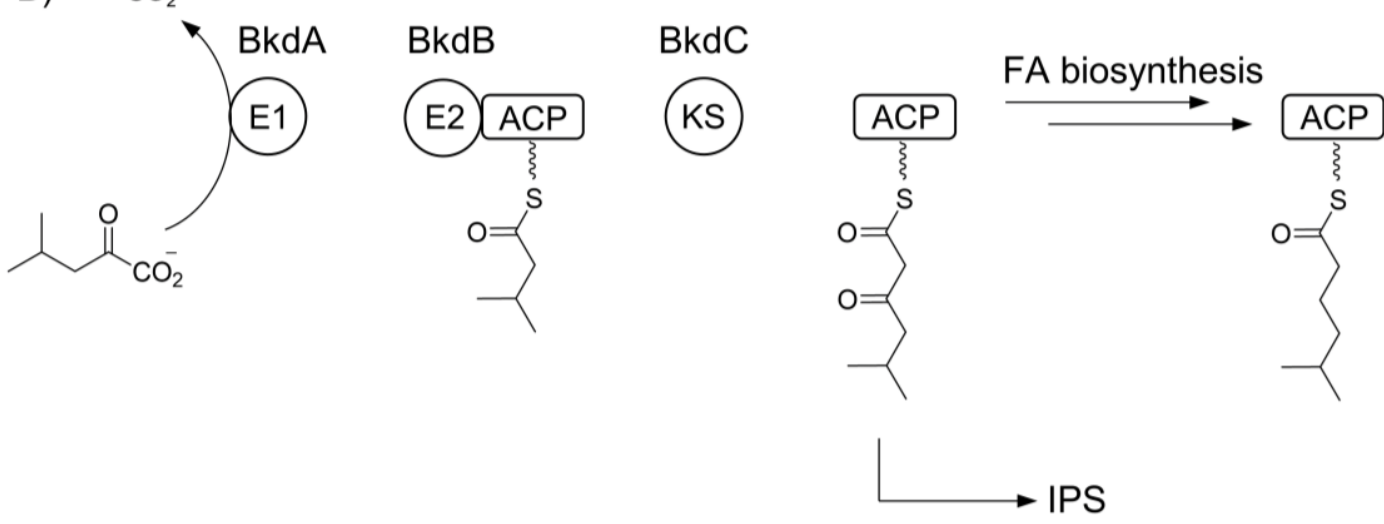

Figure 7. Scheme of Bkd complexes. A) Standard BKD complex, as in B. subtilis, resulting in soluble CoA thioesters, which can be used as starting units for FAs and polyketides B) BkdABC involved in IPS and FA biosynthesis in Photorhabdus. Figure adjusted from ${ }^{[100]}$.

The Bkd complex of Photorhabdus consists of the genes $b k d A$ and $b k d B$ encoding the dehydrogenase/decarboxylase (E1) and dihydrolipoamide acyltransferase (E2) components and bkdC encoding an unusual ketosynthase (E3) ${ }^{[14,101]}$. The deaminated branched-chain amino acids of leucine, isoleucine and valine which get converted into branched-chain acyl-ACP molecules are subsequently used as precursors for BCFA biosynthesis but also for IPS, or other SMs based on isobranched FAs ${ }^{[14]}$ (Figure 8). Branched-chain acyl-ACP molecules are elongated through the activity of the ketosynthase (E3) for Photorhabdus ${ }^{[14]}$ (Figure 7B). $B$. subtilis harbours a Bkd complex but uses a specialised $\mathrm{FabH}$ for the elongation step of the biosynthesis of BCFAs (Figure 7A). Instead of the linear acetyl-CoA derivatives, which are used for the biosynthesis of straight chain FAs the branched precursors isovaleryl-CoA, isobutyryl-CoA, and 2-methylbutyryl-CoA are used as primers ${ }^{[102]}$. 
phurealipids<smiles>[R]NC(=O)NCCCCCCCCCC</smiles><smiles>[R]NC(=O)NCCCCCCCCC(C)C</smiles>

\begin{tabular}{lll} 
& $\mathrm{n}$ & $\mathrm{R}$ \\
\hline Desmethyl-C & 2 & $\mathrm{H}$ \\
$\mathrm{C}$ & 2 & $\mathrm{CH}_{3}$
\end{tabular}



$\begin{array}{lll}\text { A } & 1 & \mathrm{CH}_{3} \\ \text { Desmethyl-B } & 3 & \mathrm{H} \\ \text { B } & 3 & \mathrm{CH}_{3}\end{array}$

photopyrones<smiles>CCCCCc1c(O)cc(CC(C)C)oc1=O</smiles><smiles>CC(C)CCCc1c(O)cc(CC(C)C)oc1=O</smiles>

$$
\begin{array}{cc} 
& n \\
\hline A & 1 \\
C & 3 \\
\text { E } & 5 \\
\text { G } & 7
\end{array}
$$$$
\begin{array}{ll} 
& n \\
\hline \text { B } 1
\end{array}
$$$$
\text { D } 3
$$$$
\text { F } 5
$$$$
\text { H } 7
$$

glidobactins
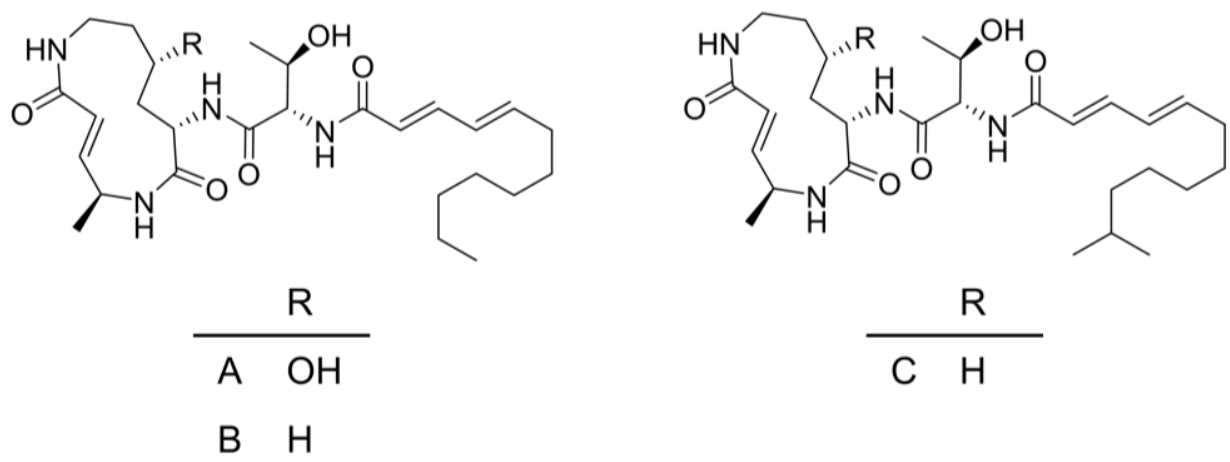

Figure 8. SMs produced by $P$. laumondii with branched groups. Different natural derivatives of phurealipids ${ }^{[103]}$, photopyrones ${ }^{[104]}$ and glidobactins ${ }^{[45]}$ are shown. 
Potentially, the influence on BCFAs or other SMs based on iso-branched FAs can be an unseen factor, which also could have an impact on nematode support. For instance in the nematode Caenorhabditis elegans the BCFAs iso 15:0 and iso 17:0 are essential for development ${ }^{105]}$. Therefore, the importance of BCFAs the Bkd complex of Photorhabdus will be part of this study.

\subsection{Aim of this work}

This study focuses on the physiological functions of the Photorhabdus SMs towards nematode development. Their influence on different stages in nematode development should be analysed by a nematode bioassay. One factor that is suggested to support nematode recovery is represented by the SM IPS, which is produced by Photorhabdus strains ${ }^{[14]}$. For that reason, the biosynthetic pathway of IPS (Figure 5) was used as a starting point to investigate the recovery and reproduction state of nematodes. Looking at the different intermediates, side products and derivatives involved, each step of the IPS biosynthetic pathway should be analysed for any effect on the nematode development. Therefore, different deletion strains were created which were analysed with HPLC-MS based methods for unknown intermediates or novel products. As the Bkd complex is involved in the biosynthesis of other SMs based on iso-branched FAs and BCFAs, these should also be investigated. In the following, the impact on the nematode will be analysed phenotypically in a nematode bioassay (Figure 9). As it is difficult to see nematode development inside the insect, the in vitro bioassay (all steps of the workflow will be explained in chapter 6.11) should imitate similar nutritional conditions on a petri dish. This facilitates the observation of the nematode life cycle under the dissecting microscope. Another aim is to investigate NG-IJ development to have an overlook of the SMs involved not only in recovery but in consideration of the whole nematode life cycle. As Photorhabdus also forms EPS from IPS, this SM needs to be investigated as well and new compounds derived from EPS should be identified. 


\section{Material and methods}

\subsection{Cultivation of strains}

Cryo cultures (stored at $-80^{\circ} \mathrm{C}$ in $15 \%(\mathrm{v} / \mathrm{v})$ glycerol) of $P$. laumondii strains were plated on lysogeny broth (LB) agar $(1 \%(\mathrm{w} / \mathrm{v})$ tryptone; $0.5 \%(\mathrm{w} / \mathrm{v})$ yeast extract; $0.5 \%(\mathrm{w} / \mathrm{v}) \mathrm{NaCl}, \mathrm{pH} 7.5$, add $1.5 \%(\mathrm{w} / \mathrm{v})$ agar) and incubated for 2-3 days at $30{ }^{\circ} \mathrm{C}$. Cell material from these plates was grown in LB-medium overnight at $30^{\circ} \mathrm{C}$ to create an overnight culture. E. coli strains taken from the cryo culture were grown on LB agar plates and incubated overnight at $37^{\circ} \mathrm{C}$. Cell material from these plates was grown in LB-medium overnight at $37^{\circ} \mathrm{C}$ The cultures were inoculated in shaking flasks (Roth riplates, shaker: Heidolph Titramax 1000, shaking at $180-200 \mathrm{rpm}$ ).

Nematode IJs were stored in cell culture flasks in Ringer's solution $(147 \mathrm{mM} \mathrm{NaCl}$, $4 \mathrm{mM} \mathrm{KCl}$ and $2.3 \mathrm{mM} \mathrm{CaCl}_{2}$ ) for up to one month. For cultivation of nematodes, $1 \mathrm{ml} \mathrm{IJs}$ in Ringer's solution was dropped on a round Whatman® filter paper and 2-4 Galleria mellonella insect larvae were placed on the Whatman paper. After $72 \mathrm{~h}$ dead insects were placed on a "white trap" as described elsewhere ${ }^{[106]}$. NGIJs were collected from the water of the "white trap", vacuum filtered and diluted in Ringer's solution.

\subsection{Isotope labelling and reverse feeding}

A dilution of 1:100 of an overnight culture was inoculated in $\mathrm{LB}$ or ${ }^{13} \mathrm{C}$-medium (ISOGRO from Sigma Aldrich) medium. For inoculation in ${ }^{13} \mathrm{C}$-medium, the overnight culture was washed once with this medium. For isotope labelling, $1 \mathrm{mM}$

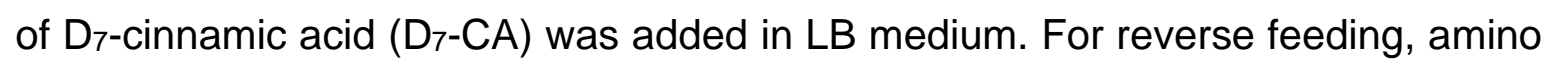
acids were added when required at the concentration of $1 \mathrm{mM}$ in ${ }^{13} \mathrm{C}$-medium. 


\subsection{Oligonucleotides}

In Table 1 all oligonucleotides used in this study are listed.

Table 1. Oligonucleotides used in this study.

\begin{tabular}{|c|c|c|}
\hline Name & Sequence & Details \\
\hline HE45 & $\begin{array}{l}\text { TTTTGGAGGCTAGCATATGAGGTTGG } \\
\text { GGATGGAATTGGT }\end{array}$ & $\begin{array}{l}\text { Deletion of plu2134 in } \\
\text { TTO1: }\end{array}$ \\
\hline HE46 & $\begin{array}{l}\text { TAGCCATTCATGGAATAAGAAATTTTA } \\
\text { ATTGCTATGTTATCACTCGCC }\end{array}$ & $\begin{array}{l}\text { Amplification of upstream } \\
\text { region of plu2134 }\end{array}$ \\
\hline HE47 & $\begin{array}{l}\text { TAGCAATTAAAATTTC } \\
\text { TTATTCCATGAATGGCTAAG }\end{array}$ & $\begin{array}{l}\text { Amplification of downstream } \\
\text { region of plu2134 }\end{array}$ \\
\hline HE48 & $\begin{array}{l}\text { GGAATTCCCGGGAGAGCTCTCCACTT } \\
\text { TCAGCAACCATTG }\end{array}$ & \\
\hline $\begin{array}{l}\text { HE49 } \\
\text { HE50 }\end{array}$ & $\begin{array}{l}\text { TGTTTCTGAATACCTGATTC } \\
\text { GCGAGATTCGCTTTTATCCA }\end{array}$ & $\begin{array}{l}\text { Verification of deletion } \\
\text { TTO1 } \Delta \text { plu2134 }\end{array}$ \\
\hline HE51 & $\begin{array}{l}\text { TTAAATTTTGGAGGCTAGCGCTGGAT } \\
\text { GCAATGGTTTTCT } \\
\text { ATAATCAAAAACAAAAAAAGATGTTCT } \\
\text { AАCCTTTATGAATATTT }\end{array}$ & $\begin{array}{l}\text { Deletion of plu2163-2165 in } \\
\text { TTO1: Amplification of } \\
\text { upstream region of plu2163- } \\
2165\end{array}$ \\
\hline HE53 & $\begin{array}{l}\text { ATTCATAAAGGTTAGAACATCTTTTTTT } \\
\text { GTTTTTGATTATTTG } \\
\text { GGAATTCCCGGGA } \\
\text { GAGCTCCACTGTTCAAGCAGCTCAGG }\end{array}$ & $\begin{array}{l}\text { Deletion of plu2163-2165 in } \\
\text { TTO1: Amplification of } \\
\text { downstream region of } \\
\text { plu2163-2165 }\end{array}$ \\
\hline $\begin{array}{l}\text { HE55 } \\
\text { HE56 }\end{array}$ & $\begin{array}{l}\text { TTAAATTTCCACAATGTGA } \\
\text { AAAGATGATGCACCAAAACG }\end{array}$ & $\begin{array}{l}\text { Verification of deletion } \\
\text { TTO1 } \Delta \text { plu2163-2165 }\end{array}$ \\
\hline HE67 & $\begin{array}{l}\text { GGATCGATCCTCTAGAGTCGACCTGC } \\
\text { ATATGTTGATATCCTACTAATTGC } \\
\text { CATAAATTGTGCCTCAAAGACACAAAT } \\
\text { AGTTAACGTGGTAG }\end{array}$ & $\begin{array}{l}\text { Deletion of plu1883-1885: } \\
\text { Amplification of upstream } \\
\text { region of plu1883-1885 }\end{array}$ \\
\hline HE69 & $\begin{array}{l}\text { CTACCACGTTAACTATTTGTGTCTTTG } \\
\text { AGGCACAATTTATG } \\
\text { GGGAGAGCTCAGATCTACGCGTTTCA } \\
\text { AAACCTTTAATTCCTCTGGC }\end{array}$ & $\begin{array}{l}\text { Deletion of plu1883-1885: } \\
\text { Amplification of downstream } \\
\text { region of plu1883-1885 }\end{array}$ \\
\hline $\begin{array}{l}\text { HE101 } \\
\text { HE102 }\end{array}$ & $\begin{array}{l}\text { GTAACAGTGGAATGGATGACC } \\
\text { CAGTCACTGAATATTTCCTGC }\end{array}$ & $\begin{array}{l}\text { Verification of deletion } \\
\text { TTO1 } \Delta \text { plu1883-1885 }\end{array}$ \\
\hline
\end{tabular}




\subsection{Plasmids}

Plasmids used in this study are listed in Table 2. Briefly, up- and downstream homologous regions of the gene of interest were fused between the restriction sites of Ndel and Sacl. The plasmid was integrated into the genome of the $P$. laumondii strain TTO1 via homologous recombination.

Table 2. Plasmid constructs used in this topic.

\begin{tabular}{ll}
\hline Name & Description \\
\hline pCK_cipB & R6K ori, CMR , oriT, sacB, tral \\
pCK_cipB_plu2134 & pCK_cipB with flanking regions of the gene plu2134 (stlB) \\
$\begin{array}{l}\text { pCK_cipB_plu2163- } \\
2165\end{array}$ & $\begin{array}{l}\text { pCK_cipB with flanking regions of the genes plu2163-2165 } \\
(\text { stlCDE })\end{array}$ \\
\hline pEB17 & $\begin{array}{l}\text { R6K ori, Kan } \\
\text { pEB17_priT, sacB, tral } \\
\text { pEB17 } 1883-1885\end{array}$ \\
\hline
\end{tabular}

\subsection{Strains}

In Table 3 all strains used in this study are listed.

Table 3. Strains used in this study.

\begin{tabular}{|c|c|c|}
\hline Name & Description & Reference \\
\hline E. coli S17-1 $\lambda$ pir & $\begin{array}{l}\text { TpR SmR recA, thi, pro, hsdRM+ } \\
\text { RP4: 2- Tc:Mu:Km Tn7 Apir }\end{array}$ & Invitrogen \\
\hline S17-11pir_pCK_cipB_plu2134 & S17 1 pir + pCK-cipB_plu2134 & This study \\
\hline S17גpir_pCK_cipB_plu2163-2165 & S17入pir + pCK-cipB_plu2163-2165 & This study \\
\hline S17^pir_pCK_cipB_plu1883-1885 & S17 & This study \\
\hline $\begin{array}{l}\text { Photorhabdus laumondii } \\
\text { ssp. laumondii TTO1 }\end{array}$ & Wildtype iff $^{R}$ & [107] \\
\hline$\Delta h f q$ & Deletion of plu4581 in TTO1 & [76] \\
\hline$\Delta n g r A$ & Deletion of plu0992 in TTO1 & [13] \\
\hline$\Delta s t / A$ & Deletion of plu2234 in TTO1 & $\begin{array}{l}\text { Alexander } \\
\text { Brachmann } \\
\text { unpublished }\end{array}$ \\
\hline$\Delta s t / B$ & Deletion of plu2134 in TTO1 & This study \\
\hline$\triangle s t / C D E$ & Deletion of plu2163-2165 in TTO1 & This study \\
\hline$\triangle b k d A B C$ & Deletion of plu1883-1885 in TTO1 & This study \\
\hline
\end{tabular}




\begin{tabular}{lll}
$\begin{array}{l}\Delta \text { pliA } \\
\Delta \text { ppyS }\end{array}$ & Deletion of plu2076 in TTO1 & {$[103]$} \\
\hline $\begin{array}{lll}\text { Photorhabdus luminescens TTO1 } \\
\text { Dplu2236 }\end{array}$ & Weletion of plu4844 in TTO1 & {$[108]$} \\
\hline Heterorhabditis bacteriophora & Deletion of plu2236 in TTO1 & {$[86]$} \\
& Wild type & $\begin{array}{l}{[86]} \\
\text { provided by } \\
\text { Heermann } \\
\text { group }\end{array}$ \\
\hline Galleria mellonella & Wild type & $\begin{array}{l}\text { Commercial } \\
\text { shop for pet }\end{array}$ \\
& & supplies \\
\hline Tenebrio molitor & Wild type & Commercial \\
& & shop for pet \\
& & supplies \\
\hline
\end{tabular}

\subsection{Conjugation}

From an overnight culture of the respective E. coli S17-1Apir mutant 1:100 dilution and a 1:25 dilution of $P$. laumondii TTO1 strain were inoculated. The cells were incubated at $37^{\circ} \mathrm{C}$ for $\mathrm{S} 17-1 \lambda$ pir and $30^{\circ} \mathrm{C}$ for TTO1 respectively up to an $\mathrm{OD}_{600}$ about 0.6-1. A volume of $1 \mathrm{ml}$ of each culture was centrifuged at $13000 \mathrm{rpm}$ at room temperature for $1 \mathrm{~min}$. The pellets were washed in $1 \mathrm{ml}$ LB-medium to remove remaining antibiotics. After a second centrifugation step, the cells were resuspended in $400 \mu \mathrm{LB}$-medium. Then, a ratio of the bacterial suspensions S171 $\lambda$ pir and TTO1 of 1:3 was spotted on a LB agar plate and gently mixed. The plates were incubated at $37^{\circ} \mathrm{C}$ for $3 \mathrm{~h}$, then at $30^{\circ} \mathrm{C}$ for $21 \mathrm{~h}$. The cell plaque was scraped from the plate and resuspended in LB-medium. A volume of 50, 100 and $200 \mu \mathrm{l}$ of this cell suspension were plated on a LB agar plate with chloramphenicol/kanamycin and rifampicin and incubated for $72-90 \mathrm{~h}$ at $30^{\circ} \mathrm{C}$.

\subsection{Creating deletion strains}

PCR fragments for homologous regions upstream and downstream of the gene of interest were amplified using primers listed in Table 1. The plasmids PCK_cipB and pEB17 were linearized using the restriction enzymes Ndel and Sacl. The fragments were fused via polymerase chain reaction (PCR) and subsequently cloned into the linearized plasmid via hot fusion cloning ${ }^{[109]}$. The plasmid construct was transformed into $E$. coli $\$ 17-1 \lambda$ pir and further transformed into $P$. laumondii TTO1 strain via conjugation (chapter 6.6). $5 \mu \mathrm{l}$ and $25 \mu \mathrm{l}$ of an overnight culture of 
the TTO1 insertion strain was spread on two agar plates containing LB medium supplemented with the antibiotic rifampicin and $6 \%(\mathrm{v} / \mathrm{v})$ sucrose (stock solution: $60 \%(\mathrm{w} / \mathrm{v})$ sucrose). The plates were incubated at $30^{\circ} \mathrm{C}$ for $48-72 \mathrm{~h}$, where second recombination occur due to $s a c B$ selective marker. Finally, the deletions were verified using oligonucleotides listed in Table 1.

\subsection{HPLC-MS analysis}

A dilution of 1:100 of an overnight culture of respective TTO1 strains was added to $10 \mathrm{ml}$ LB-medium in shaking flasks. If required, adsorbent resin beads (XAD16 (Amberlite), $2 \%(\mathrm{v} / \mathrm{v}))$ were added to the cultures and incubated for $72 \mathrm{~h}$ at $30^{\circ} \mathrm{C}$. LB- and ${ }^{13} \mathrm{C}$-medium cultures without XAD16 were extracted 1:2 with methanol. When XAD16 was added, the beads were filtered from the culture. One culture volume of methanol was added to the XAD16 beads in shaking flasks and stirred for $1 \mathrm{~h}$ at room temperature. XAD16 beads were filtered from the extracts, which were centrifuged for $15 \mathrm{~min}$ at $13000 \mathrm{rpm}$ and room temperature before measurement.

All extracts were dried in the Eppendorf speedvac at $45^{\circ} \mathrm{C}$ and stored at $-20^{\circ} \mathrm{C}$. An amaZonX or an impact II MS system (Bruker) coupled to an UltiMate 3000 RS (Thermo Scientific) HPLC systems was used for analyses. Separation was achieved by chromatography with the reverse phase C18 UPLC-column $(50 \mathrm{~mm} x$ $2.1 \mathrm{~mm} \times 1.7 \mu \mathrm{l}$, Acquity Waters $\mathrm{GmbH}$ ) through gradient elution with acetonitrile ( $5 \%$ up to $95 \%$ ) in $\mathrm{ddH}_{2} \mathrm{O}$ for $16 \mathrm{~min}$ with a flow rate of $0.4 \mathrm{ml} / \mathrm{min}$.

Raw data was analysed using Bruker Compass DataAnalysis 4.2

\subsection{GC MS conditions}

The procedure for Identification and relative quantification of FAs is described elsewhere[110]. Briefly, samples were prepared by harvesting bacterial cells of $3 \mathrm{~d}$ old liquid culture of Photorhabdus or Xenorhabdus strains. After centrifugation, the cell pellet was solved in aqueous $\mathrm{NaCl}$ solution $(1 \% \mathrm{w} / \mathrm{v})$ and transferred into a glass vial. Samples of insect larvae were prepared by freezing with liquid $\mathrm{N}_{2}$ and grinded with a mortar. Cell pellets or grinded insects were dried in a vacuum concentrator. 
Fatty acid methyl esters (FAME) were produced by adding $500 \mu \mathrm{l}$ of a mixture of methanol, toluene, and sulfuric acid (50:50:2 $\mathrm{v} / \mathrm{v} / \mathrm{v})$ to the dried biomaterial or to $200 \mu \mathrm{l}$ of lipids and incubated at $60^{\circ} \mathrm{C}$ overnight. After the mixture was cooled to room temperature, $400 \mu \mathrm{l}$ of an aqueous $\mathrm{NH}_{4} \mathrm{HCO}_{3}$ solution $(0.5 \mathrm{M})$ was added, and phase separation was achieved by centrifugation. To $75 \mu$ of the upper organic phase, $25 \mu \mathrm{l}$ of $\mathrm{N}$-methyl-N-trimethylsilyltrifluoroacetamide (MSTFA) (Macherey-Nagel, Düren, Germany) was added, and the mixture was allowed to react for $30 \mathrm{~min}$ at $37^{\circ} \mathrm{C}$.

GC MS measurement was carried out on an Agilent 6890N gas chromatograph with a 5973 electron impact mass selective detector (Agilent, Waldbronn, Germany) using a dimethyl-(5\% phenyl)-polysiloxane capillary column (Agilent HP- $5 \mathrm{~ms}, 0.25 \mathrm{~mm}$ by $30 \mathrm{~m}$ by $0.25 \mu \mathrm{m}$ ) and helium as the carrier gas at a flow rate of $1 \mathrm{ml} / \mathrm{min}$. A volume of $1 \mu \mathrm{l}$ of the sample was injected in split mode (split ratio, 10:1). The column temperature was kept at $70^{\circ} \mathrm{C}$ for $2.5 \mathrm{~min}$, increased to $130{ }^{\circ} \mathrm{C}$ at a rate of $120^{\circ} \mathrm{C} / \mathrm{min}$, and then ramped to $240{ }^{\circ} \mathrm{C}$ at $5{ }^{\circ} \mathrm{C} / \mathrm{min}$ with a following ramping to $300^{\circ} \mathrm{C}$ at $30^{\circ} \mathrm{C} / \mathrm{min}$. Finally, the column was held at $300^{\circ} \mathrm{C}$ for $5 \mathrm{~min}$ and ramped down to $130^{\circ} \mathrm{C}$ at $30^{\circ} \mathrm{C} / \mathrm{min}$ and held at this temperature for $1 \mathrm{~min}$. Other temperatures were as follows: inlet, $250^{\circ} \mathrm{C}$; GC-MS transfer line, $280^{\circ} \mathrm{C}$; ion source, $230^{\circ} \mathrm{C}$; and quadrupole, $150^{\circ} \mathrm{C}$. The mass selective detector was operated in scan mode, scanning the mass range from $\mathrm{m} / \mathrm{z} 40$ to 700 . Data analysis was carried out with AMDIS software ${ }^{[111]}$, version 2.64 (NIST, Gaithersburg, MD), using the value "integrated signal" for quantification. Amounts were calculated in percentages relative to the sum of integrals of a predefined (standard measurements were performed by Wolfram Lorenzen and Tilman Ahrend: WLO+TA database) subset of FAME.

\subsection{Extracting lipids from bacteria}

Extraction of lipids from P. laumondii and E. coli were performed using the Bligh and Dyer extraction method ${ }^{[12]}$. Briefly, a mixture of chloroform, methanol and water was added to bacteria cell pellet. One volume of cell pellet chloroform and 2 volumes of methanol was added and mixed. Afterwards, 1 volume of $\mathrm{dd}_{2} \mathrm{O}$ was added and mixed again. Following the centrifugation step (15 min at $4000 \mathrm{rpm}$, 
Eppendorf centrifuge) led to phase separation and the lower phase was analysed with FAME (chapter 6.9) and used as feeding components for the nematode bioassay.

\subsection{Nematode bioassay}

The in vitro nematode bioassay was established based on the protocols described elsewhere ${ }^{[76,113]}$. The assay was performed on nutrient rich lipid agar $(1 \%(\mathrm{w} / \mathrm{v})$ corn syrup, $0.5 \%(\mathrm{w} / \mathrm{v})$ yeast extract, $2.5 \%(\mathrm{w} / \mathrm{v})$ nutrient agar, $0.5 \%(\mathrm{v} / \mathrm{v}) \operatorname{cod}$ liver oil and $\left.0.2 \%(\mathrm{w} / \mathrm{v}) \mathrm{MgCl}_{2} \cdot 6 \mathrm{H}_{2} \mathrm{O}\right) .40 \mathrm{ml}$ medium was used per plate $(92 \times 16 \mathrm{~mm})$. For complementation experiments $1 \mathrm{mM}$ CA or $20 \mu \mathrm{g} / \mathrm{ml}$ IPS (purified and kindly provided by Lei Zhao) was added directly into the agar medium if required. An overnight culture of Photorhabdus or Xenorhabdus was diluted to an $\mathrm{OD}_{600}$ of 5.0. $200 \mu \mathrm{l}$ of this dilution was dropped in Z-form on the lipid agar plates and incubated for $72 \mathrm{~h}$ at $30^{\circ} \mathrm{C}$. After incubation, 50 surface-sterilized IJs of the nematode Heterorhabditis or Steinernema were added to bacteria colonies. IJs were surface-sterilized with a solution of hyamine $(0.4 \%(\mathrm{w} / \mathrm{v}))$ one time and PBS buffer (137 mM NaCl, $2.7 \mathrm{mM} \mathrm{KCl}, 10 \mathrm{mM} \mathrm{Na}_{2} \mathrm{HPO}_{4}, 1.8 \mathrm{mM} \mathrm{KH}_{2} \mathrm{PO}_{4}$ ) three times. The number of IJs was determined by counting from ten $10 \mu$ droplets under a dissecting microscope, (Carl Zeiss, 40x magnifications) and an average out of the numbers in every droplet was calculated. After the IJs were added to the bacteria colonies, the plates were placed into larger petri dishes $(150 \times 20 \mathrm{~mm})$ containing sterilized $\mathrm{ddH}_{2} \mathrm{O}$ and incubated for $4 \mathrm{~d}$ at $30^{\circ} \mathrm{C}$. The number of recovered nematodes on the plates was counted under the dissecting microscope at $8 \mathrm{x}$ magnifications. The assay was made with at least ten replicates per strain. Further, the plates were again incubated at $30^{\circ} \mathrm{C}$ for $2-3$ weeks until IJ outbreaking point. The IJs were counted under the dissecting microscope at $40 \mathrm{x}$ magnifications. If the number of IJs was too dense, ten $10 \mu \mathrm{l}$ droplets were counted and calculated for the whole volume. A schematic overview of the nematode bioassay is presented in Figure 9. 

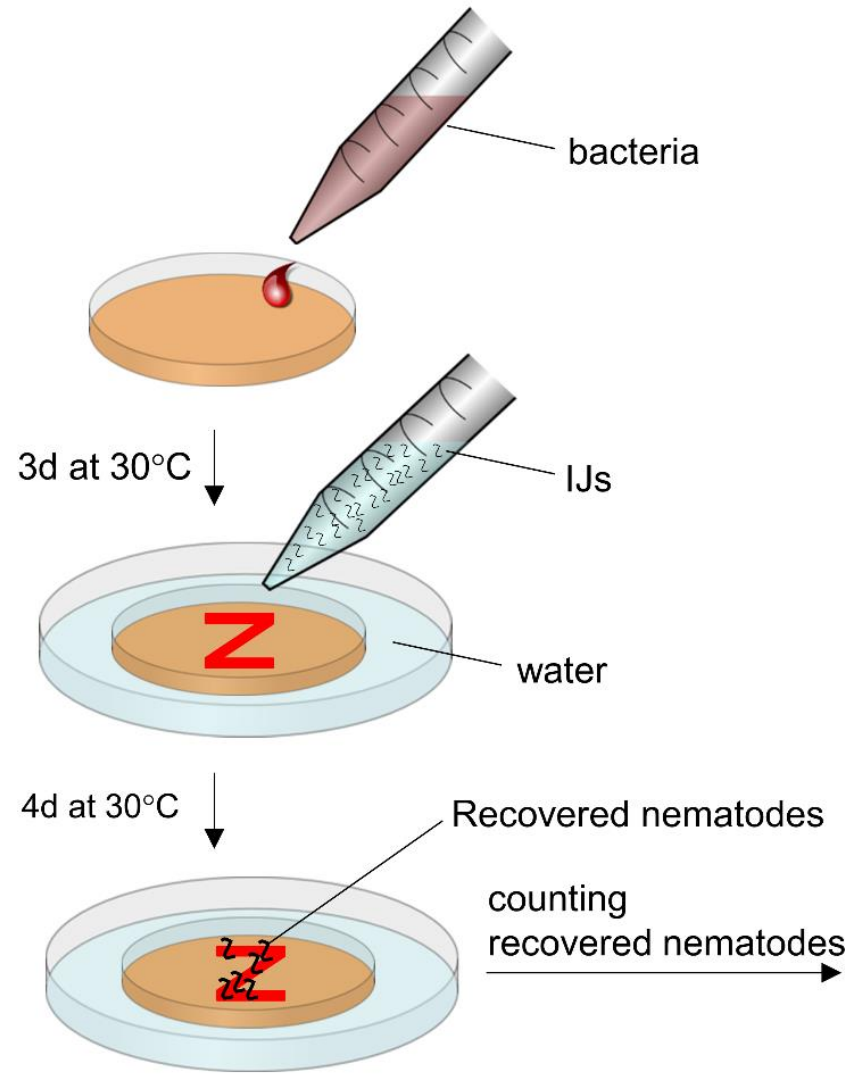

$14 \mathrm{~d}$ at $30^{\circ} \mathrm{C}$
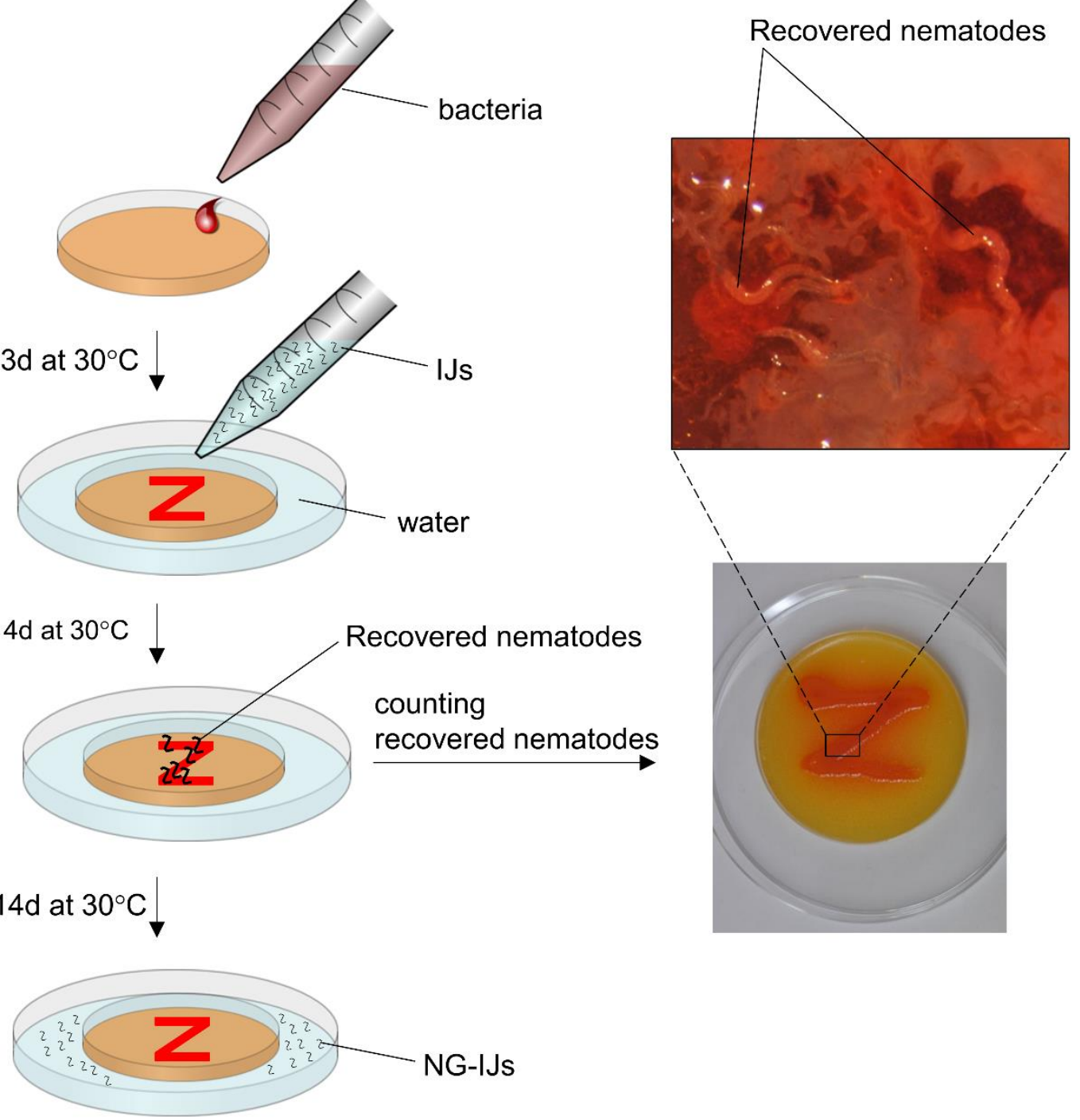

counting NG-IJs in $\checkmark$ water droplets

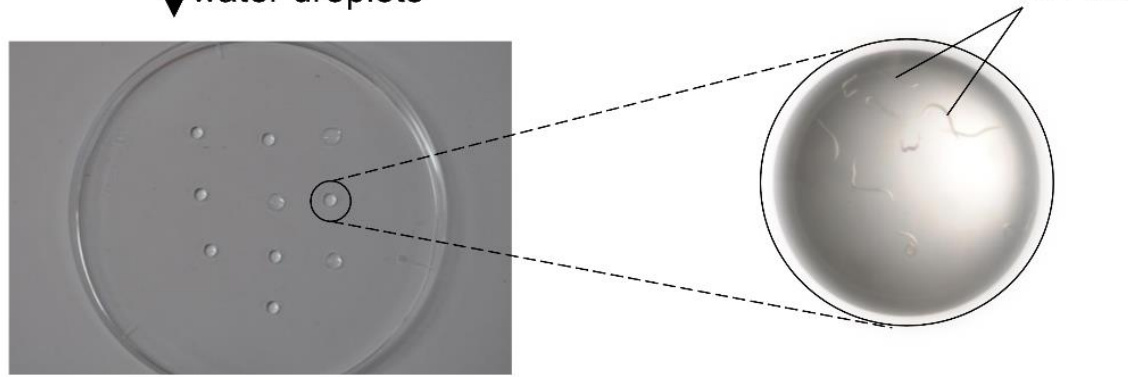

Figure 9. Schematic overview of the nematode bioassay. First, Photorhabdus bacteria were spread on a petri dish containing medium. After incubation Heterorhabditis IJs were added to the bacteria. Recovered nematodes were observed on top of the "Z" shaped bacteria colonies under the dissecting microscope after $4 \mathrm{~d}$ of IJ placement. NG-IJs were observed inside the water under the dissecting microscope. If the number of IJs was too dense, $10 \times 10 \mu \mathrm{l}$ droplets were counted and calculated for the whole volume. 


\subsection{Scanning electron microscopy (SEM)}

$H$. bacteriophora hermaphrodites were picked from the nematode bioassay plate and placed in hourglasses filled with PBS buffer. For fixation, the worms were incubated at $4{ }^{\circ} \mathrm{C}$ in fixing solution $(2 \%$ sucrose $(\mathrm{w} / \mathrm{v}), 2 \%$ glutardialdehyde $(\mathrm{v} / \mathrm{v})$ in aqueous natriumcacodylat buffer $\left(0.1 \mathrm{M}\left(\mathrm{CH}_{3}\right)_{2} \mathrm{AsO}_{2} \mathrm{Na} \mathrm{pH}=7.3\right)$ overnight. Following dehydration step was accomplished in graduated series of ethanol $\left(30 / 50 / 70 / 90 / 100 \%(v / v)\right.$ in $\left.d_{d H_{2}} \mathrm{O}\right)$ for 30 min for each ethanol concentration.

The process of drying was carried out using a critical point of $\mathrm{CO}_{2}$ (Baltec CPD 030). The samples were assembled on bases for SEM (Hitachi S-4500) covered with gold. Drying with the critical point of $\mathrm{CO}_{2}$ and operating the SEM was conducted by Niklas Döring.

\subsection{Insect killing assay}

To sedate G. mellonella the larvae were incubated on ice for at least $15 \mathrm{~min}$. A $10 \mu \mathrm{l} \mathrm{Hamilton}$ glass syringe was sterilized in $70 \%(\mathrm{v} / \mathrm{v})$ ethanol and rinsed in sterilized $\mathrm{ddH}_{2} \mathrm{O}$. A volume of $10 \mu \mathrm{l}$ of the $P$. laumondii overnight LB-culture, or LBmedium as a control, was injected inside the larvae. The insects were stored in empty petri plates at $30^{\circ} \mathrm{C}$ for $4 \mathrm{~d}$. Insect death was determined by missing movement of the larvae. LB medium was injected as a control. 


\section{Results}

\subsection{The influence of isopropyl stilbene towards nematode development}

The aim of this study was the analysis of different deletion strains from the IPS biosynthetic pathway steps, as stated in Figure 5, to investigate possible effect of its intermediates on nematodes. It was shown in the literature, that nematode development is reduced when grown on a lawn of a stIA (plu2234) deletion strain, interrupting the initial reaction from phenylalanine to CA of the IPS biosynthetic pathway (Figure 5). The authors could complement this effect by feeding purified IPS or $\mathrm{CA}^{[14]}$. However, considering only one mutant disrupting the initial reaction of the biosynthetic pathway disregards the potential of other derivatives. Therefore, this topic will focus on the phenylalanine derived intermediate steps of the IPS biosynthetic pathway (Figure 5 highlighted in orange). The investigations of the strains should always be compared to wild type and to a proper negative control.

\subsubsection{Nematode bioassay: Finding the right strain for negative control}

The nematode bioassay, described in detail in chapter 6.11 , is a tool to investigate the life cycle of $H$. bacteriophora under in vitro conditions. To simulate the insect carcass, a special lipid rich medium (chapter 6.11) was used to cultivate different $P$. laumondii TTO1 strains. The IJ stage nematodes were then placed onto the grown TTO1 biomass to investigate with a microscope the different nematode stages as described in chapter 5.2 and Figure 1.

To investigate the influence of bacterial SMs in nematode development a proper control is fundamental. For this, the TTO1 deletion strains $\Delta h f q$ and $\Delta n g r A$ were chosen. Hfq is a global posttranslational regulator. In the $\Delta h f q$ mutant, all SMs are abolished and nematode development is strongly reduced ${ }^{[76]}$. NgrA is a PPTase, essential for the functionality of NRPS and PKS (Figure 4) and therefore required for activation of most SM production. Consequently, the $\triangle$ ngrA mutant is unable to produce SMs making it a suitable control for the nematode bioassay as well. 
Recovery of nematodes grown on the $\Delta$ could be partly complemented by crude TTO1 wild type extract, containing all known SMs in one mixture ${ }^{[76]}$ indicating the importance of SMs towards nematode development.

In the nematode bioassay, IJ nematodes are applied to start the life cycle growing on the TTO1 cells cultivated on the nematode bioassay lipid agar plates (Figure 9). Feeding on the medium and bacterial biomass, the IJs first develop into $\mathrm{J} 4$ stage and then into adult hermaphrodites (Figure 1, Figure 11). To investigate morphological differences of developed hermaphrodites fed on TTO1 wild type, $\Delta n g r A$ or $\Delta h f q$ strain (Table 3 ), the size of the worms was calculated using SEM pictures (chapter 6.12) to compare pleiotropic effects by their different morphology (Figure 10).

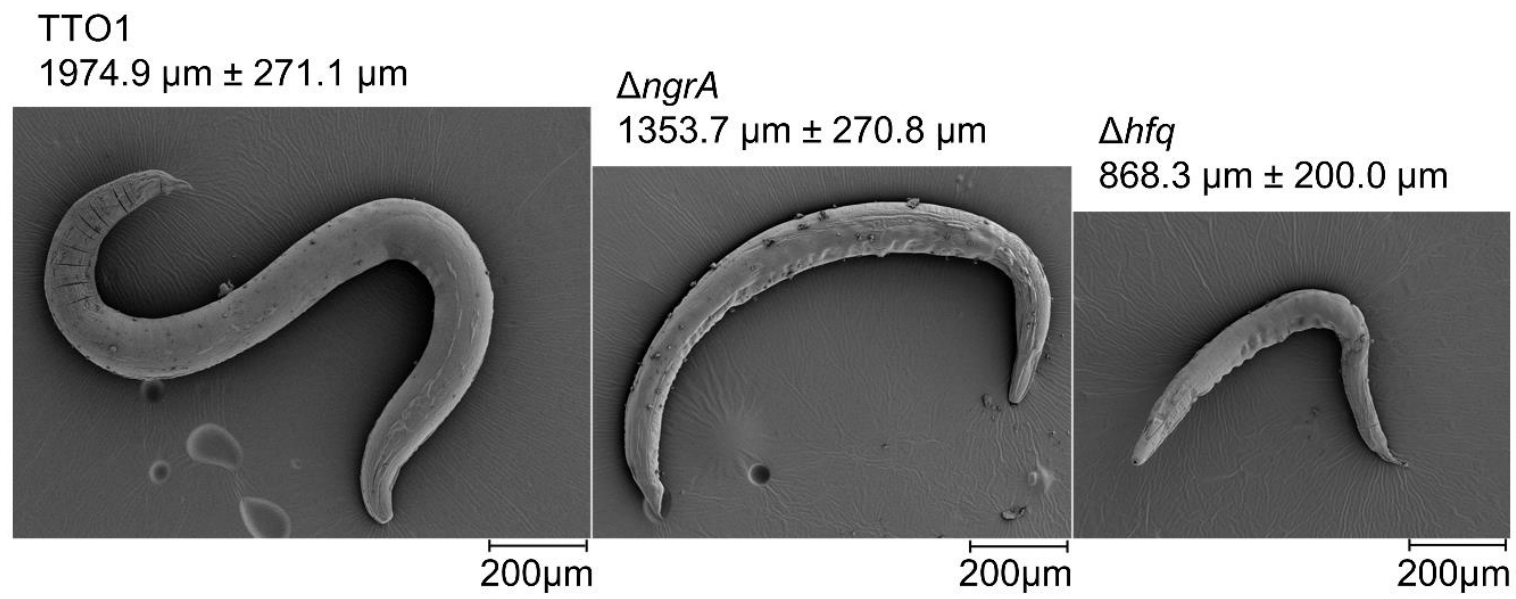

Figure 10. SEM pictures of Heterorhabditis hermaphrodites grown on nematode bioassay. Length of the Hermaphrodites grown on TTO1 was measured with ImageJ. For statistical analysis, T-test generated by GraphPad Prism was used; TTO1 $\mathrm{n}=9 ; \Delta n g r A$ $\mathrm{n}=10 \Delta h f q \mathrm{n}=8$ TTO1 vs. $\triangle n g r A \mathrm{p}=0,0002$, TTO1 vs. $\Delta h f q \mathrm{p}=<0,0001)$. Operating the SEM and taking pictures were performed by Niklas Döring.

The size of the hermaphrodites grown on the deletion mutants $\Delta h f q$ or $\Delta n g r A$ was significantly smaller compared to those that developed on TTO1 wild type and compared to one another. Furthermore, different strains also affected the total number of recovered nematodes out of the initial placed $50 \mathrm{IJS}$ (chapter 6.11). Did all 50 IJs recover or only some or even none of them recovered? The more IJs recover, the better the development support of the bacterial strain. On lipid agar plates the high density of the biomass of the $P$. laumondii bacteria complicates the differentiation between $\mathrm{J} 4$ and hermaphrodites but they could clearly be 
distinguished from the IJ stage (Figure 11). Therefore, all recovered nematodes were taken into account without distinguishing $\mathrm{J} 4$ and hermaphrodites as both stages demonstrate success in recovery. The nematode bioassay was used as a tool to quantify the total recovery out of $50 \mathrm{IJs}$ placed on a plate (Figure 12).

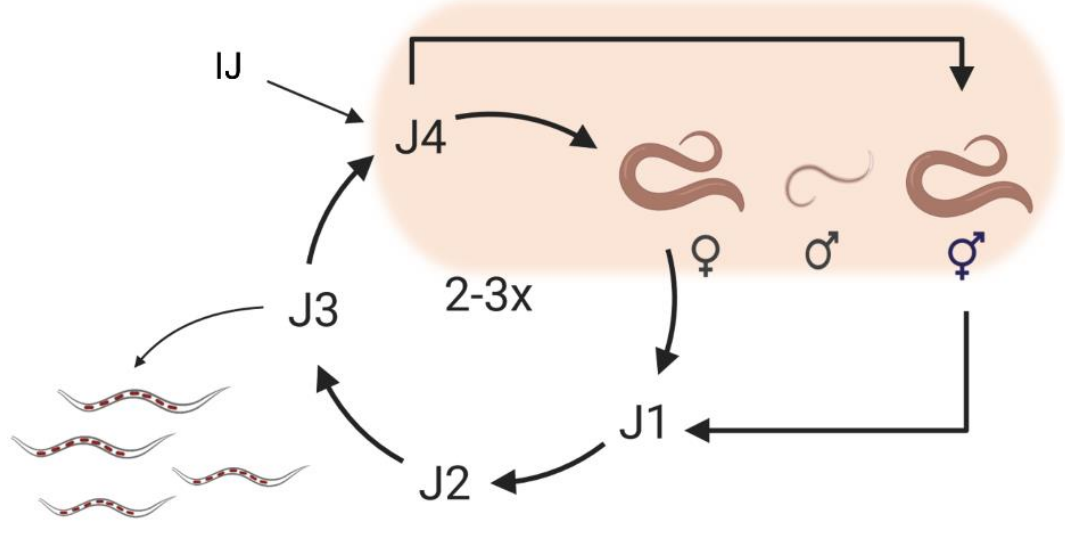

NG-IJs

Figure 11. Life cycle of $H$. bacteriophora with highlighted part for recovered nematodes that were counted.

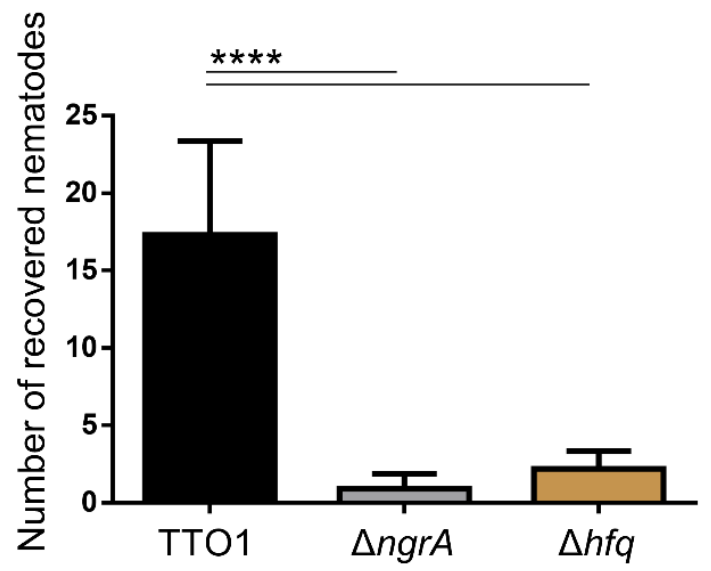

Figure 12. Counted recovered nematodes after $4 \mathrm{~d}$, grown on TTO1 $\Delta h f q$. Each column represents the mean of 10 individual experiments with standard deviation. Statistical analysis was done with Tukey's multiple comparisons test (generated by GraphPad Prism). Stars represent significant differences between two strains at a time indicated by lines.

The number of recovered nematodes was significantly reduced when IJs were cultivated on $\Delta n g r A$ bacteria and almost completely absent when fed on the $\Delta h f q$ deletion strain. Both deletion strains were in principle suitable as a negative control for the nematode bioassay. Therefore, the $\Delta n g r A$ deletion strain was further used 
as a negative control for the nematode bioassay as this deletion only affects most SMs, whereas the deletion of $h f q$ have pleiotropic effects, as for example growth defects $^{[76]}$.

\subsubsection{Feeding experiments with CA and IPS}

This part of the work focuses on the influence of IPS or another derivative or side product of its biosynthesis on nematode recovery. Does IPS alone support nematode recovery or are other SMs also involved in this process? Feeding either IPS or CA (precursor of the phenylalanine derived pathway, Figure 5, highlighted in orange), was performed by adding the dissolved compounds to the medium of the nematode bioassay (chapter 6.11). Three different deletion strains, all from the phenylalanine derived pathway of IPS biosynthesis (Figure 5), $\Delta s t / A, \Delta s t / B$ and $\triangle$ st/CDE (chapter 6.5, 0 and Table 3), were compared to TTO1 wild type and to the $\Delta n g r A$ strain as negative control. CA was fed to the $\triangle s t / A$ mutant as it is the product of the phenylalanine ammonium lyase $S t \mid A$, and to $\Delta s t B$ and as this strain is unable to produce IPS, so CA derived side products can be investigated, and to $\Delta n g r A$ strain as a control. IPS was fed in a nematode bioassay containing $\Delta h f q$ deletion strain as an approach to the study which showed recovery complementation by feeding crude extract ${ }^{[76]}$ Further, IPS was fed to a nematode bioassay growing on the $\Delta s t / A$ mutant, similar as published elsewhere ${ }^{[14]}$, and to the mutants $\Delta s t / B$ and $\Delta n g r A$ (Figure 13). Recovered nematodes were determined as displayed in Figure 11. 
A)

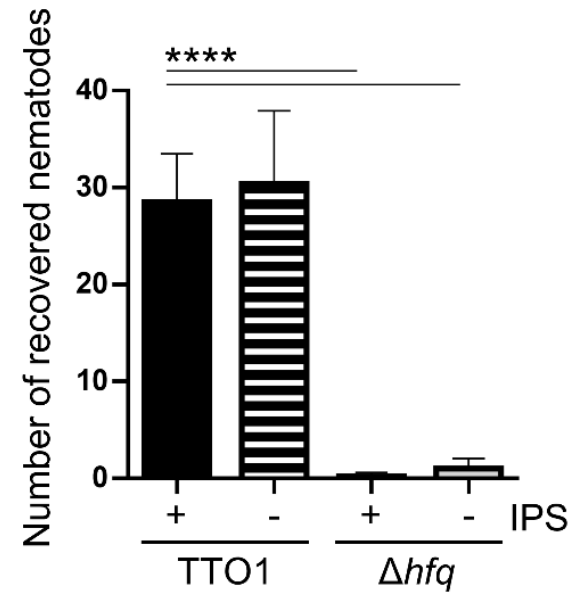

B)

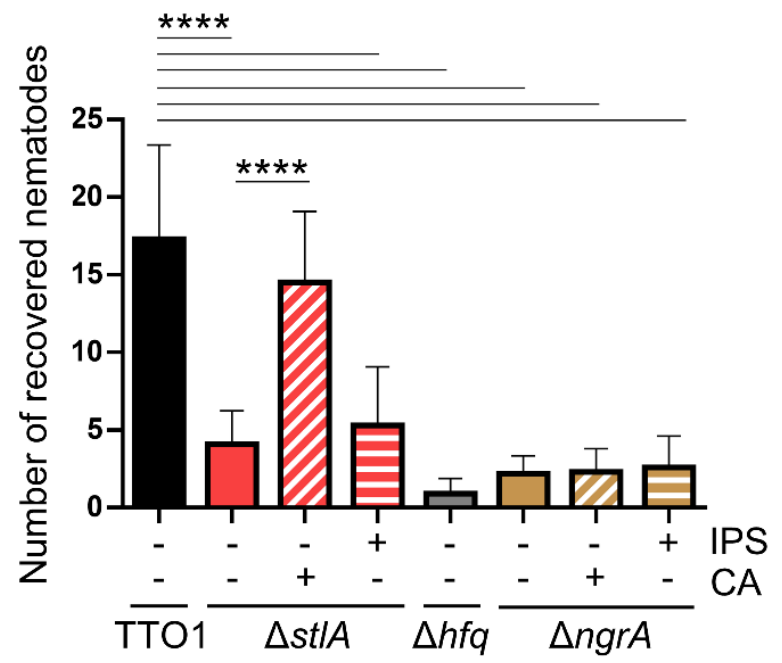

C)

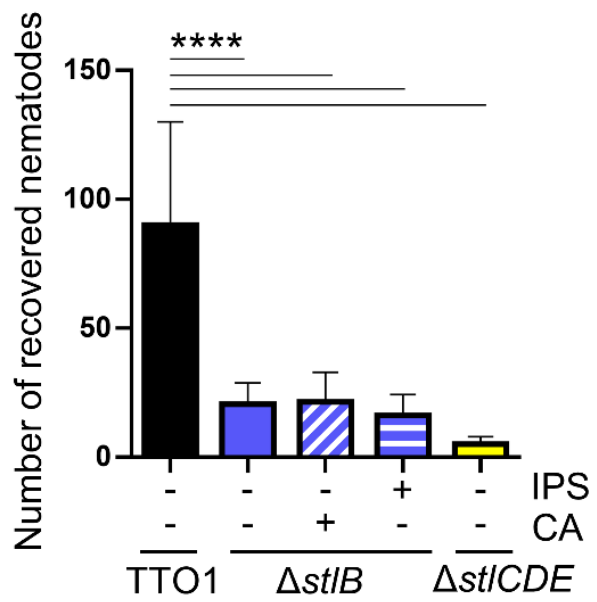

Figure 13. Recovered nematodes on nematode bioassay. Recovered nematodes were counted after $4 \mathrm{~d}$ IJ incubation A) Recovered nematodes grown on assays with $\Delta h f q$ and feeding IPS B) Recovered nematodes grown on assays with $\Delta s t / A$ and $\Delta$ ngrA mutants with feeding in both strains of CA or IPS, respectively and with $\Delta h f q$ mutant C) Recovered nematodes grown on assays with $\triangle$ st/B mutant with feeding of CA or IPS, respectively and with $\triangle s t / C D E$ mutant. Each column represents the mean of 10 individual experiments with standard deviation. Statistical analysis was done with Tukey's multiple comparisons 
test (generated by GraphPad Prism) with stars showing significant difference between two strains at a time showed by the lines.

The crude extract, containing all SMs, including IPS and derivatives thereof, produced by wild type TTO1 could complement the $\Delta h f q$ mutant ${ }^{[76]}$. Our aim was to test whether feeding purified IPS could have the same effect. Adding IPS to nematode bioassay containing TTO1 wild type or $\Delta h f q$ bacteria biomass has shown no significant improvement in nematode recovery (Figure 13A).

Feeding experiments of CA and IPS were done with $\triangle n g r A$ as this strain is missing all ACP/PCP dependent SMs (Figure 13B). Again, we could not see any significant complementation of nematode recovery. Feeding of CA and IPS was performed to the IPS biosynthetic pathway deletion strains $\triangle s t / A$, which converts phenylalanine into $C A$ (Figure 13B), and $\Delta s t / B$, which forms cinnamoyl-CoA out of CA (Figure 13C). CA could complement $\Delta s t / A$ to almost wild type level. IPS could not complement any tested strain as it showed no significant improvement in the number of developed nematodes.

\subsection{Branched-chain fatty acids are essential for IJ development}

\subsubsection{SM production is influenced by Bkd}

In Figure 13 it was shown that feeding IPS could not complement the defects in nematode development when growing on deletion strains derived from phenylalanine (Figure 5 , highlighted in orange) of the biosynthetic pathway ( $\triangle s t / A$ and $\Delta s t / B$ ). However, feeding $C A$ to nematodes grown on $\Delta s t / A$ mutant could complement the recovery process (Figure 13B). Thus, another compound derived from CA must be one of the food signals. Ethyl stilbene (Figure 6) could function as such food signal for the nematodes instead, as production is complemented with feeding CA to $\triangle s t / A$ mutant but not with feeding of IPS (Figure 13B). Using the $\triangle b k d A B C$ deletion mutant for nematode bioassay experiments could elucidate the role of ethyl stilbene towards recovery process. However, a missing Bkd complex might lead to abrogation of all SMs based on iso-branched FAs (Figure 8), which could also have effects on the nematodes. Thus, we analysed the MS data whether SMs based on iso-branched FAs are dependent on the Bkd complex (Figure 14) to further analyse this kind of SMs in the nematode bioassay as well. 
The Bkd complex encoded by $b k d A B C$ is also responsible for the production of BCFAs, which should be analysed for effects on nematodes.

The analysis of culture extract from the deletion mutants $\triangle b k d A B C$ and $\triangle s t / C D E$ (Figure 14) demonstrate the importance of the Bkd complex to produce SMs based on iso-branched FAs.

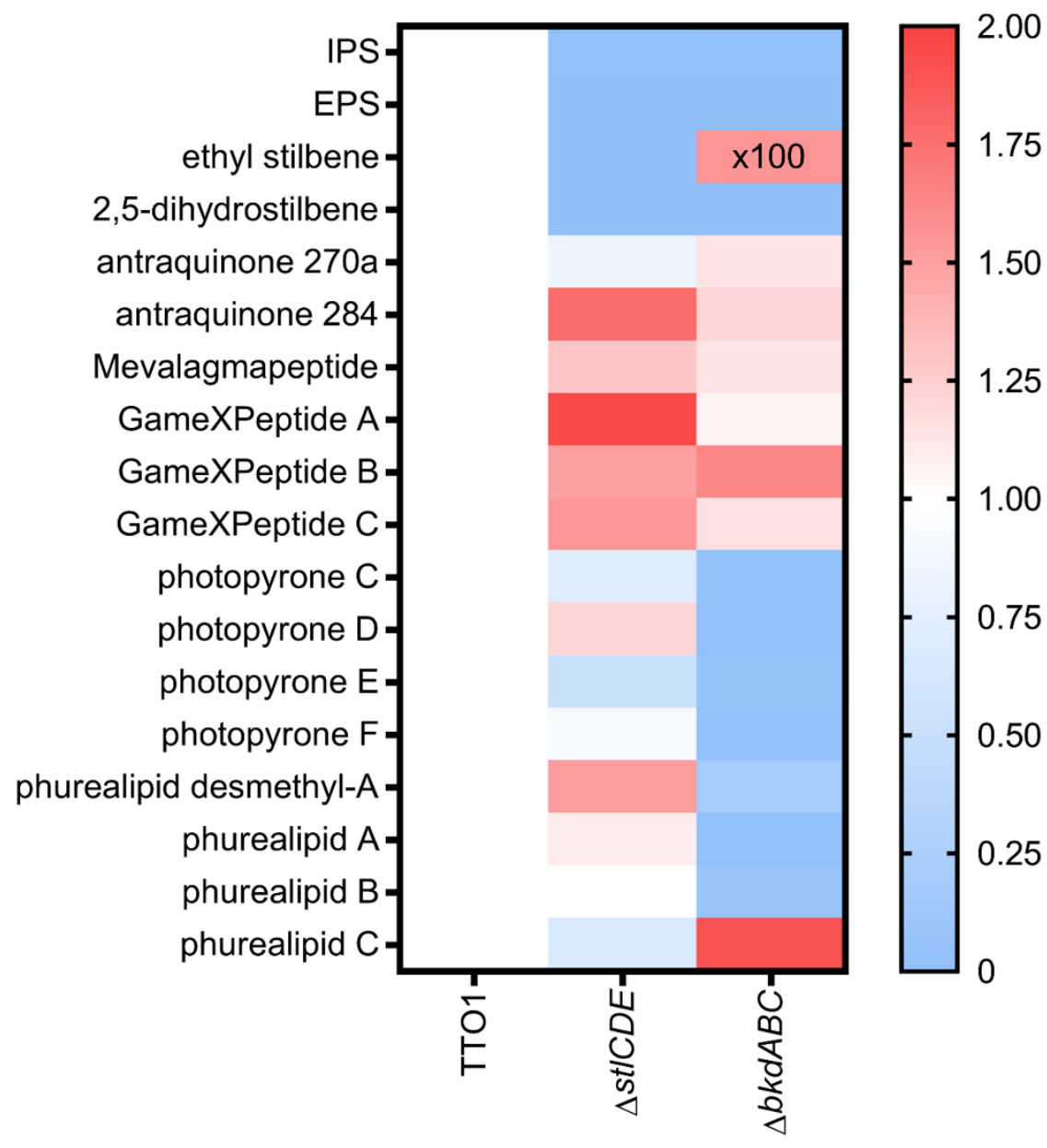

Figure 14. SMs production in TTO1 wild type and deletion strains ( $\triangle S t / C D E, \triangle b k d A B C)$ measured with HPLC-ESI-MS. Quantification of the SMs was performed in the deletion mutants. Wild type level production was set to 1 .

Bkd derived BCFAs serve as precursors for the biosynthesis of IPS and other SMs based on iso-branched FAs like for example photopyrones and phurealipids (Figure 8). The stilbene molecules IPS, EPS, ethyl stilbene and 2,5dihydrostilbene (Figure 6) were absent in the $\triangle s t / C D E$ strain. Due to their isobranched precursors, IPS, EPS and the 2,5-dihydrostilbene were also not produced in the $\triangle b k d A B C$ strain (Figure 14). However, ethyl stilbene was 
produced in 100-fold more in the $\triangle b k d A B C$ strain than in the wild type (Figure 14). The branched phurealipids and photopyrones (Figure 8) were not produced by the $\triangle b k d A B C$ mutant but their production was not significantly affected by the deletion of $s t / C D E$. Consequently, the linear phurealipid $C$ is produced in higher amounts by the $\triangle b k d A B C$ mutant. The SM based on iso-branched FAs glidobactin as shown in Figure 8 was not detected in any strain. Antraquinone and GameXPeptide are overproduced by $\triangle S t / C D E$ but are not influenced in the $\triangle b k d A B C$ strain. The production of Mevalagmapeptide seem to be unaffected by the deletion strains (Figure 14)

The following nematode bioassay was planned based on the analysis of the SMs profiling of the $\triangle b k d A B C$ strain. Consequently, the effects on nematode development of different deletion strains and respective SMs were analysed: phurealipids $(\triangle p l i A)$ and photopyrones $(\triangle p p y S)$, IPS deficient strains $\triangle s t / C D E$ and $\triangle b k d A B C$, TTO1 wild type and $\triangle n g r A$ as a negative control (Figure 15).

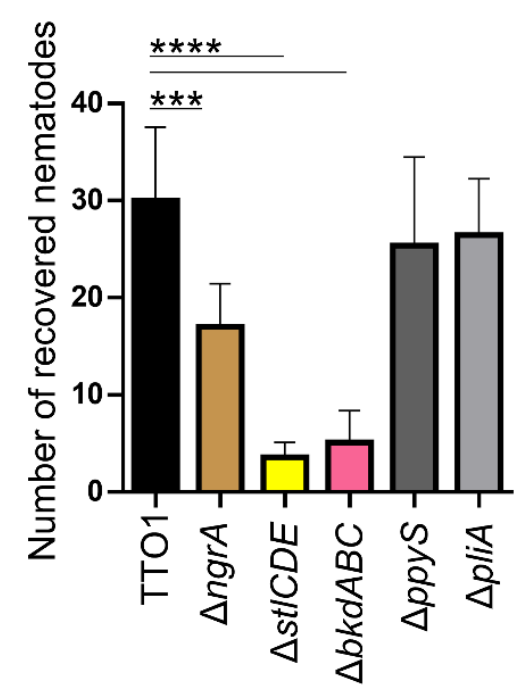

Figure 15. Nematode bioassay with different deletion strains. Recovered nematodes were counted after $4 \mathrm{~d} \mathrm{IJ}$ incubation. Each column represents the mean of 10 individual experiments with standard deviation. Statistical analysis was done with Tukey's multiple comparisons test (generated by GraphPad Prism) with stars showing significant difference between two strains at a time showed by the lines.

The nematode bioassay showed a significant reduced recovery of nematodes cultivated on $\triangle n g r A, \triangle s t / C D E$ and $\triangle b k d A B C$ mutants. There is no significant difference between nematodes grown on $\triangle S t / C D E$ and $\triangle b k d A B C$, mutants, meaning that ethyl stilbene is most likely not involved in nematode development. 
The strains $\Delta p p y S$ and $\Delta$ pliA showed no significant difference in comparison with the wild type. This shows that photopyrones and phurealipids are not involved in nematode development. Thus, the effects on the nematode development can be determined to the IPS biosynthetic pathway related compounds.

\subsubsection{Fatty acid profiles}

Since no side effects on nematode development from missing photopyrones and phurealipids in the $\triangle b k d A B C$ mutant were observed (Chapter 7.2.1), in a next step the impact of the loss of BCFAs on the nematode development was investigated. Using FAME of bacterial cell pellets and analysis via GC-MS (Chapter 6.9), the loss of BCFAs in the $\triangle b k d A B C$ strain needed to be verified and comparatively, the contribution of BCFAs in wild type and the negative control strains $\triangle n g r A$ and $\Delta h f q$ were determined (Table 4).

Table 4. FA profile of $P$. laumondii strains in triplicates. Relative quantification was done using data generated with GC-MS using the FAME method. FAs were annotated using the NIST database and WLO+TA (implemented database, based on standard measurements done by former colleges Wolfram Lorenzen and Tilman Ahrend).

\begin{tabular}{|c|c|c|c|c|}
\hline FA content [\%] & TTO1 & $\triangle b k d A B C$ & $\Delta n g r A$ & $\Delta h f q$ \\
\hline $\begin{array}{c}12: 0 \\
18 n-0\end{array}$ & $1.3 \pm 0.2$ & $2.9 \pm 0.2$ & $2.2 \pm 0.0$ & $2.1 \pm 0.3$ \\
\hline $14: 0$ & $4.8 \pm 0.6$ & $9.9 \pm 0.9$ & $8.1 \pm 0.1$ & $5.4 \pm 0.8$ \\
\hline iso- $15: 0$ & $22.3 \pm 2.3$ & & & $12.4 \pm 1.9$ \\
\hline anteiso-15:0 & $0.8 \pm 0.6$ & & & \\
\hline $16: 1 \omega-7$ & $9.4 \pm 0.9$ & $19.3 \pm 2.9$ & $16.7 \pm 0.1$ & $17.0 \pm 2.7$ \\
\hline $16: 0$ & $16.4 \pm 1.5$ & $35.4 \pm 5.2$ & $32.3 \pm 0.2$ & $21.9 \pm 3.0$ \\
\hline iso- $17: 1 \omega-11$ & $3.2 \pm 1.1$ & & & \\
\hline iso- $17: 1 \omega-5$ & $4.8 \pm 1.1$ & & & \\
\hline iso- $17: 0$ & $6.6 \pm 0.6$ & & & $3.9 \pm 0.8$ \\
\hline $17: 0$ & $6.6 \pm 0.6$ & & & $5.2 \pm 1.2$ \\
\hline anteiso-17:0 & $6.6 \pm 0.6$ & & & $2.9 \pm 1.5$ \\
\hline $18: 1 \omega-11$ & $5.8 \pm 0.7$ & $12.2 \pm 2.8$ & $13.5 \pm 0.2$ & $10.1 \pm 4.0$ \\
\hline $18: 1 \omega-9$ & $4.5 \pm 1.6$ & $10.1 \pm 4.0$ & $13.5 \pm 0.2$ & $9.6 \pm 4.3$ \\
\hline
\end{tabular}

As expected, in the $\triangle b k d A B C$ and in the $\triangle$ ngrA mutants, BCFAs were not produced. In the $\triangle h f q$ mutant the BCFAs iso-13:0, anteiso-15:0 and iso-17:1 were not produced. In comparison, in TTO1 wild type the FA with the highest abundance is iso-15:0 with $22.3 \%$ followed by $16: 0$ with $16.4 \%$. TTO1 produces both, unsaturated FAs like 16:1 and 18:1 and BCFAs like iso-13:0, iso-15:0, 
anteiso-15:0, iso-17:0 and anteiso-17:0. With iso-17:1w11c and iso-17:1w5c, TTO1 even contains two FAs with a double bond and an iso-branch.

Usually, BCFAs have the same function as unsaturated FAs to increase the fluidity of the membrane ${ }^{[94,95]}$. To determine whether there is another food source for BCFAs, which originates from the insect, or in case of the nematode bioassay from the lipid component added to the medium, FAME extracts and GC-MS analysis (chapter 6.9) were carried out with crushed insect and cod liver oil, respectively (Table 5). The insect species, Galleria mellonella and Tenebrio molitor, were chosen for analysis as $P$. laumondii is able to kill them.

Table 5. FA composition of cod liver oil, Galleria and Tenebrio. Relative quantification was done using data generated with GC-MS using the FAME method. FAs and cholesterol were annotated using the NIST database.

\begin{tabular}{|c|c|c|c|}
\hline FA content [\%] & Cod liver oil & Galleria & Tenebrio \\
\hline 14:0 & 8.62 & & 4.6 \\
\hline iso- $14: 0$ & 1.52 & & \\
\hline 4,8,12-trimethyltridecanoic acid & 0.46 & & \\
\hline iso-15:0 & 0.40 & & \\
\hline anteiso-15:0 & 0.07 & & \\
\hline $15: 0$ & 0.59 & & \\
\hline $16: 4 \omega-1,4,7,10$ & 0.62 & & \\
\hline $16: 1 \omega-11$ & & & 1.3 \\
\hline $16: 1 \omega-7$ & 0.10 & 1.0 & 2.7 \\
\hline $16: 1 \omega-5$ & 13.74 & & \\
\hline $16: 0$ & 21.25 & 28.7 & 10.4 \\
\hline $17: 0$ & 0.37 & & \\
\hline iso-17:0 & 0.24 & & \\
\hline anteiso-17:0 & 0.18 & & \\
\hline 17:1 (Isomer 2) & 0.47 & & \\
\hline iso- $17: 1 \omega-11$ & 0.47 & & \\
\hline $18: 2 \omega-9,12$ & & 29.6 & 19.1 \\
\hline $18: 1 \omega-11$ & & & 30.3 \\
\hline $18: 1 \omega-9$ & 0.70 & 26.9 & 29.5 \\
\hline $18: 1 \omega-5$ & 4.80 & & \\
\hline 18:0 & 4.48 & 6.1 & 1.6 \\
\hline $20: 5 \omega-3,6,9,12$ & 0.05 & & \\
\hline $20: 1$ & 2.61 & & \\
\hline iso- $20: 0$ & 0.11 & & \\
\hline $20: 5 \omega-3,6,9,12,15$ & 0.93 & & \\
\hline $22: 6 \omega-3,6,9,12,15,18$ & 19.34 & & \\
\hline $22: 1$ & 15.84 & & \\
\hline $24: 1 \omega-9$ & 0.71 & & \\
\hline cholesterol & 1.33 & 7.7 & 0.5 \\
\hline
\end{tabular}


For a better and more graphical overview, Figure 16 shows the overall content of linear and branched, both saturated and unsaturated FAs from the insects Galleria and Tenebrio, cod liver oil and the $P$. laumondii wild type in comparison.

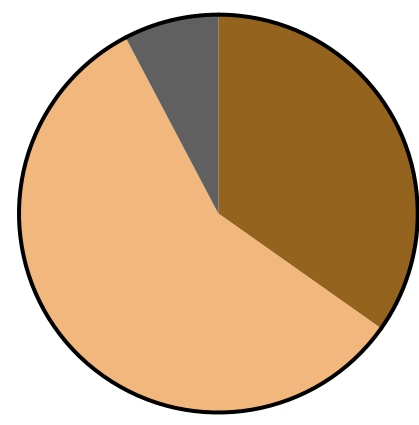

Galleria

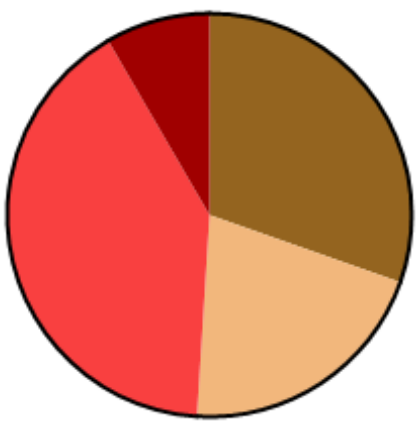

TTO1

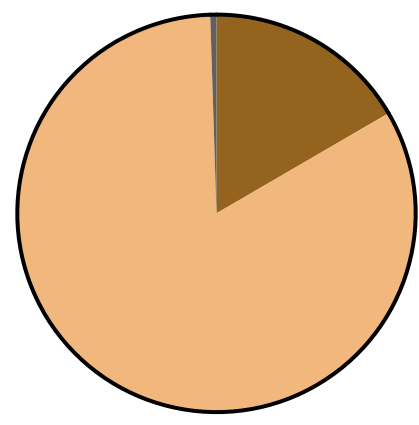

Tenebrio

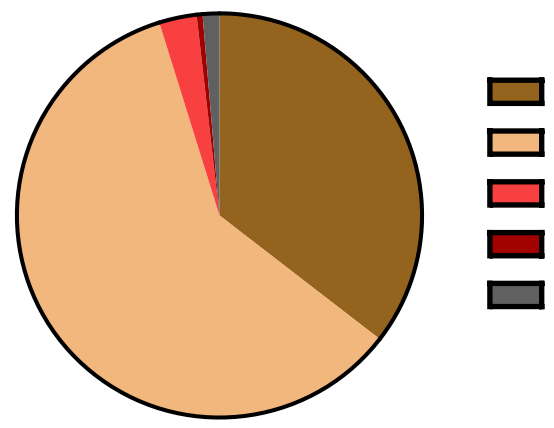

Cod liver oil saturated

unsaturated

branched saturated

branched unsaturated

cholesterol

Figure 16. Characterization of overall content of FAs in insects Galleria and Tenebrio, TTO1 and the lipid compound cod liver oil from the nematode assay medium. Annotation was done using WLO+TA (implemented database, based on standard measurements done by former colleges Wolfram Lorenzen and Tilman Ahrend) and NIST databases for TTO1 and NIST database for Cod liver oil and insects. A more detailed description of the composition of cod liver oil is shown in Table 5.

In FAME extracts from the insect species Galleria and Tenebrio no BCFAs were detected. P. laumondii wild type strain produces a high amount of BCFAs (Table 4). Cod liver oil also contains BCFAs. Consequently, performing a nematode bioassay with $\triangle b k d A B C$ mutant growing on it, the missing BCFAs deriving from cod liver oil might partly complement the lack of BCFAs from the mutant. This might lead to unseen effects when nematode bioassay is performed with the $\triangle b k d A B C$ strain. Therefore, it was tested whether leaving out the cod liver oil used in the medium for the nematode assay shows an effect on nematode recovery (Figure 11). Additionally, cholesterol was found in insects and in cod liver oil but 
not in TTO1. Leaving out cod liver oil from the medium would lead to absence of cholesterol as well. Thus, we also tested with and without addition of cholesterol to see whether it has an effect on nematode recovery (Figure 17).

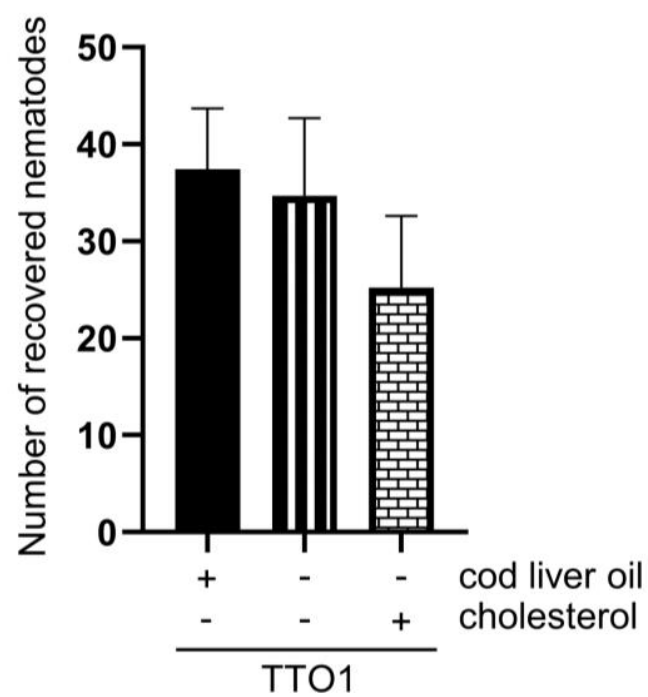

Figure 17. Nematode bioassay to test the absence (-) and presence (+) of cod liver oil and cholesterol. Recovered nematodes were counted after 4d IJ incubation. Each point represents the mean of 10 individual experiments with standard deviation. Statistical analysis was done with Tukey's multiple comparisons test (generated by GraphPad Prism).

There was no significant difference in nematode recovery cultivated on TTO1 in the absence of cod liver oil compared to cultivation on lipid containing medium and no significant changes when cholesterol alone was added to the medium. In a next nematode bioassay, $\triangle s t / C D E$ and $\triangle b k d A B C$ mutants were tested with and without cod liver oil to investigate potential complementary effects of the BCFAs of the oil towards nematode recovery. Nematode recovery, as stated in Figure 11, seems to be independent of the added cod liver oil as the number of developed nematodes is not significantly higher in neither $\triangle s t / C D E$ nor $\triangle b k d A B C$ strain (Figure 18). 


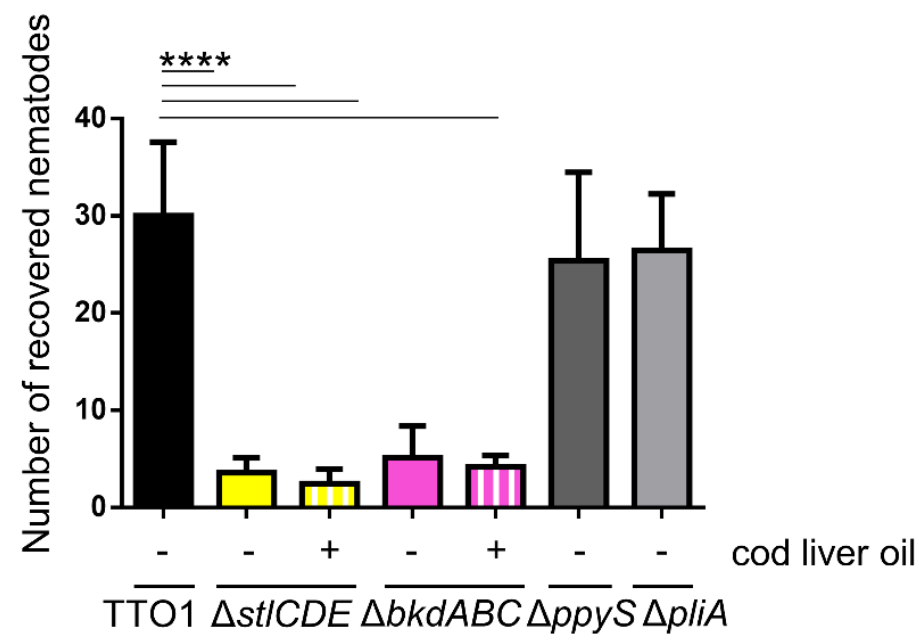

Figure 18. Nematode bioassay to test influence on the absence (-) and presence $(+)$ of cod liver oil with different deletion strains. Recovered nematodes were counted after $4 \mathrm{~d}$ IJ incubation. Each column represents the mean of 10 individual experiments with standard deviation. Statistical analysis was done with Tukey's multiple comparisons test (generated by GraphPad Prism) with stars showing significant difference between two strains at a time showed by the lines.

In a next step, the stage of NG-IJs outbreak was investigated (Figure 19). On the plate of the nematode bioassay, the nematodes bread until the food of the medium is depleted. NG-IJs develop and try to break out of the plate, as they would behave in the insect carcass. Hence, the nematode bioassay plates were incubated for additional $14 \mathrm{~d}$ after time point of $4 \mathrm{~d}$ of the first counting of the adult nematodes. The total number of produced NG-IJs demonstrates if BCFAs are involved in this stage of the life cycle of the nematodes.

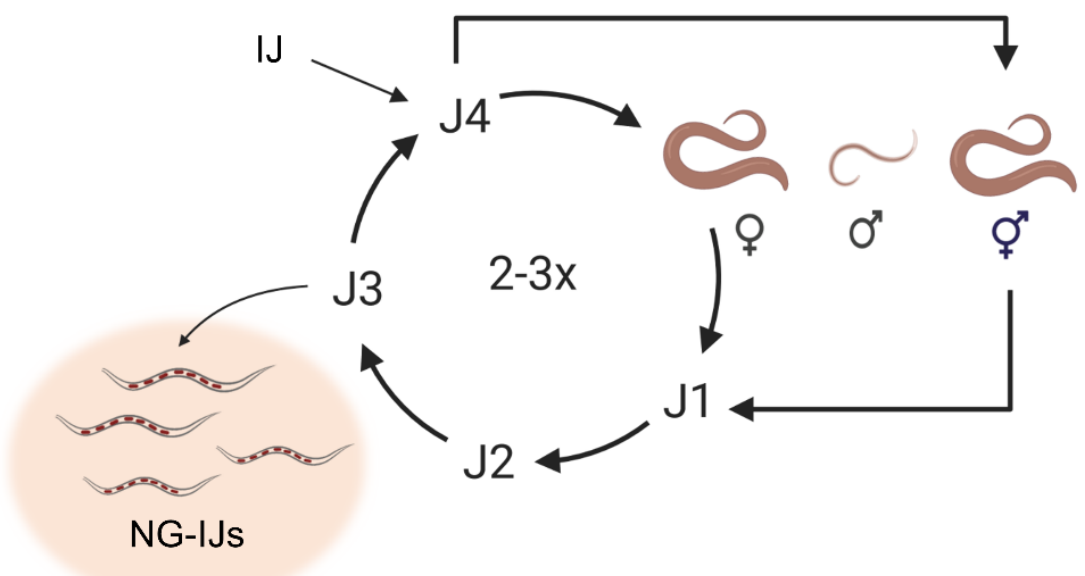

Figure 19. Life cycle of $H$. bacteriophora with highlighted part of the outbreaking point of the NG-IJs, which was used for nematode bioassay counting. 
The water from the surrounding petri dish (chapter 6.11), was collected and the number of NG-IJs was determined by counting ten droplets of $10 \mu \mathrm{l}$ (Figure 9) and projected to the total water volume. The outbreak of NG-IJs developed on the $\Delta$ pliA strain lacking phurealipids and the $\Delta p p y S$ lacking photopyrones were counted (Figure 20), were nematode recovery was observe before (Figure 18).

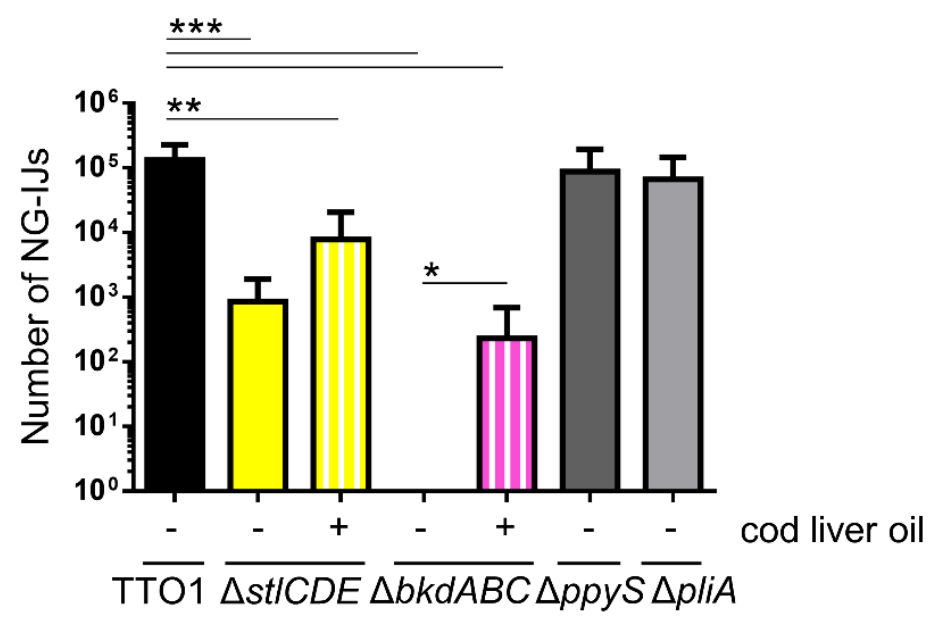

Figure 20. NG-IJs harvested from the surrounding water in the second plate after 14d incubation. The presence or absence of cod liver oil inside the medium is shown as + and - signs. Each column represents the mean of 10 individual experiments with standard deviation. Statistical analysis was done with Tukey's multiple comparisons test (generated by GraphPad Prism) with stars showing significant difference between two strains at a time showed by the lines.

The addition of cod liver oil could significantly restore NG-IJs formation after $14 d$ when grown on the $\triangle b k d A B C$ strain. Although the complementation is not strikingly significant, a trend is recognizable. Thus, the oil component was left out for the upcoming bioassays focused on analysing the $\triangle b k d A B C$ mutant to simplify the analysis. To confirm the importance of BCFAs in NG-IJ development, isolated lipids from TTO1, $\triangle b k d A B C$ and $E$. coli S17-1 strain (chapter 6.10) were added to the medium of nematode bioassays performed with the $\triangle b k d A B C$ mutant. TTO1 lipids should be able to complement the $\triangle b k d A B C$ strain (as it contains the BCFAs). Lipid extracts from $\triangle b k d A B C$ strain and $E$. coli served as negative control, as they contain only linear FAs. The nematode bioassay was performed by counting the number of recovered adult nematodes and the number of NG-IJs grown on TTO1 wild type, $\triangle$ st/CDE as an IPS deficient strain but still able to produce BCFAs, and $\triangle b k d A B C$ strain unable to produce both. In separate assays 
different lipid extracts were added to investigate complementary effects (Figure 21)

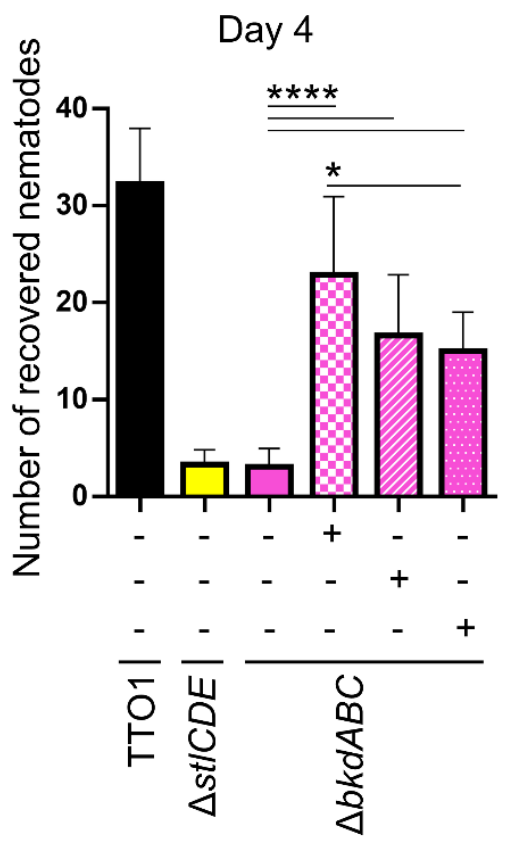

Day 17

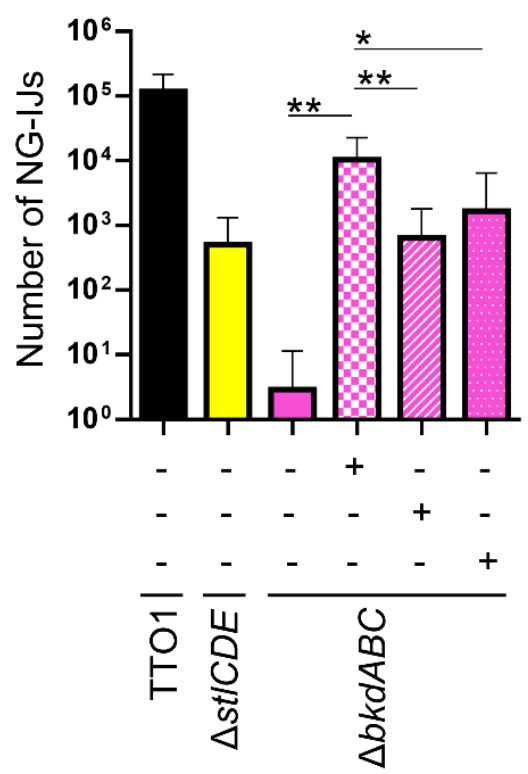

Day 14

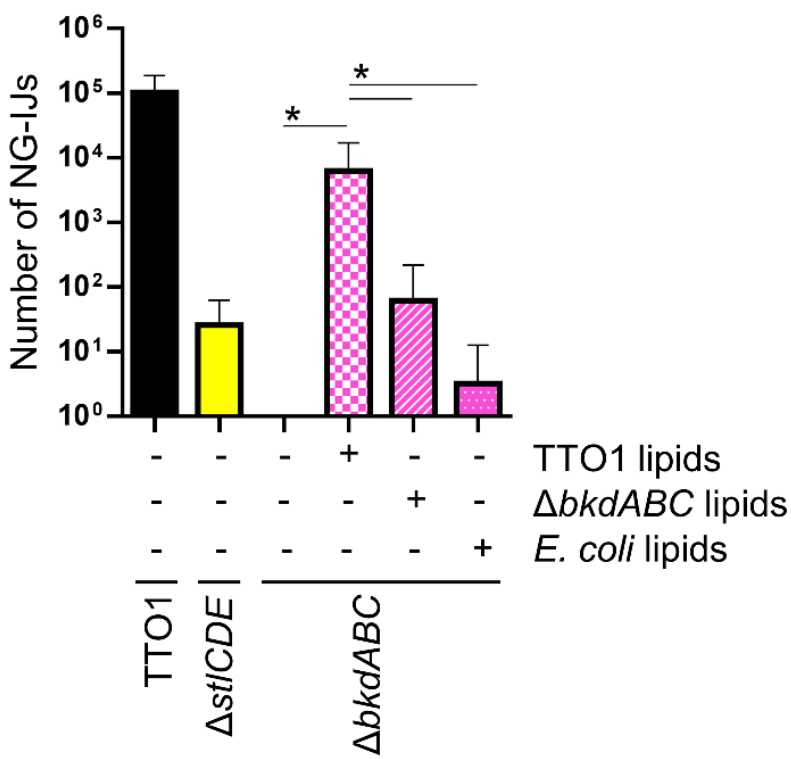

Day 20

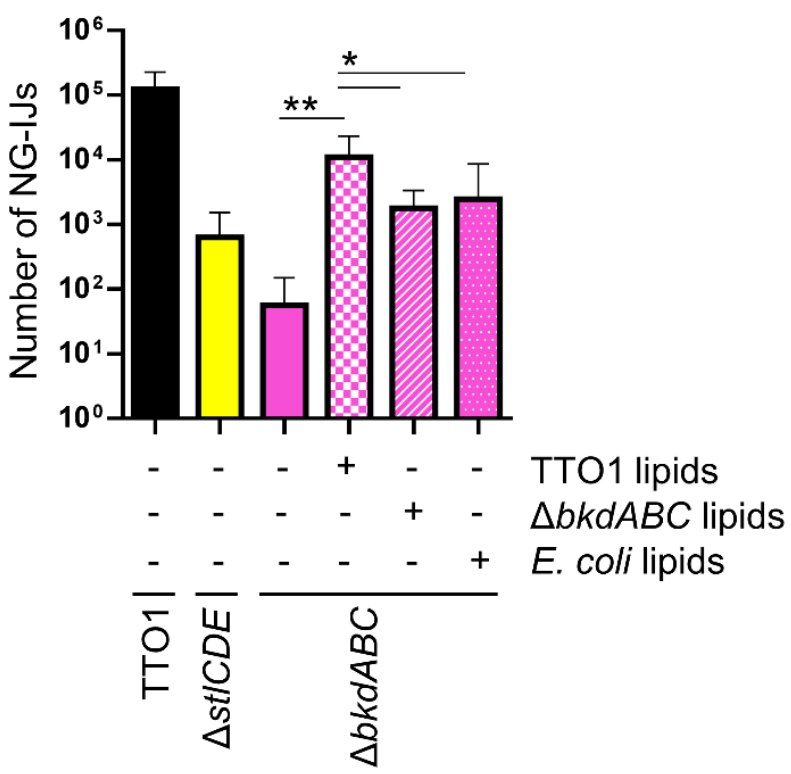

Figure 21. Nematode bioassay. Each column represents the mean of 10 individual experiments with standard deviation. Recovered nematodes were counted after $4 \mathrm{~d}$ of IJ incubation. NG- IJs were harvested from the surrounding water in the second plate after $14 d, 17 d$ and $20 d$ of incubation. Statistical analysis was done with the Tukey's multiple comparisons test (generated by GraphPad Prism) with stars showing significant difference between two strains at a time showed by the lines. 
Nematode recovery was significantly improved when lipids were added to the $\triangle b k d A B C$ mutant independent of which bacterial strain they originated from $(p=<0.0001)$. Lipids in general seem to boost recovery but not necessarily BCFAs. Afterwards, the same nematode bioassay plates were incubated again and NG-IJs were counted after 14, 17 and 20 days of incubation (Figure 21).

NG-IJs emerged into the surrounding water already after $14 \mathrm{~d}$ of incubation but, as assumed, extending incubation time leads to an increase in NG-IJ number. After $14 \mathrm{~d}$ the overall number of NG-IJs developed on TTO1 wild type was in total $1 \times 10^{5}$, $1.1 \times 10^{5}$ after $17 \mathrm{~d}$ and $1.2 \times 10^{5}$ after $20 \mathrm{~d}$ of incubation. In comparison, nematodes grown on $\triangle s t / C D E$ strain have produced approximately $26 \mathrm{NG-IJs}$ and nematodes grown on $\triangle b k d A B C$ strain have produced any NG-IJs on the day 14. The NG-IJs developed time delayed as the number increased on the day 17 and day 20 to

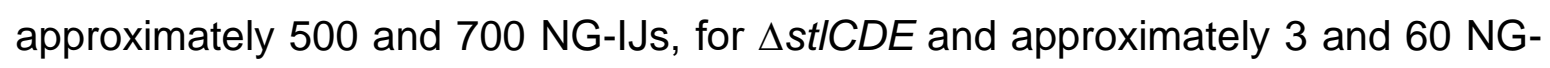
IJs for $\triangle b k d A B C$, respectively. Compared to NG-IJs developed on the TTO1 wild type, the number of NG-IJs developing on the deletion strains were decreased in general. Feeding TTO1 lipids to $\triangle b k d A B C$ increased the overall number of developed NG-IJs to $6.3 \times 10^{3}$ on day $14,1 \times 10^{4}$ on day 17 and finally to $1.1 \times 10^{4}$ on day 20. Feeding lipids without BCFAs, extracted from $\triangle b k d A B C$ and E. coli, also increased the number of developed NG-IJs to 1800 and 2500 on day 20, respectively but not as high as observed with added TTO1 lipids. The time delay for NG-IJ development is more distinct when BCFAs lacking lipids were fed to $\triangle b k d A B C$. The overall number differs even after $20 \mathrm{~d}$ of incubation. 


\subsection{Epoxy stilbene derivatives with unknown function}

In chapter 7.1.2, it was shown that IPS has no effect on nematode development. However, IPS is an interesting SM because of its activity against different pro- and eukaryotic organisms ${ }^{[63-65]}$. Additionally, $P$. laumondii produces several derivatives of IPS, including an epoxidated version called EPS (Figure 6). In this chapter, the structure of novel EPS adducts were characterised by feeding experiments and subsequent analysis by HPLC-MS experiments.

\subsubsection{HPLC-MS based characterisation of unknown EPS adducts}

EPS bound compounds were already found in a previous study (Yvonne Engel, unpublished data) but were not characterised in detail yet. However, considering the fragment pattern of the $\mathrm{MS}^{2}$ spectra of these compounds, the incorporation of EPS was suggested. The $\triangle s t / A$ strain is unable to convert phenylalanine into CA, thus no EPS can be produced. In further experiments, this strain was used as a reference and complementation experiments were carried out by feeding $C A$ to the $\triangle s t / A$ mutant, which restored production of IPS, EPS and also potential unknown EPS adducts were identified in HPLC-MS analysis of respective extracts (Figure 22). 


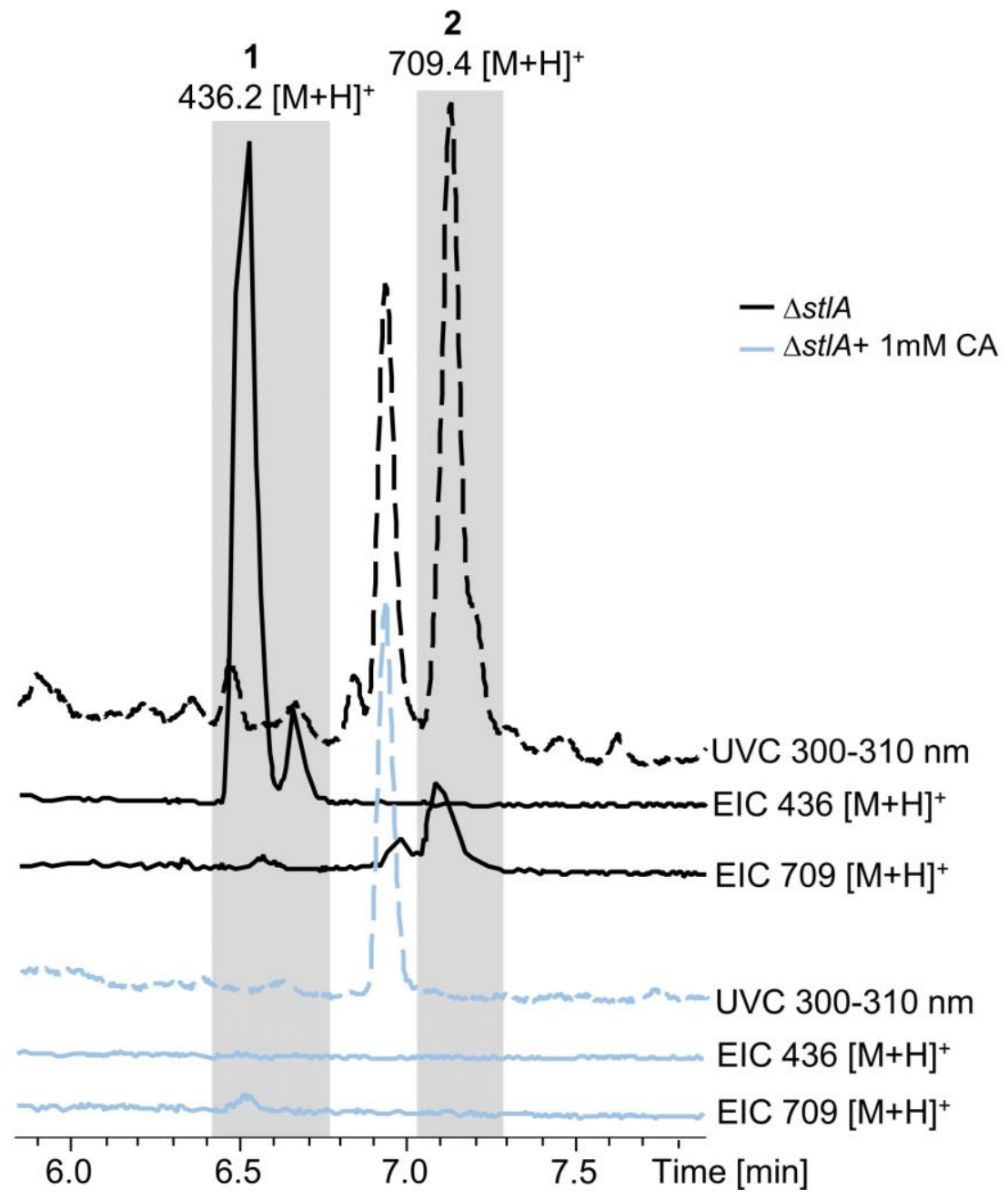

Figure 22. HPLC-MS data of new EPS adducts $1436.2[\mathrm{M}+\mathrm{H}]^{+}$and $2709.4[\mathrm{M}+\mathrm{H}]^{+}$in $\Delta s t I A$. Cultivation was done in LB for $3 \mathrm{~d}$ with and without $1 \mathrm{mM} \mathrm{CA}$ added.

HPLC-MS analysis of culture extracts from $\Delta s t / A$ deletion strain showed a double peak missing signal of unknown compound with the mass of $m / z 436.2[\mathrm{M}+\mathrm{H}]^{+}(\mathbf{1})$ and a single peak missing signal of unknown compound with a mass of $m / z 709.4$ $[\mathrm{M}+\mathrm{H}]^{+}(2)$, which could be restored by feeding CA. The UV signal at the retention time of minute 6.9-7 is CA unrelated as it is present in the deletion without CA feeding.

In a next step, deuterated CA was fed to the $\Delta s t / A$ mutant. A mass shift of $7 \mathrm{Da}$ for incorporation of deuterated CA in 1 and a mass shift of $7 \mathrm{Da}$ for incorporation of deuterated CA in 2 was confirmed (Figure 23). 

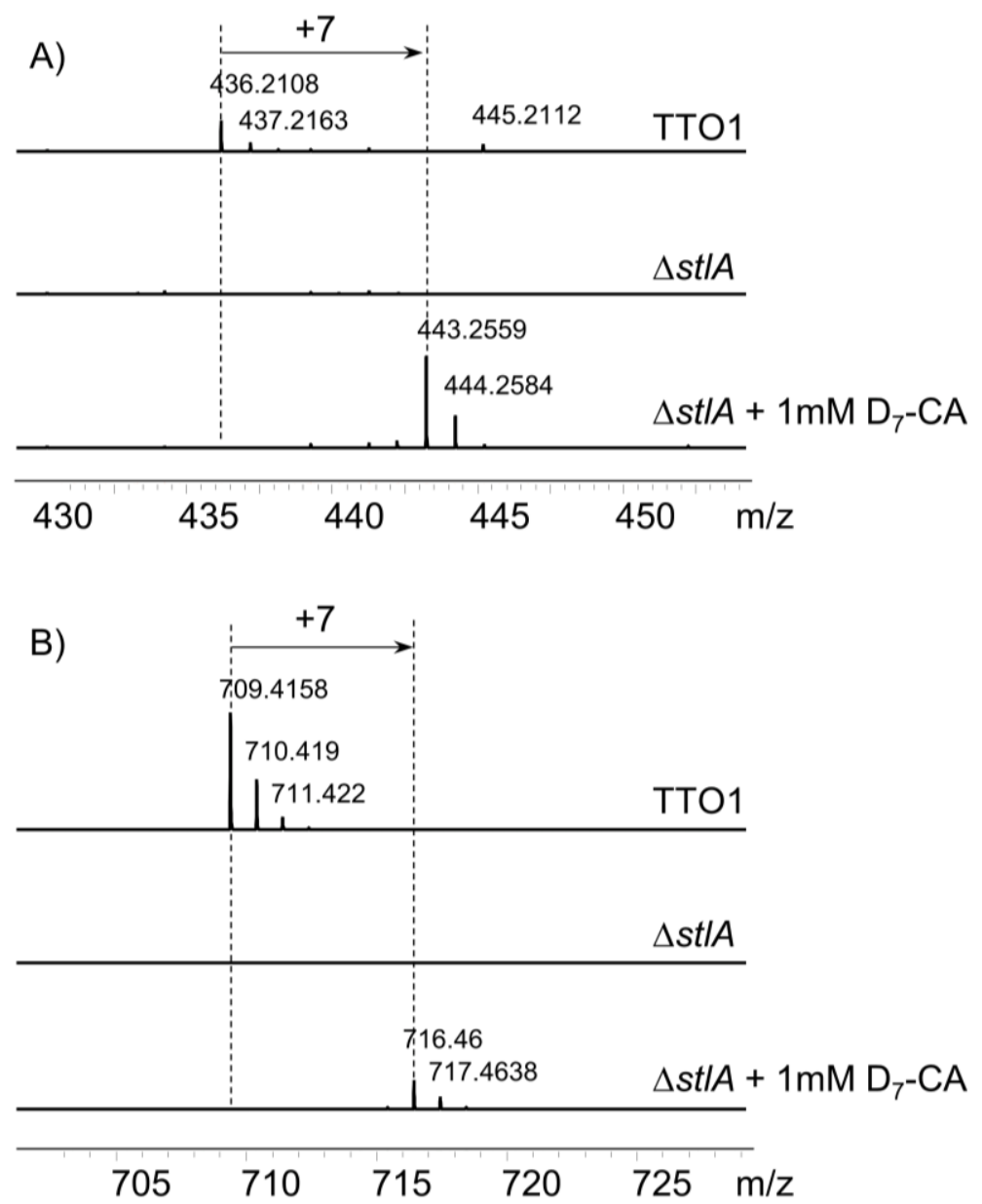

Figure 23. MS spectra $A$ ) of 1 in TTO1 wild type, $\Delta s t / A$ mutant and $\Delta s t / A$ fed with deuterated $\mathrm{CA}$ and $\mathrm{B}$ ) of $\mathbf{2}$ in TTO1 wild type, $\Delta s t / A$ mutant and $\Delta s t I A$ fed with deuterated CA.

For further elucidation of $\mathbf{1}$ and $\mathbf{2}$, the $\mathrm{MS}^{2}$ spectrum of extracts of TTO1 fed with deuterated CA were analysed. $\mathrm{MS}^{2}$ of 2 is depicted in Figure 24. 


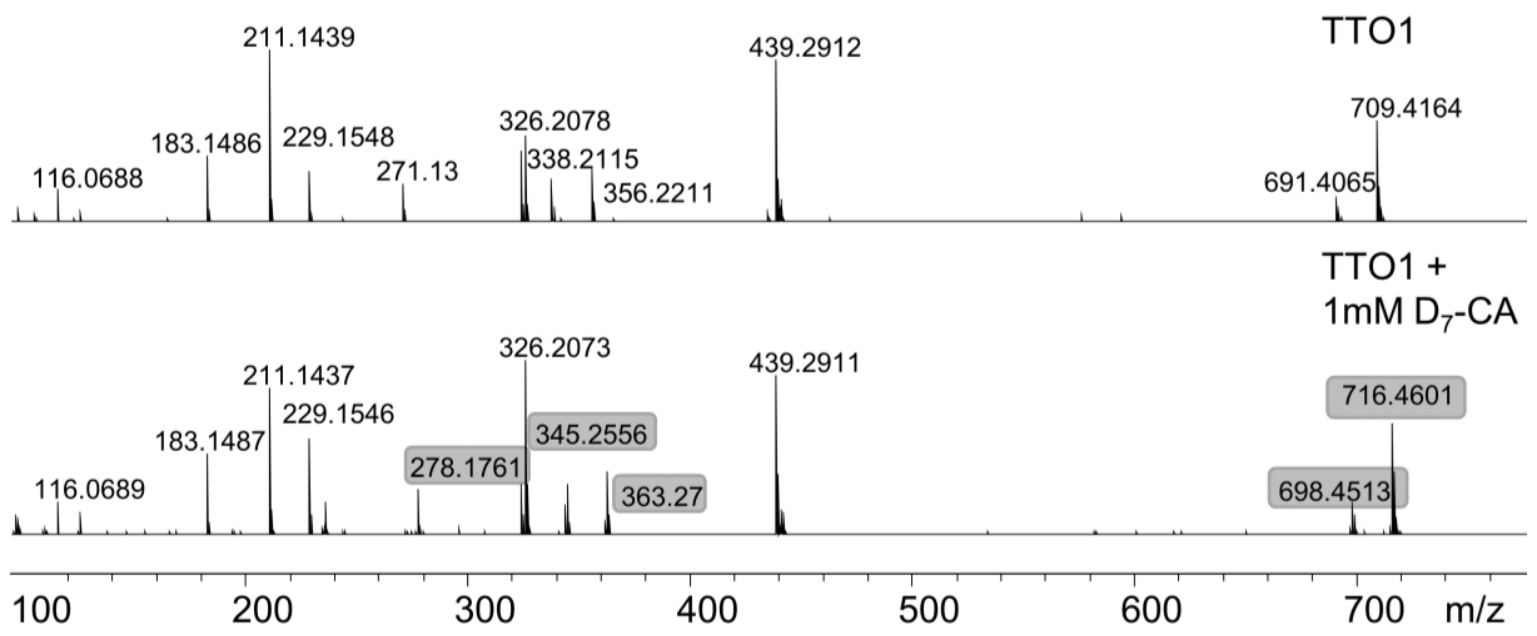

Figure 24. $\mathrm{MS}^{2}$ spectra of 2 in TTO1 fed with deuterated CA. The shifted masses of +7Da are highlighted.

The mass shift of $\mathrm{m} / \mathrm{z} 271$ to $\mathrm{m} / \mathrm{z} 278$ indicates the incorporation of CA into 1 and 2, which are also precursors of EPS $\left(271[\mathrm{M}+\mathrm{H}]^{+}\right)$. To verify the incorporation of EPS, feeding experiments were performed in an epoxidase deficient mutant strain $\Delta$ plu2236 (strain kindly provided by Jason Crawford, Yale university) as the epoxidase catalyses the conversion from IPS into EPS. Stilbene oxide (STO) was used as a complementing feeding substance because it harbours the same epoxide group as EPS (Figure 25) and is commercially available.

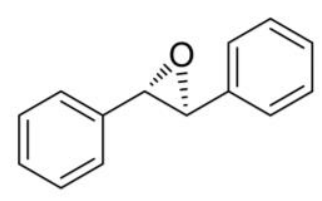

STO<smiles>CC(C)c1c(O)cc(C(=O)[C@@H]2O[C@H]2c2ccccc2)cc1O</smiles>

EPS

Figure 25. Chemical structures of STO and EPS. Both compounds harbour an epoxide group. STO is missing the iso-branch FA and two hydroxy groups.

STO served as precursor substance for the unknown compounds 1 and 2 (Figure 26). The feeding of STO resulted in a mass shift of $m / z 74[\mathrm{M}+\mathrm{H}]^{+}$for $\mathbf{1}$ and $\mathbf{2}$, as STO lacks the two hydroxy- and the isopropyl-group in comparison to EPS (Figure 25). STO has a mass of $m / z 197[\mathrm{M}+\mathrm{H}]^{+}$and EPS has a mass of $m / z 271[\mathrm{M}+\mathrm{H}]^{+}$. 


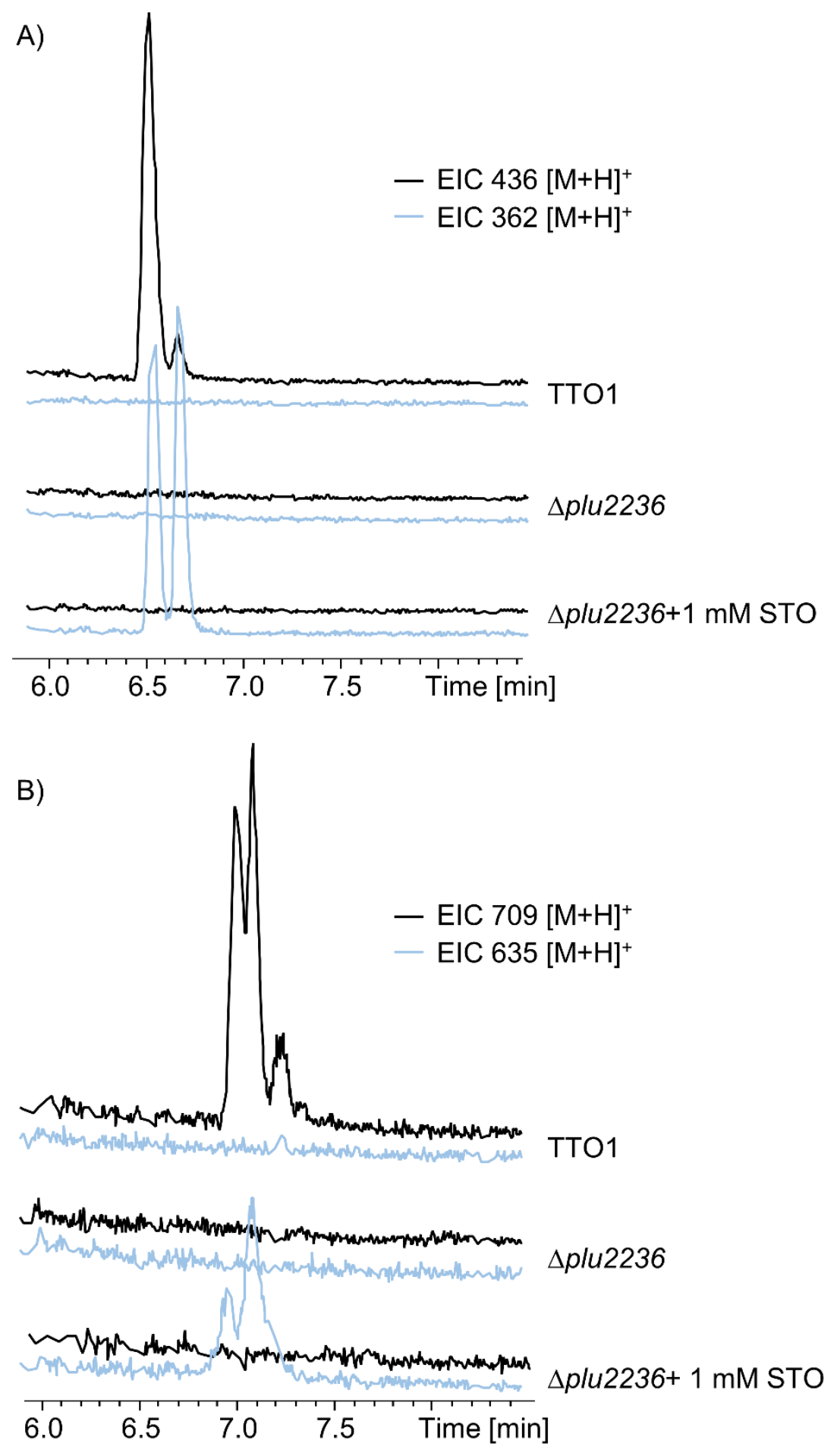

Figure 26. Confirming EPS incorporation into 1 und 2. A) Extracted ion chromatogram of $\mathrm{m} / \mathrm{z} 436.2[\mathrm{M}+\mathrm{H}]^{+}$in TTO1 and $\Delta$ plu2236, and $\mathrm{m} / \mathrm{z} 362.2[\mathrm{M}+\mathrm{H}]^{+}$in $\Delta$ plu2236+STO and MS spectrum of TTO1 and $\Delta$ plu2236+STO. B) Extracted lon chromatogram of $\mathrm{m} / \mathrm{z} 709.4$ $[\mathrm{M}+\mathrm{H}]^{+}$in TTO1 and $\Delta$ plu2236, and $635.4[\mathrm{M}+\mathrm{H}]^{+}$in $\Delta$ plu2236+STO and MS spectrum in TTO1 and $\Delta$ plu2236+STO.

The signals for 1 and 2 were not detected in the $\Delta$ plu2236 mutant but were restored by feeding of STO. With a mass difference of $74 \mathrm{Da}$, detection was a 
mass of $\mathrm{m} / \mathrm{z} 362.2[\mathrm{M}+\mathrm{H}]^{+}$(3) instead of $463.2[\mathrm{M}+\mathrm{H}]^{+}$and a mass of $\mathrm{m} / \mathrm{z}$ $635.2[\mathrm{M}+\mathrm{H}]^{+}(4)$ instead of $709.2[\mathrm{M}+\mathrm{H}]^{+}$, respectively was detected (Figure 26).

At the epoxy group of EPS or STO, both regiostereomers of adducts are possible, resulting in two peak signals. Both compounds most likely incorporate EPS. To find out what binds to EPS in 1 and 2 the corresponding $\mathrm{MS}^{2}$ spectra were analysed (Figure 27).
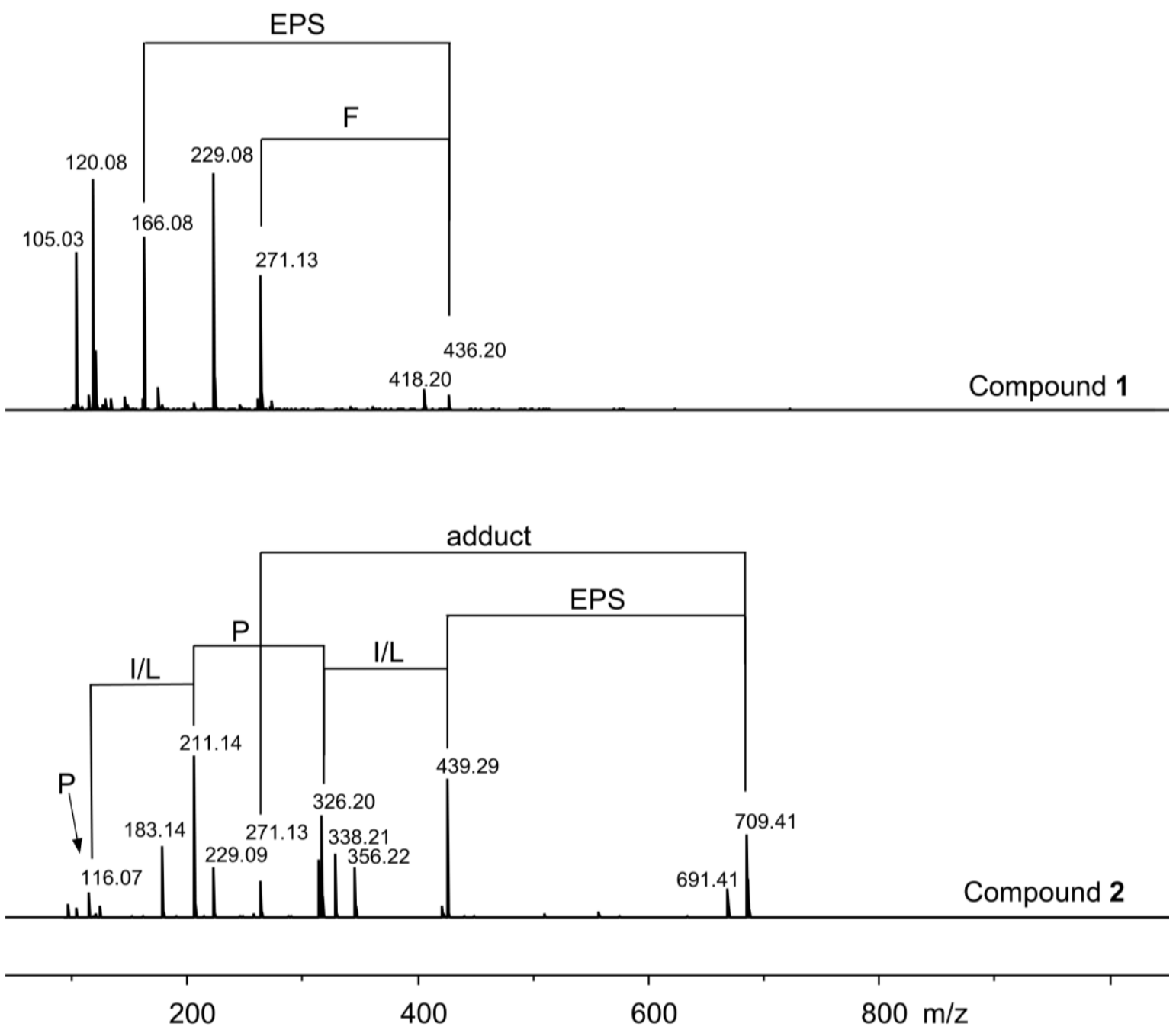

Figure 27. $\mathrm{MS}^{2}$ spectra of 1 with suggested amino acid phenylalanine and 2 with suggested amino acids iso-/leucine and proline.

In the $\mathrm{MS}^{2}$ spectrum of 1 , besides the EPS neutral loss (270 Da) from the parent mass of $m / z 436.2[\mathrm{M}+\mathrm{H}]^{+}$an additional loss of water and the increment mass of a phenylalanine $(F)$ were detected. For 2 a loss of water and EPS neutral loss was 
detected. Here, two prolines (P) and the increment mass of two leucines/isoleucines (L/I) were detected.

To confirm the incorporation of the suggested amino acids in $\mathbf{1}$ and $\mathbf{2}$, a reversed feeding experiment was carried out. TTO1 was cultivated in ${ }^{13} \mathrm{C}$ isotope labelled medium, while the respective ${ }^{12} \mathrm{C}$ amino acids were fed. As a control TTO1 was cultivated in LB. The extracts were analysed by HR-HPLC-MS. In the experiment for 1, phenylalanine $(F)$ was fed to the culture. For 2, the tetra peptides L-Leu/LPro/L-Leu/L-Pro (LPLP) and L-Pro/L-Leu/L-Pro/L-Leu (PLPL) (synthesis and purification of LPLP and PLPL was kindly conducted by Frank Wesche, Bode group) were used for feeding (Figure 28). 


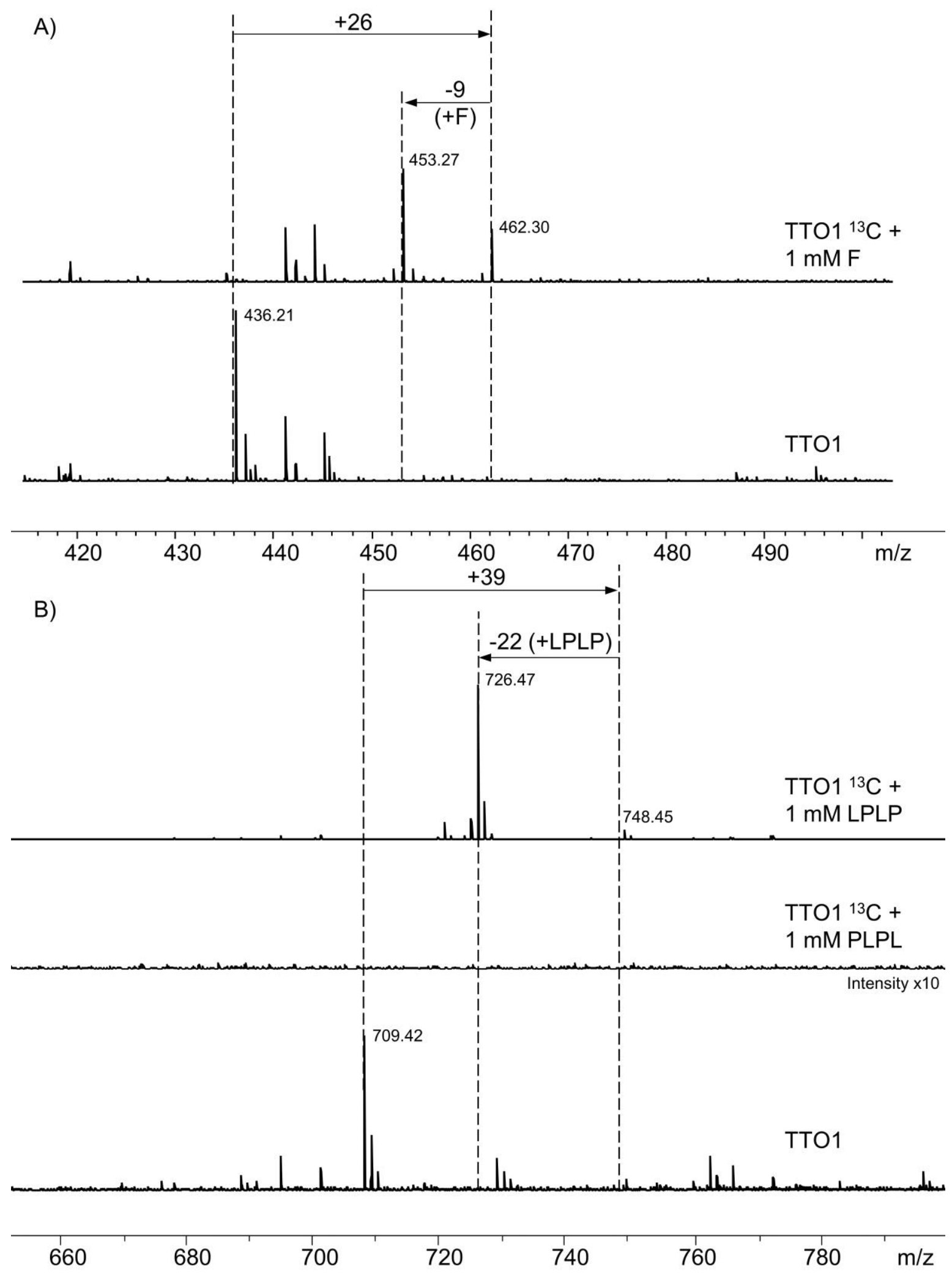

Figure 28. Reverse isotope labelled feeding experiment. A) $\mathrm{MS}^{1}$ of compound $\left.1 \mathrm{~B}\right) \mathrm{MS}^{1}$ of compound 2. 
The spectra of TTO1 cultivated in LB and in ${ }^{13} \mathrm{C}$ labelled medium show the characteristic mass signal of the EPS adducts 1 and 2, respectively. For the nonfed strains, cultivated in ${ }^{13} \mathrm{C}$, the signal of 1 shifts to $\mathrm{m} / \mathrm{z} 462(+26 \mathrm{Da})$. Feeding of non-labelled $\left({ }^{12} \mathrm{C}\right) \mathrm{F}$ led to a shift to $\mathrm{m} / \mathrm{z} 453(-9 \mathrm{Da})$ which is the number of carbon atoms in $\mathrm{F}$ (Figure 28A). The signal of 2 shifts produced in ${ }^{13} \mathrm{C}$ shifts to $\mathrm{m} / \mathrm{z} 748$ (+39 Da). Feeding of non-labelled $\left({ }^{12} \mathrm{C}\right)$ LPLP tetrapeptide resulted in a shift of $\mathrm{m} / \mathrm{z}$ $726(-22 \mathrm{Da})$ which is the number of carbon atoms of the tetrapeptide LPLP (Figure 28B).

In feeding experiments regarding 2, the tetra peptides LPLP and PLPL were used. Potentially, there are more combination possibilities for the proline and leucine tetra peptide and even incorporation of isoleucine is possible. The incorporation of LPLP was detected but other combinations of a tetrapeptide containing leucine and proline could also be possible, as they were not tested yet. PLPL on the other hand was not incorporated in 2 (Figure 28B).

Based on the MS data from Figure 27 and Figure 28 a structure and fragmentation pattern are suggested in Figure 29 and Figure 30.

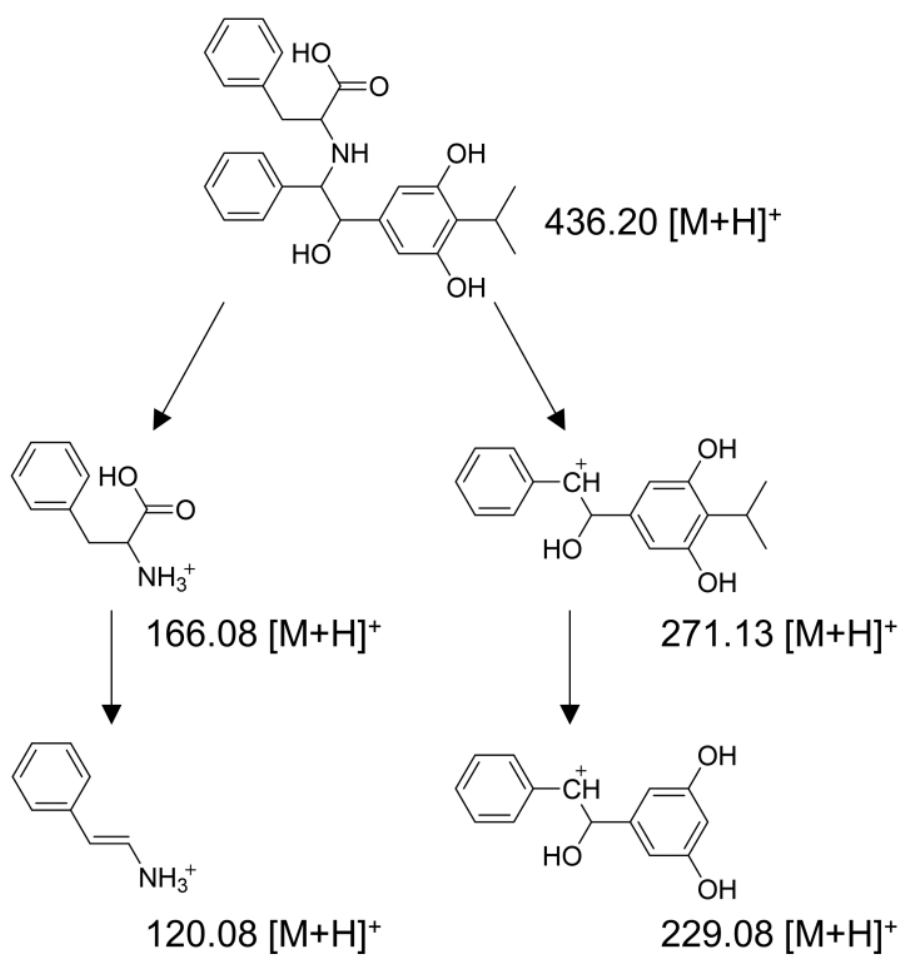

Figure 29. Suggested chemical structure for 1 with proposed fragmentations. 

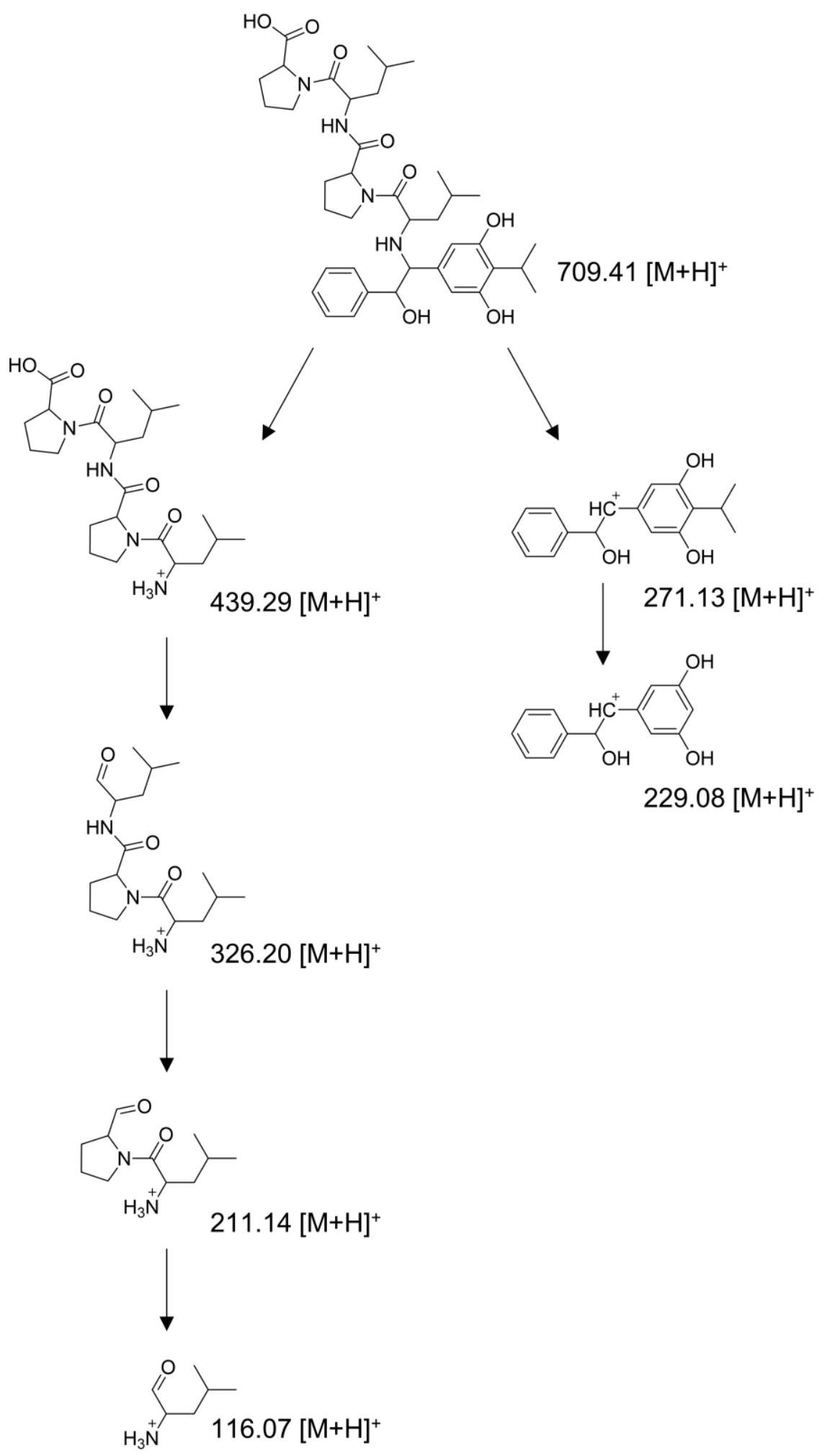

Figure 30. Suggested chemical structure for 2 with proposed fragmentations.

In conclusion, we postulate a possible structure for $\mathbf{1}$ and $\mathbf{2}$ with steric arrangements (Figure 31). 
Compound 1
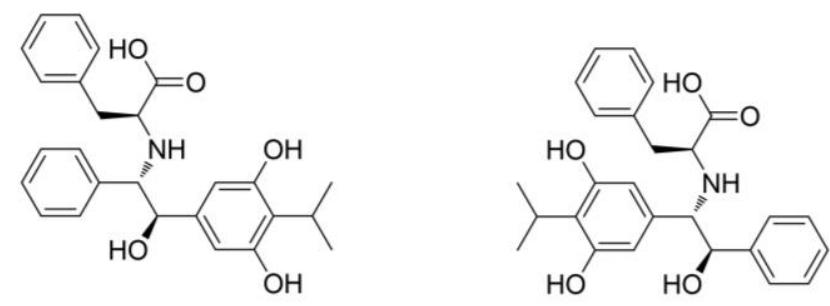

Compound 2
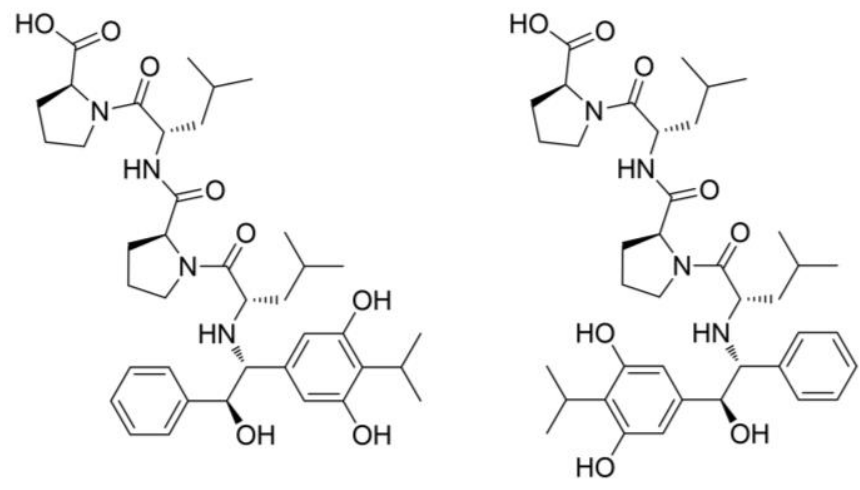

Figure 31. Suggested chemical structure with regioisomers of 1 and 2.

Based on the restored peaks of the STO feeding experiments (Figure 26), the expected structures are suggested in Figure 32.

Compound 3

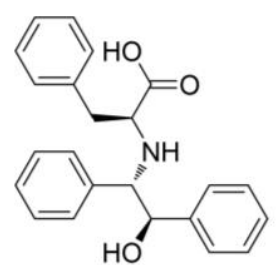

Compound 4



Figure 32. Suggested chemical structure of STO adducts 3 and 4. 


\subsubsection{Insect extracts reveal another unknown EPS derivative}

After clarifying the most probable structure for the EPS adducts 1 and $\mathbf{2}$ in chapter 7.3.1, the question of the biological function of these compounds arises. As EPS most likely reacts with free amino acids, it is possible that Photorhabdus function as an amino acid scavenger inside the insect prey by producing EPS. Another EPS compound bound to one proline has been characterized using an insect-like medium [86]. Consequently, Galleria mellonella and Tenebrio molitor maggots were infected with TTO1 wild type and with the EPS deficient $\Delta$ plu2236 strain (both strains kindly provided by Jason Crawford group, Yale university). The dead insects were extracted (chapter 6.13) followed by HPLC-MS analysis (chapter 6.8) to not only look for $\mathbf{1}$ and $\mathbf{2}$ but also to look for other EPS adducts or derivatives. Additionally, G. mellonella was infected with $\Delta s t / A$ and fed with $\mathrm{D}_{7} \mathrm{CA}$ to look for mass shifts (Figure 33). 
A)

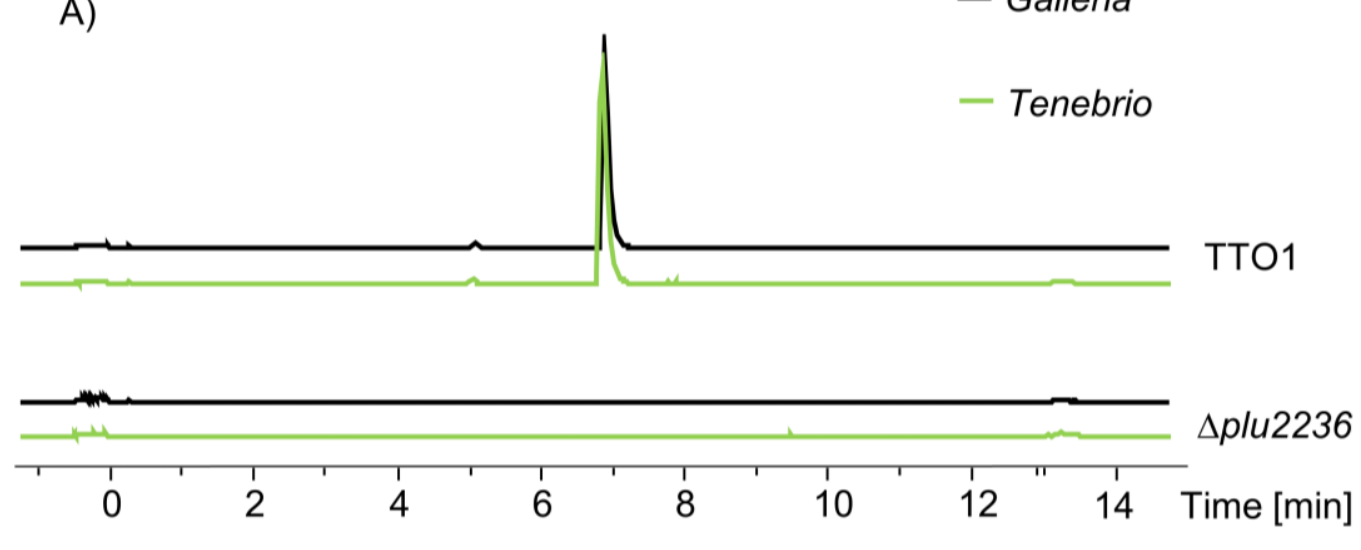

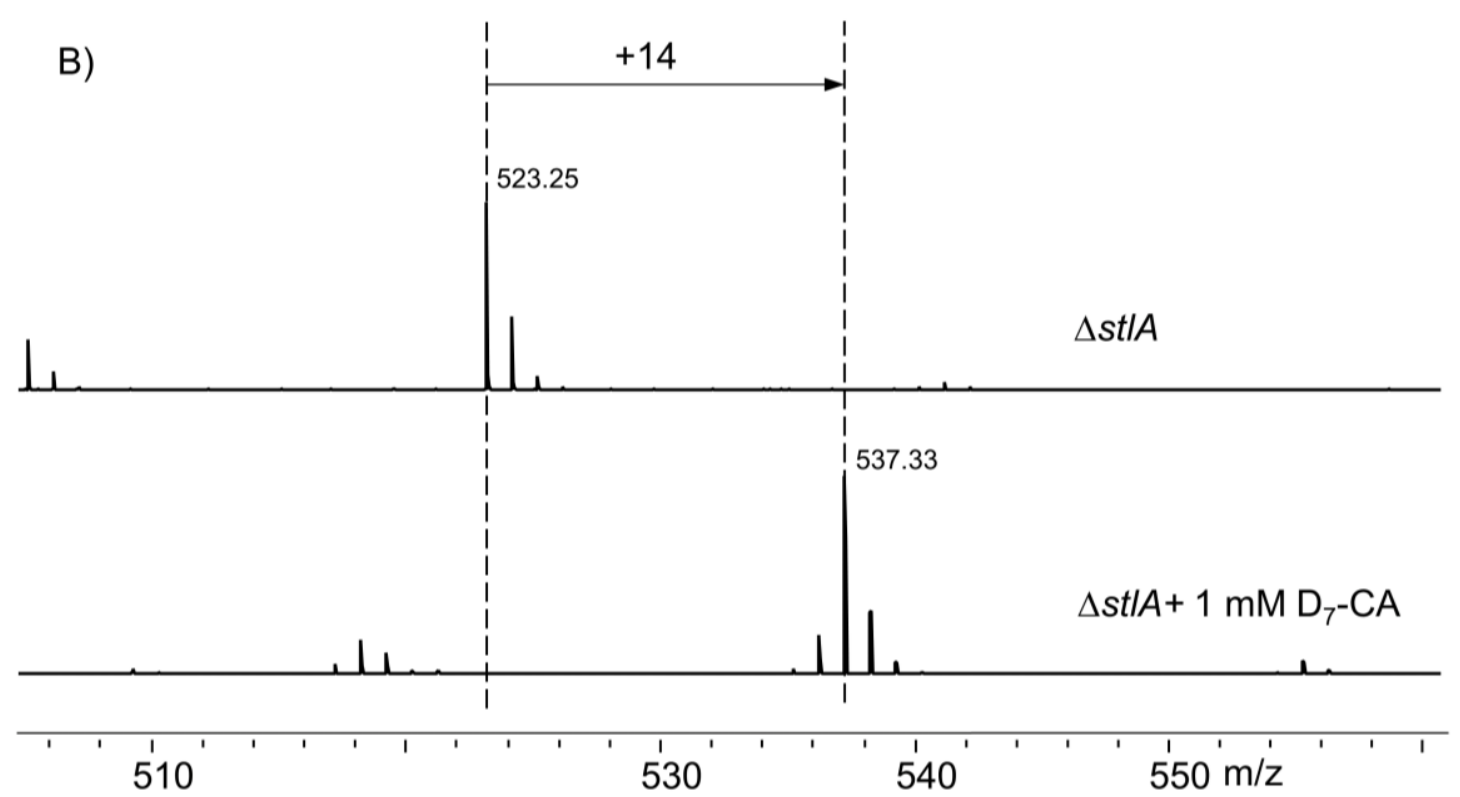

Figure 33. HPLC-ESI-MS analysis of extracts from infected insect. A) Extracted ion chromatogram of $\mathrm{m} / z 523[\mathrm{M}+\mathrm{H}]^{+}$. B) $\mathrm{MS}^{1}$ spectra of feeding experiment with deuterated CA.

While 1 and 2 were not detected in insect extracts, a new compound $m / z 523$ $[\mathrm{M}+\mathrm{H}]^{+}(\mathbf{5})$, was identified (Figure 33A). The signal could only be detected in insect extracts upon infection with wild type Photorhabdus but was not detectable upon infection with the epoxides deletion mutant $\triangle$ plu2236, which indicates its EPS associated origin. The feeding of $\mathrm{D}_{7}-\mathrm{CA}$ to the $\Delta$ stlA mutant showed a mass shift of $+14 \mathrm{Da}$ instead of the expected $+7 \mathrm{Da}$. Therefore. it is suggested that either two EPS molecules are combined, or one EPS and one IPS molecule. Both possible scenarios would result in $\mathbf{5}$ and the incorporation of two $\mathrm{D}_{7}-\mathrm{CA}$ molecules. The 
$M^{2}$ spectrum was analysed of feeding experiments in TTO1, which were fed with deuterated CA and leucine, respectively. Resulting mass shifts should help to further elucidate the structure of 5 (Figure 34).

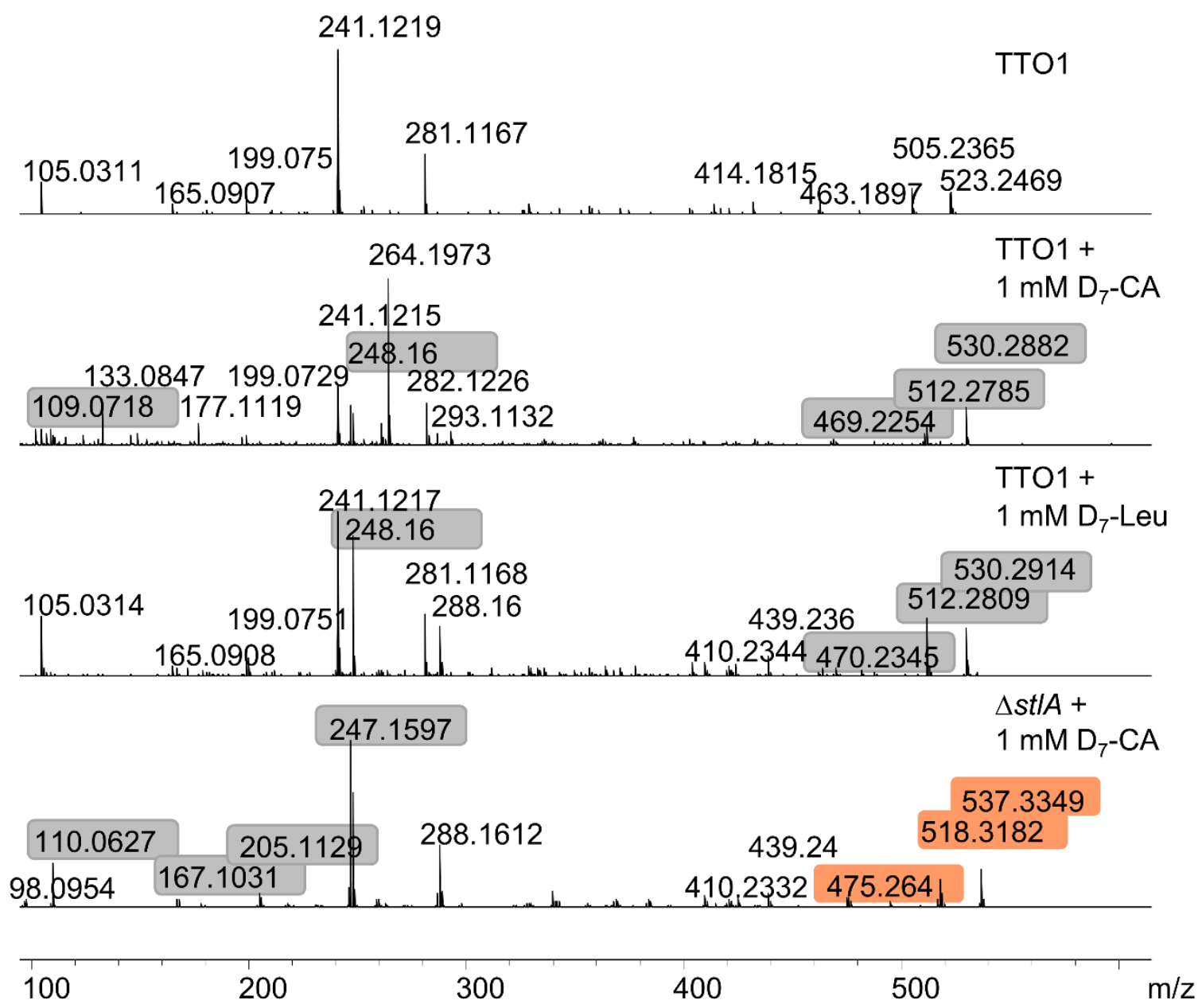

Figure 34. Analysis of $\mathrm{MS}^{2}$ spectra of 5 in extracts of TTO1 after feeding with deuterated $\mathrm{CA}$ and leucine, respectively and $\Delta s t I A$ mutant after feeding with deuterated CA. Shifted masses are highlighted in grey and double shifted masses in orange.

Based on the $\mathrm{MS}^{2}$ spectra of Figure 34, corresponding sum formulas were determined for all fragments (Table 6) and a chemical structure with a fragmentation tree could be suggested (Figure 35). 
Table 6. Fragments with sum formulars, calculated by Smart fomular function of Data analysis.

\begin{tabular}{|l|l|l|}
\hline Fragment mass $[\mathrm{M}+\mathrm{H}]^{+}$ & Sum formular & ppm \\
\hline 523.2469 & $\mathrm{C}_{34} \mathrm{H}_{35} \mathrm{O}_{5}$ & 0.8 \\
\hline 505.2365 & $\mathrm{C}_{34} \mathrm{H}_{35} \mathrm{O}_{4}$ & 1.9 \\
\hline 463.1897 & $\mathrm{C}_{31} \mathrm{H}_{31} \mathrm{O}_{4}$ & 3.8 \\
\hline 281.1167 & $\mathrm{C}_{18} \mathrm{H}_{17} \mathrm{O}_{3}$ & 1.4 \\
\hline 241.1219 & $\mathrm{C}_{16} \mathrm{H}_{17} \mathrm{O}_{2}$ & 1.1 \\
\hline 165.0907 & $\mathrm{C}_{10} \mathrm{H}_{13} \mathrm{O}_{2}$ & 1.5 \\
\hline 105.0311 & $\mathrm{C}_{7} \mathrm{H}_{5} \mathrm{O}$ & -0.8 \\
\hline
\end{tabular}
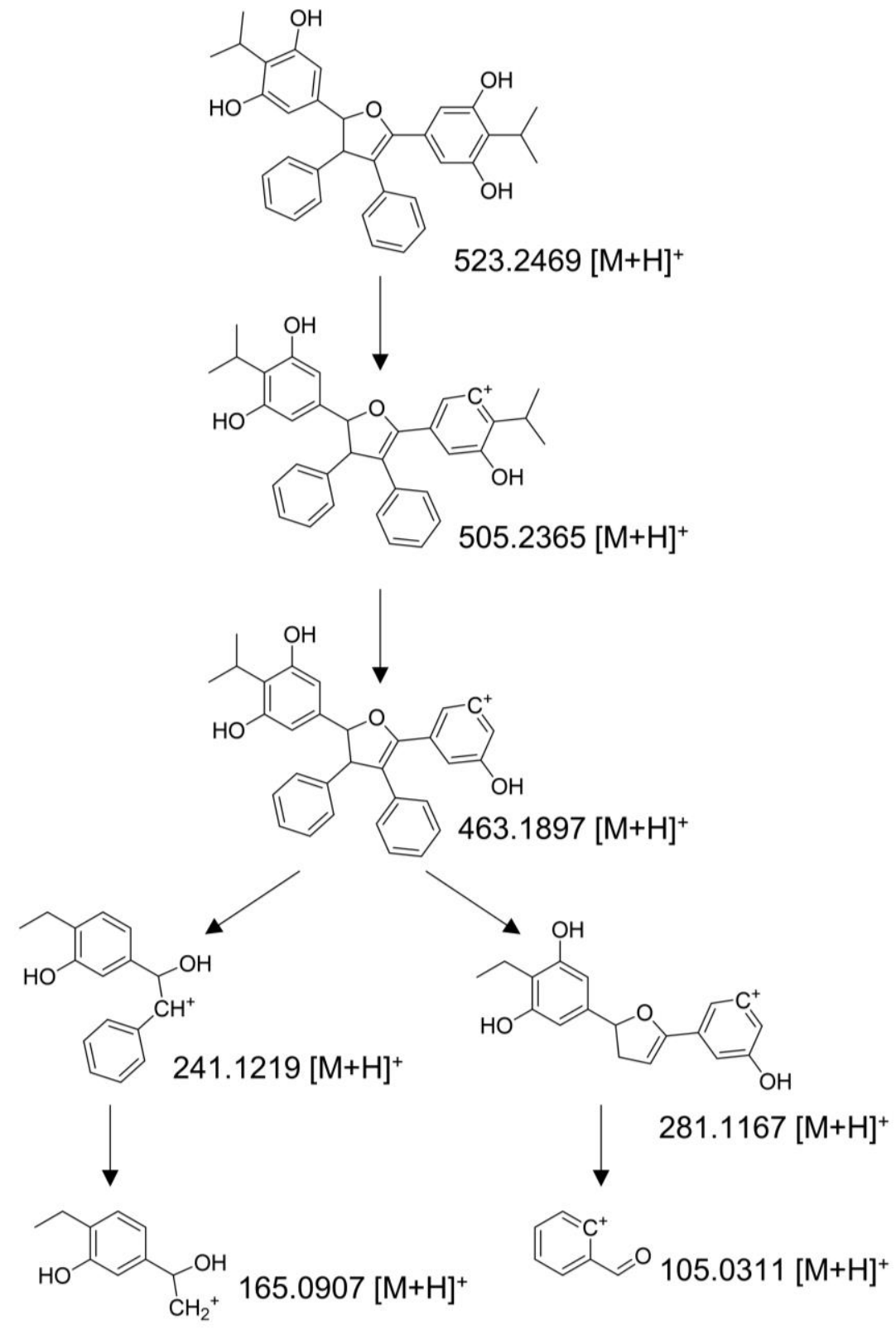

Figure 35. Suggested chemical structure for $\mathbf{5}$ with proposed fragmentations. 


\section{Discussion}

Inoculation of Photorhabdus for cultivation of Heterorhabditis nematodes is an essential aspect, as the bacteria produces food signals in artificial medium for Heterorhabditis to support nematode development as they would do in an insect prey in nature[114]. The aim of this study was to elucidate which food signals are essential for the development of nematodes. The right food signals can then be added to the liquid medium of the fermenter to improve IJ yield for biocontrol agent usage.

\section{1 $\Delta h f q$ and $\Delta n g r A$ as control strains}

The in vitro nematode bioassay was used as a tool for a better understanding on the bacteria-nematode interaction. To analyse the role of Photorhabdus SMs as potential food signals, the aim was to use deletion strains of $P$. laumondii in parallel to wild type strain and a proper negative control in the nematode bioassay. In the absence of the posttranslational regulator $\mathrm{Hfq}$, the production of all known SMs, besides a small amount of IPS and desmethyl-phurealipid, is lost and nematode recovery could not be observed for nematodes grown on these strains ${ }^{[76]}$. A similar effect could be observed for strains with deletion of the Sfp-like PPTase encoded by $n g r A^{[13]}$. Consequently, the strains $\Delta h f q$ and $\Delta n g r A$, respectively were used as negative controls for the nematode bioassay.

Comparing the length of hermaphrodites developed on TTO1 wild type $(1974.9 \mu \mathrm{m} \pm 271.1 \mu \mathrm{m})$, the length of hermaphrodites developed on $\triangle$ ngrA mutant decreased into approximately $31 \%$ smaller individuals $(1353.7 \mu \mathrm{m} \pm 270.8 \mu \mathrm{m})$ and hermaphrodites grown on $\Delta h f q$ were approximately $56 \%$ smaller $(868.3 \mu \mathrm{m} \pm 200.0 \mu \mathrm{m})$ (Figure 10). Because of the pleiotropic effect of missing $\mathrm{Hfq}$, it is unclear where the growth defect of the hermaphrodites developed on $\Delta h f q$ strain comes from. However, the growth defect on hermaphrodites developed on $\Delta$ ngrA strain strongly indicates, that SMs play a major role in the nematode growth and development process.

The fact that nematodes incubated on a deletion strain are smaller than the nematodes grown on TTO1 wild type is also important for quantitative analysis. Counting recovered nematodes, the smaller one need to be counted as well and 
must not be confused with IJ nematodes. Quantitatively the nematode recovery was almost completely absent when grown on $\Delta h f q$ and also highly affected when grown on $\triangle$ ngrA (Figure 12).

The development differences between the two mutants might be that other than the $\Delta h f q$ mutant, the $\Delta n g r A$ mutant is partly complemented under selective pressure in the nematode, as $P$. laumondii contains two additional PPTases. The PPTase AntB is part of the anthraquinone biosynthetic pathway but is so far described to be unable to complement $\mathrm{NgrA}$ and vice versa ${ }^{[115]}$. Otherwise, the AcpS-type PPTase responsible for FA biosynthesis in $P$. laumondii could most likely complement NgrA, as it has been shown for Bacillus subtilis ${ }^{[74]}$.

In complementation experiments, the feeding of TTO1 crude extract containing all SMs to the $\Delta h f q$ strain could restore nematode recovery performed in a nematode bioassay ${ }^{[76]}$. This observation additionally confirms the importance of SMs towards nematode recovery and in this work it was tested, whether the same effect can be accomplished by IPS alone, as it was observed before ${ }^{[14]}$

In this work, the feeding of purified IPS to nematodes grown on $\Delta h f q$ bacteria could not significantly complement their recovery. However, the pleiotropic effect on $P$. laumondii missing this global regulator could be too extensive to find out the missing food signals for the recovery, as not only SMs production is disrupted. The primary metabolism could be affected as well, which is for instance indicated by the diminished growth of this mutant ${ }^{[76]}$ or by missing of some FAs (Table 4). This is also the reason why further investigations were proceeded with the $\triangle n g r A$ strain as a negative control.

Feeding of purified IPS to nematodes grown on $\triangle$ ngrA bacteria did also not significantly complement the defect in recovery (Figure 13B). The missing complementation draw attention to the real significance of IPS. Therefore, the biosynthetic pathway was investigated, to see whether a side product or intermediate instead of IPS itself might function as a food signal and was overseen so far. 


\subsection{The influence of stilbenes and derivatives towards nematode development}

IPS was postulated as an food signal for recovery ${ }^{[14]}$. Indeed, strains lacking IPS led to a significant decrease but not a complete loss in recovery (Figure 13,). However, feeding IPS in the IPS deficient strains $\Delta s t / A$ and $\Delta s t / B$ could not restore nematode recovery (Figure 13). This finding was surprising as it contradicts observations of another study suggesting IPS as an important factor for recovery, observed with a similar feeding experiment ${ }^{[14]}$.

It is no doubt that a CA derived SM is important for recovery, as it is reduced when the nematodes grow on $\Delta s t I A$ (Figure 13B). Further, a StICDE dependent SM is important for recovery (Figure 13C). As feeding IPS could not complement recovery in nematode bioassay with $\Delta n g r A, \Delta s t / A$ and $\Delta s t / B$ strains (Figure 13), another CA derived SM must be the food signal. These contradictory results might be due to the purified IPS. The authors do not show any HPLC-MS spectra to confirm the purity of the extract. It is possible that the authors did use an IPS extract, which included derivatives of IPS as well, which were able to complement recovery and was falsely connected to the IPS. The extract used in this study was pure IPS with fewer contaminations of other compounds. No 2,5-dihydrostilbene or ethyl stilbene were detected but one additional mass of $\mathrm{m} / \mathrm{z} 295$, which represents an unknown compound and $m / z 213$, which is a fragment of IPS was detected in the extract (Figure 36). These missing compounds, or other unknown compounds, might be responsible and thus, nematode development could not be complemented with our extract. Photorhabdus most likely produce IPS exclusively to get rid of organisms competing for the insect prey, as it shows activity against bacteria $^{[63]}$, fungi[ ${ }^{[64]}$ and nematodes ${ }^{[65]}$. 
A)

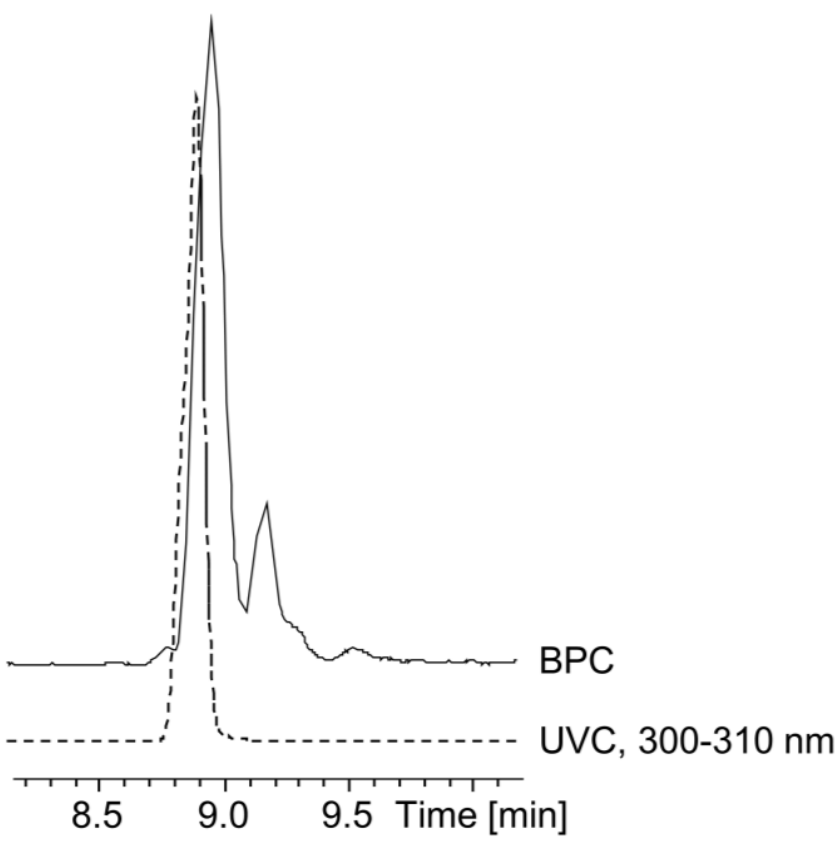

B)

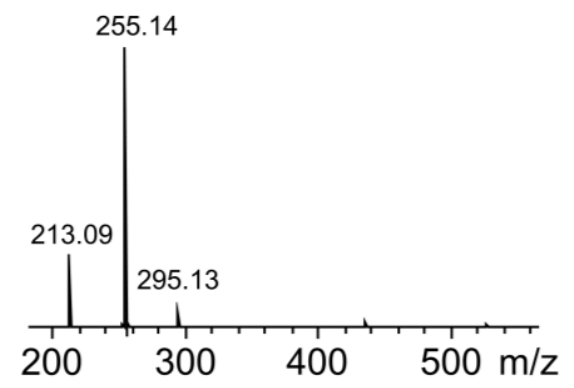

Figure 36. HPLC-MS analysis of purified IPS. A) A base peak chromatogram and a UV chromatogram are displayed B) a MS spectrum if the whole signal.

As shown in chapter 5.4.2, there are many derivatives and adducts originating of the IPS biosynthetic pathway, most of which are originating from the highly reactive EPS. However, a bioassay with the deletion strain of EPS $\Delta$ plu2236 has shown no significant impact on nematode recovery[86]. The role of EPS and its adducts will be discussed in a separate chapter.

Another study showed a relaxed substrate specificity for the aromatase StIC and the ketosynthase StID, thus generating different stilbene derivatives ${ }^{[16]}$, which might function as food signals. By deleting the st/CDE operon, the IPS derivatives ethyl stilbene and 2,5-dihydrostilbene were also missing (Figure 14), and the number of recovered nematodes was reduced (Figure 15). Which of the derivatives are an important factor for nematode recovery cannot be comprehended under the tested conditions, as deletions of st/CDE would also lack 
all of the derivatives (Figure 6). For further investigations, it is important to figure out which SMs, contrary to IPS function as a real food signal. However, some derivatives can already be excluded as potential food signals.

Ethyl stilbene (Figure 6 ) is most likely not involved and will be discussed in the following chapter 8.3. However, the effect of 2,5-dihydrostilbene (Figure 6) on nematode recovery should be tested and analysed as pure compound. Feeding experiments into the nematode bioassay would possibly elucidate the role of 2,5dihydrostilbene towards nematode recovery.

Not only IPS derivatives but also other products derived from CA could function as potential food signals: lumiquinone (Figure 37) is also a SM absent in the $\triangle S t / C D E$ mutant.

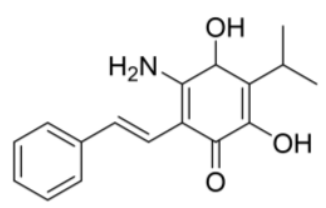

Figure 37. Structure of lumiquinone ${ }^{[117]}$.

It is possible that lumiquinone is a nematode food signal inducing recovery since it is also missing in all deletion strains. Feeding $\mathrm{CA}$ in a nematode bioassay associated with the $\triangle s t / A$ mutant could complement defects in recovery to wild type level (Figure 13). Since CA is the product of the phenylalanine ammonium lyase StIA IPS and lumiquinone production is restored likewise. Lumiquinone is a recently found $S M$ and its function is still unknown. The authors suggest $\alpha$ aminomalonate instead of a malonate substrate as extension unit and a serine dehydrogenase (Plu2233) to be involved into its biosynthesis ${ }^{[177]}$. Consequently, deleting plu2233 would lead to a strain unable to produce lumiquinone while still able to produce IPS, unlike the st/CDE deletion strain missing both. Investigations of the influence of lumiquinone on nematode recovery and development could be performed with a lumiquinone deficient $\Delta$ plu2233 mutant.

In summary, two StICDE dependent SMs are suggested to be the real food signal triggering recovery: 2,5-dihydrostilbene and lumiquinone. Both can be added to the nematode bioassay with nematodes grown on $\triangle s t / C D E$ as purified compounds 
to look for complementation. In case of lumiquinone a $\Delta p / u 2233$ mutant can be performed in the nematode bioassay to look for defects in recovery to elucidate its potential role as a food signal. The biosynthesis of both of these SMs are also dependent on the Bkd complex, which will be discussed in the following chapter.

\subsection{Branched-chain fatty acids are essential for IJ development}

The Bkd complex of $P$. laumondii, is responsible for branched precursors for some SMs based on iso-branched FAs and for BCFAs. As expected, IPS, photopyrones and iso-branched phurealipids were no longer produced in the $\triangle b k d A B C$ deletion strain (Figure 8, Figure 14). As a result, ethyl stilbene, not possessing an isobranch, is produced 100-fold higher compared the wild type level (Figure 14). Nematodes growing on $\triangle b k d A B C$ deletion strain had a highly reduced recovery (Figure 15). Therefore, either SMs based on iso-branched FAs or BCFAs are also essential for nematode recovery. In a first step, a potential influence of the missing SMs phurealipids and photopyrones on the nematode development was investigated but could be excluded by testing deletion strains in the nematode bioassay regarding recovery and development, where no significant changes compared to the wild type were observed (Figure 15). Therefore, the effect can only originate from other SMs based on iso-branched FAs or BCFAs. The SMs 2,5-dihydrostilbene and lumiquinone, which were suggested as recovery inducing food signals, are also absent in the $\triangle b k d A B C$ deletion strain, which might explain the reduced recovery. Ethylated versions of 2,5-dihydrostilbene and lumiquinone were not detected in HPLC-MS runs of culture extracts from $\triangle b k d A B C$ deletion strain.

\subsubsection{The hidden effect of cod liver oil towards NG-IJ development}

The presence or absence of cod liver oil do not influence nematode recovery when grown on TTO1 wild type (Figure 17) or when grown on $\triangle s t / C D E$ and $\triangle b k d A B C$ strains (Figure 18). However, NG-IJ development could be significantly complemented with adding cod liver oil to the $\triangle b k d A B C$ strain (Figure 20).

No significant difference was detected in the total number of NG-IJs when growing on $\Delta$ ppyS and $\Delta$ pliA strains compared to wild type independent of addition of cod liver oil (Figure 20), meaning that these SMs based on iso-branched FAs are not 
involved in NG-IJ development. However, nematodes grown on the $\triangle b k d A B C$ strain developed NG-IJs only upon addition of cod liver oil (Figure 20). Maybe the overall smaller number of recovered nematodes leads to less developed NG-IJs. Maybe the NG-IJs need the greasy surface, originated by the cod liver oil to escape the medium plate. However, NG-IJs would not be present on other strains too, which is not the case for nematodes when grown on for example the $\triangle s t / C D E$ mutant. As recovery is nearly the same in these two deletion strains, the outcome of NG-IJs should also be the same. NG-IJ production was independent of presence or absence of cod liver oil when grown on $\triangle S I t C D E$ strain (Figure 20). This means that no greasy surface in needed for the IJs to escape the medium plate.

The content of cod liver oil might be important instead. This fatty component of the nematode bioassay does contain BCFAs (Figure 16). However, the natural preys of $P$. laumondii insect species $G$. mellonella and $T$. molitor do not contain any BCFAs (Figure 16). Therefore, in the natural environment a second source for BCFAS other than from the symbiotic bacteria is not possible. The $\triangle S t / C D E$ strain is still able to produce BCFAs as it harbours the Bkd complex which might be the reason why NG-IJ development is still possible in absence of cod liver oil, whereas no NG-IJ development was observed when nematodes were grown on $\triangle b k d A B C$ strain in absence of cod liver oil (Figure 20).

\subsubsection{BCFAs as food signal for NG-IJs development}

Under the given circumstances, it is impossible to determine the food signal as cod liver oil contain a high variety of different branches and different length of FAs (Table 5). In the next step extracted lipids from bacteria were used (TTO1 wild type and $\triangle b k d A B C$ strain, and $E$. coli) for the nematode bioassay to confirm the influence on bacterial BCFAs.

Even though $\triangle b k d A B C$ strain with added TTO1 lipids was unable to restore wild type level of developed NG-IJs, it was still significantly more than with $\triangle b k d A B C$ alone (around 100x higher) or with $\triangle b k d A B C$ lipids (around 10x higher) or E. coli lipids (around 10x higher). Further, adding $\triangle b k d A B C$ lipids or $E$. coli lipids could not improve the number of NG-IJs significantly compared to $\triangle b k d A B C$ alone. In 
conclusion, only the addition of TTO1 wild type lipids containing the BCFAs could complement the NG-IJs development in the $\triangle b k d A B C$ deletion strain significantly (Figure 21).

There was a significant improvement in recovery when the extracted lipids were fed, no matter of presence or absence of BCFAs. However, extracts of $P$. laumondii in general led to a slightly better recovery (Figure 11, Figure 21). It is possible, that the nematodes digest and degrade the bacterial lipids using them as an energy source for growing and recovery.

A significant improvement of NG-IJs development could only be achieved with the TTO1 lipid extract (Figure 21). NG-IJ development could be observed with nematode assay containing $\triangle b k d A B C$ bacteria when we incubated the nematode assay plates longer (Figure 21). However, even with long time incubation, the NGIJ development was never wild type level. The time delay was also complemented with the BCFAs containing TTO1 extract added but not with the other extracts.

The overall smaller number of recovered nematodes grown on $\triangle S t / C D E$ and $\triangle b k d A B C$ mutants consequently led to a smaller number of NG-IJs as less adults are present to breed. However, only nematodes grown on $\triangle b k d A B C$ mutant show a time delay in developing NG-IJs. As this time delay can be complemented with TTO1 lipids, we postulate that BCFAs play a significant role in NG-IJ development. Eventually, NG-IJs are produced even in supposedly complete absence of BCFAs. However, maybe $P$. laumondii finds an alternative pathway to produce BCFAs in absence of a Bkd complex to uphold the life cycle.

The Pdh complex consists of pyruvate dehydrogenase/decarboxylase (E1), acetyltransferase (E2) and dihydrolipoamide dehydrogenase (E3) which is a part of the tricarboxylic acid cycle by the formation of acetyl-CoA from pyruvate ${ }^{[118]}$. These E1, E2 and E3 enzymes are homologous to the Bkd complexes E1, E2 and E3 [119]. In Listeria monocytogenes BCFA production could be complemented by the Pdh complex in a Bkd deficient strain ${ }^{[91]}$. The myxobacterium Myxococcus xanthus as an example harbours an alternative pathway using a zinc binding dehydrogenase (MXAN_4266) to produce isovaleryl-CoA when the bkd operon is deleted from the genome ${ }^{[120]}$. A BLASTp analysis revealed homology of such a 
zinc binding dehydrogenase in $P$. laumondii $(28.21 \%$ identity/similarity). This indicates that these species might also be capable to use an alternative pathway to produce BCFAs.

Such a complementation was not detectable in FAME analysis for the $P$. laumondii $\triangle b k d a b c$ deletion strain, as BCFAs were completely absent (Table 4). However, FAME analysis was performed in artificial medium without their nematode symbiont. When the nematodes are unable to produce offspring, the life cycle ends for both organisms. It is possible, that in presence of its nematode symbiont, $P$. laumondii deletion strain $\triangle b k d A B C$ start to produce BCFAs with alternative pathways, which would explain the time delay.

In conclusion, BCFAs are a food signal that triggers the nematodes to switch from J2 to IJ stage (Figure 1). In the next step, it is important to find out which one of the BCFAs function as such a food signal.

For further studies, it would be interesting to observe a TTO1 mutant, which is able to produce more BCFAs or even only BCFAs. Such a mutant might be possible by deleting $\mathrm{fabH}$. However, as $\mathrm{FabH}$ is essential for straight chain FAs and thus is essential for living, it is questionable whether such a mutant is achievable.

Another possibility would be to test lipid extracts from other organisms. So far, lipids extracted from P. laumondii and E. coli were tested. However, the Bligh and Dyer method is a crude extraction and a small amount (approximately $2 \%$ of the whole extract) of non-lipid compounds can be present in the TTO1 extract ${ }^{[112]}$. To prove that the complementation originated from the BCFAs and not from these non-lipid compounds, lipid extracts of other species should be tested. For example a lipid extract of Bacillus subtilis a Gram-positive bacterium that also produces BCFAs can be tested[121-123]. Another possibility would be heterologous expression of TTO1 $b k d A B C$ in an E. coli strain, subsequently extracting the lipids and testing them with the nematode bioassay. As the heterologous expression should enable BCFA production in the E. coli strain, a complementation of NG-IJ production would further proof the food signal to be the BCFAs and not the non-lipid compounds. 
To finally determine which BCFA specifically function as a food signal for NG-IJ development, complementation experiments with single, purified BCFAs should be performed within the nematode bioassay. To avoid searching for the needle in the haystack, it might be helpful to compare Heterorhabditis with other nematode species.

\subsubsection{Some nematodes produce their own BCFAs}

In the free-living nematode Caenorhabditis elegans it was proven that the BCFA iso17:0 is essential for postembryonic development. The iso17:0 is incorporated in phospholipids, ensuring proper membrane dynamics in early embryos ${ }^{[124]}$. To synthesize BCFAs, organisms must have a system for supplying branched-chain primers along with the enzymes elongating them ${ }^{[125]}$. C. elegans is the first reported eukaryote to produce its own BCFAs ${ }^{[105]}$. C. elegans harbour a Bkd complex homolog ${ }^{[126]}$ providing iso-branched precursors further utilized by FA synthase enzymes, subsequently by the elongation enzymes Elo-5 and Elo-6, which specifically only elongate BCFAs ${ }^{[105]}$.

A BLASTp search for Bkd and for Elo-5 proteins in the Heterorhabditis genus showed no matches, meaning that Heterorhabditis is most likely not able to produce its own BCFAs. This further strengthen the hypothesis that BCFAs from their bacterial symbiont are essential.

The $P$. laumondii wild type most frequently produced FAs are BCFAs, especially iso15:0 and iso17:0 (Figure 16 and Table 4). These two BCFA are also postulated to be essential for the postembryonal development in $C$. elegans ${ }^{[105]}$. Elo-5 elongates specifically iso13:0 into iso15:0 and Elo-6 elongates specifically iso15:0 into iso17:0[127]. It was described that in $C$. elegans, the elo-5 knock down strain was unable to produce iso15:0 and iso17:0. As a result, the mutant was arrested in the L1 stage ${ }^{[105]}$, which is equivalent to the Heterorhabditis J1 stage (Figure 1). This strongly indicates, that BCFAs are essential for development from $\mathrm{J} 1$ to $\mathrm{J} 2$ and explains the defects in NG-IJs development when nematodes were grown on $\triangle b k d A B C$ mutant, as IJs are a J3 stage nematodes. Maybe without the BCFAs delivered from $P$. laumondii they can also not develop beyond J1 so no NG-IJ development is possible. 
BCFAs were found in $C$. elegans eggs ${ }^{[126]}$. The same experiment can be conducted with our nematode Heterorhabditis, by isolating eggs from gravid hermaphrodites. As recovery is still possible when nematodes are grown on a nematode bioassay on $\triangle b k d A B C$ strain (Figure 15), the recovered nematodes could be collected from the medium plate and the hermaphrodites can be determined morphologically using light microscopy. Their eggs can be isolated and analysed with GC-MS. The results should be compared with conducting the same experiments but extracting eggs from hermaphrodites grown on TTO1 wild type. If the eggs, which were bred on wild type bacteria do contain BCFAs and the eggs grown on $\triangle b k d A B C$ do not contain BCFAs the source of BCFAs inside the lipids of the egg membrane must originate from the symbiotic bacteria.

\subsection{New epoxy stilbene derivatives with unknown function}

In P. laumondii a FAD-dependent epoxidase catalyses the epoxidation of IPS into EPS [117]. EPS shows antibacterial and antifungal bioactivity ${ }^{[128]}$. Initially, EPS was identified in extracts of insects killed by Photorhabdus[128], indicating that it might play a role in the process of insect killing. An EPS adduct with proline named "prolbene" (Figure 38) has been found in an artificial insect simulating medium ${ }^{[86]}$.
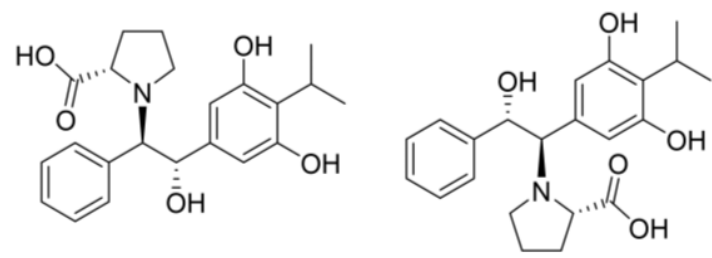

Figure 38. New introduced proline adducts named prolbene. There are two regiostereomers elucidated ${ }^{[86]}$.

EPS shows bioactivity against $B$. subtilis and $E$. coli whereas prolbene lost this acitivity ${ }^{[86]}$. Bioactivity loss can be assumed for $\mathbf{1}$ and $\mathbf{2}$ as well but need to be confirmed with the same bioactivity test as performed for prolbene ${ }^{[86]}$. A possible explanation might be a protection/detoxification mechanism of Photorhabdus.

In this study, three new adducts 1, 2 and $\mathbf{5}$ were detected (Figure 31, Figure 35). 1 consists of EPS bound to a $F$ and 2 contains the tetrapeptide LPLP. Feeding experiments with STO (Figure 25) created $\mathbf{3}$ and $\mathbf{4}$ with the same respective amino acids (Figure 26). Thus, only the epoxy group is required for the addition reaction, 
as STO lacks the iso-branch and the hydroxy groups of EPS. $\mathbf{5}$ is another adduct, first identified in TTO1 wild type infected insect extracts and not in the epoxidase deletion mutant, indicating a similar addition reaction with the epoxy group (Figure 33). Feeding deuterated CA showed integration of two CA derived compounds for 5 (Figure 34). Therefore, a dimer instead of an amino acid adduct is suggested for 5 (Figure 35).

It has been shown that EPS does not directly kill the insect, as the injection of purified EPS was unable to kill it ${ }^{[129]}$. The insect haemolymph is enriched by many free amino acids ${ }^{[129]}$. The reaction of EPS with these free amino acids is plausible. Insects harbour proline-rich antimicrobial peptides to kill bacteria by inhibiting bacterial protein translation ${ }^{[130]}$. Maybe a function of EPS is to react with the free circulating amino acids, avoiding biosynthesis of these proilne-rich peptides as a survival strategy.

For protection, epoxide hydrolases cleave the ring open to form a diol. The first epoxide hydrolase was found membrane bound in mammals to control potentially cytotoxic epoxides ${ }^{[131]}$. Also in insects epoxide hydrolases were found among others in Manduca sexta and in Galleria mellonella with the function of initiating metamorphosis by juvenile hormone degradation ${ }^{[132-134]}$. $P$. laumondii is capable to inactivate the insect epoxide hydrolase ${ }^{[103]}$, which might have the function to protect EPS from being degraded.

Extracts of insects killed by $P$ laumondii were analysed to look for similar adducts to 1 and 2 (Figure 31). The dimer 5 was detected (Figure 33). A recent study showed the formation of stilbene dimers in Photorhabdus (Figure 39) with high antibiotic activity against Gram-positive bacteria ${ }^{[135,136]}$. We expect 5 to be a similar dimer (Figure 35) as feeding isotope labelled CA showed an incorporation of two molecules in 5 (Figure 33). To further confirm these suggestions, comprehensive structure elucidation with NMR techniques need to be performed. 

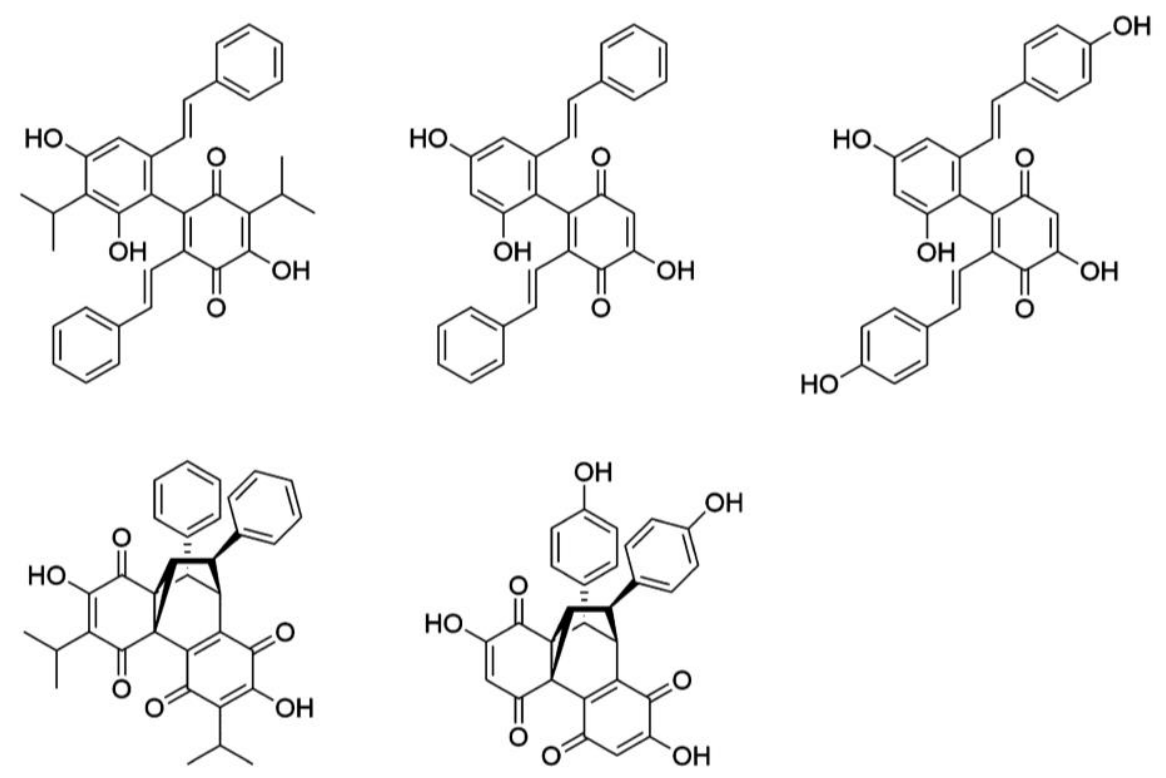

Figure 39. Dimeric stilbenes found in another study ${ }^{[136]}$.

Stilbene dimers are also present in plants, where dimerization is catalysed by peroxidases ${ }^{[137,138]}$. In Photorhabdus, an orphan bacterial cupin enzyme Plu1886 is suggested to assist the reaction of the stilbene dimers ${ }^{[135]}$. The encoding gene plu1886 is located downstream to the $b k d A B C$ operon (plu1883-1885). A catalytic role of Plu1886 in the formation of 5 is also possible. To clarify this, a $\Delta$ plu1886 deletion strain can be created and checked for the presence or absence $\mathbf{5}$. In case of missing $\mathbf{5}$ would give additional evidence of the dimeric character. However, only NMR analysis of the purified compound would elucidate the structure of 5 .

The biological function of $\mathbf{5}$ might be active against competing organisms like the published dimers shown in Figure 39. When the dimeric structure can be verified a bioactivity test towards different bacteria species with the purified 5 can be performed, to finally clarify the function of $\mathbf{5}$. If $\mathbf{5}$ is bioactive against bacteria but not against human cell lines, it has a potential to become a new antibiotic. 


\section{Conclusion}

The nematode bioassay is a great tool to screen for potential food signals involved in different stages of the nematode life cycle. In this work, a closer look into the biosynthesis could elucidate that not IPS but another CA derived SM must be a recovery inducing food signal. Two CA derived SMs, 2,5-dihydrostilbene and lumiquinone, were suggested as potential food signals but to further confirm their importance studies by adding these SMs into the nematode bioassay in combination with IPS deficient strains are crucial.

However, it is likely that several food signals are required for nematode development support and not only a CA derived one, indicated by the reduced but not diminished recovery and NG-IJ development when grown on deletion strains. It might be possible that other, CA unrelated SMs are also involved in supporting nematode development. One way to find this out would be to screen deletion strains similar to the experiments performed in this study. Another possibility would be activating one SM in a SM free background strain. In recent study the authors successfully created single SM production in $\Delta h f q$ strains by exchanging native promoter to an inducible PBAD promoter ${ }^{[139]}$. However, such a screening of only one SM at a time would take a long time and is inefficient. Especially because potential synergetic effects could be overlooked that way. Thus, a method is required which makes it possible to look at all SMs at the same time.

Another problem is that in this study most of the experiments were conducted in artificial medium. The EPS dimer found in the insect extract shows a great example on how in the natural environment inside the insect carcass other derivatives might be built. The nematode bioassay roughly mimics the macromolecular composition of the haemolymph of the insect like fat and sugar. However small molecules like hormones for instance are not included but could play an important role in the nematode life cycle and/or the bacterial metabolism. Maybe the stilbenes, or other SMs for that matter, interact with compounds of the insect, which are not included in the nematode bioassay. Maybe the bacteria trigger other SMs production inside the insect. Ideally, there would be a way to capture the SM production of Photorhabdus in their natural environment, inside the gut of the nematode and in the haemocoel of the insect. 
One way to achieve this might be by mass spectrometry imaging (MSI) especially coupled with matrix-assisted laser desorption/ionization (MALDI). MALDI-MSI can be seen as a molecular microscope providing insights of chemical communication between host and microbe ${ }^{[140]}$. Small slices of bacteria containing nematodes or insect tissue can be shock frozen and screened point per point with the laser of the MALDI resulting in ionizing produced compounds and measured with MS. On this way, not only the known SMs can be interpreted to their respective function much easier but also new SMs can be elucidated., which would never be produced in artificial cultivation conditions.

Findings of this study can already optimize the production of IJs in the fermenters to use them as biocontrol agents. A fundamental finding of this study is that bacterial BCFAs are an essential food signal for NG-IJ development. Such BCFAs can be added to the medium to see whether NG-IJ yield improve in the fermenters as well. The same can be done when it is cleared which SMs are also involved as food signals. 


\section{References}

[1] F. Bourgaud, A. Gravot, S. Milesi, E. Gontier, Plant Science 2001, 161, 839.

[2] J. Davies, The Journal of antibiotics 2013, 66, 361.

[3] A. Fleming, British journal of experimental pathology 1929, 10, 226.

[4] A. L. Demain, Applied Microbiology and Biotechnology 1999, 52, 455.

[5] L. J. Shallcross, D. S. C. Davies, The British journal of general practice : the journal of the Royal College of General Practitioners 2014, 64, 604.

[6] P. J. Dennesen, M. J. Bonten, R. A. Weinstein, Annals of medicine 1998, 30, 176.

[7] J. Fernández, J. Acevedo, M. Castro, O. Garcia, C. R. de Lope, D. Roca, M. Pavesi, E. Sola, L. Moreira, A. Silva et al., Hepatology (Baltimore, Md.) 2012 , $55,1551$.

[8] D. Bowen, T. A. Rocheleau, M. Blackburn, O. Andreev, E. Golubeva, R. Bhartia, R. H. ffrench-Constant, Science (New York, N.Y.) 1998, 280, 2129.

[9] R. L. Metcalf, Pestic. Sci. 1989, 26, 333.

[10] I. Mahmood, S. R. Imadi, K. Shazadi, A. Gul, K. R. Hakeem in Plant, soil and microbes, / Khalid Rehman Hakeem, Mohd Sayeed Akhtar, editors ; Volume 1 (Eds.: K. R. Hakeem, M. S. Akhtar), Springer, Cham, 2016, pp. 253269.

[11] T. H. Askary in Sustainable Agriculture Reviews, Vol. 3 (Ed.: E. Lichtfouse), Springer Science+Business Media B.V, Dordrecht, 2010, pp. 347-378.

[12] I. Ullah, E.-K. Jang, M.-S. Kim, J.-H. Shin, G.-S. Park, A. R. Khan, S.-J. Hong, B.-K. Jung, J. Choi, Y. Park et al., Toxins 2014, 6, 2024.

[13] T. A. Ciche, S. B. Bintrim, A. R. Horswill, J. C. Ensign, Journal of bacteriology 2001, 183, 3117.

[14] S. A. Joyce, A. O. Brachmann, I. Glazer, L. Lango, G. Schwär, D. J. Clarke, H. B. Bode, Angewandte Chemie (International ed. in English) 2008, 47, 1942.

[15] L. Lango, D. J. Clarke, Molecular microbiology 2010, 77, 1394.

[16] I. Eleftherianos, S. Boundy, S. A. Joyce, S. Aslam, J. W. Marshall, R. J. Cox, T. J. Simpson, D. J. Clarke, R. H. ffrench-Constant, S. E. Reynolds, Proceedings of the National Academy of Sciences of the United States of America 2007, 104, 2419. 
[17] K. Hu, J. M. Webster, FEMS microbiology letters 2000, 189, 219.

[18] S. Forst, B. Dowds, N. Boemare, E. Stackebrandt, Annual review of microbiology 1997, 51, 47.

[19] T. A. Ciche, J. C. Ensign, Applied and environmental microbiology 2003, 69, 1890.

[20] S.-A. Johnigk, R.-U. Ehlers, Nematol 1999, 1, 251.

[21] R. Han, R. U. Ehlers, Journal of invertebrate pathology 2000, 75, 55.

[22] R. J. Akhurst, Experimental Parasitology 1983, 55, 258.

[23] M. Fischer-Le Saux, H. Mauléon, P. Constant, B. Brunel, N. Boemare, Applied and environmental microbiology 1998, 64, 4246.

[24] A. R. Dillman, M. Macchietto, C. F. Porter, A. Rogers, B. Williams, I. Antoshechkin, M.-M. Lee, Z. Goodwin, X. Lu, E. E. Lewis et al., Genome biology 2015, 16, 200.

[25] S. Forst, K. Nealson, Microbiological Reviews 1996, 60, 21.

[26] N. SIMÕES, M. Mota, J. M. Neves, Nematol 1998, 44, 95.

[27] Y. BALIADV, T. YOSHIGA, E. KONDO, Jpn. J. Nematol. 2001, 31, 26.

[28] T. A. Ciche, K.-S. Kim, B. Kaufmann-Daszczuk, K. C. Q. Nguyen, D. H. Hall, Applied and environmental microbiology 2008, 74, 2275.

[29] S.-A. Johnigk, R.-U. Ehlers, Nematol 1999, 1, 717.

[30] F. Leulier, C. Parquet, S. Pili-Floury, J.-H. Ryu, M. Caroff, W.-J. Lee, D. Mengin-Lecreulx, B. Lemaitre, Nature immunology 2003, 4, 478.

[31] C. A. Brennan, K. V. Anderson, Annual review of immunology 2004, 22, 457.

[32] M. R. Kanost, H. Jiang, X.-Q. Yu, Immunological reviews 2004, 198, 97.

[33] M. Meister, C. Hetru, J. A. Hoffmann, Current topics in microbiology and immunology 2000, 248, 17.

[34] G. B. Dunphy, J. M. Webster, The Journal of Parasitology 1987, 73, 584.

[35] Peters, Gouge, Ehlers, Hague, Journal of invertebrate pathology 1997, 70, 161.

[36] I. Eleftherianos, P. J. Millichap, R. H. ffrench-Constant, S. E. Reynolds, Developmental and comparative immunology 2006, 30, 1099. 
[37] P. J. Daborn, N. Waterfield, M. A. Blight, R. H. ffrench-Constant, Journal of bacteriology 2001, 183, 5834.

[38] I. Eleftherianos, N. R. Waterfield, P. Bone, S. Boundy, R. H. ffrenchConstant, S. E. Reynolds, FEMS microbiology letters 2009, 293, 170.

[39] S. Yokoo, S. Tojo, N. Ishibashi, Journal of Insect Physiology 1992, 38, 915.

[40] J. M. Crawford, C. Portmann, X. Zhang, M. B. J. Roeffaers, J. Clardy, Proceedings of the National Academy of Sciences of the United States of America 2012, 109, 10821.

[41] D. Reimer, K. N. Cowles, A. Proschak, F. I. Nollmann, A. J. Dowling, M. Kaiser, R. Ffrench-Constant, H. Goodrich-Blair, H. B. Bode, Chembiochem : a European journal of chemical biology 2013, 14, 1991.

[42] D. Reimer, F. I. Nollmann, K. Schultz, M. Kaiser, H. B. Bode, Journal of natural products 2014, 77, 1976.

[43] Y.-M. Shi, H. B. Bode, Natural product reports 2018, 35, 309.

[44] A. Dudnik, L. Bigler, R. Dudler, Microbiological research 2013, 168, 73.

[45] M. L. Stein, P. Beck, M. Kaiser, R. Dudler, C. F. W. Becker, M. Groll, Proceedings of the National Academy of Sciences of the United States of America 2012, 109, 18367.

[46] D. Meusch, C. Gatsogiannis, R. G. Efremov, A. E. Lang, O. Hofnagel, I. R. Vetter, K. Aktories, S. Raunser, Nature 2014, 508, 61.

[47] D. Roderer, E. Schubert, O. Sitsel, S. Raunser, Nature communications 2019, 10, 5263.

[48] D. J. Bowen, T. A. Rocheleau, C. K. Grutzmacher, L. Meslet, M. Valens, D. Marble, A. Dowling, R. Ffrench-Constant, M. A. Blight, Microbiology (Reading, England) 2003, 149, 1581.

[49] C. Caldas, A. Cherqui, A. Pereira, N. SIMÕES, Applied and environmental microbiology 2002, 68, 1297.

[50] N. Waterfield, S. G. Kamita, B. D. Hammock, R. Ffrench-Constant, FEMS microbiology letters 2005, 245, 47.

[51] Q. Yang, J. Zhang, T. Li, S. Liu, P. Song, Z. Nangong, Q. Wang, Journal of invertebrate pathology 2017, 148. 
[52] Y. Li, X. Hu, X. Zhang, Z. Liu, X. Ding, L. Xia, S. Hu, FEMS microbiology letters 2014, 356, 23.

[53] M. C. Joshi, A. Sharma, S. Kant, A. Birah, G. P. Gupta, S. R. Khan, R. Bhatnagar, N. Banerjee, The Journal of biological chemistry 2008, 283, 28287.

[54] J. Banerjee, J. Singh, M. C. Joshi, S. Ghosh, N. Banerjee, Journal of bacteriology 2006, 188, 7957.

[55] R. J. Watson, S. A. Joyce, G. V. Spencer, D. J. Clarke, Molecular microbiology 2005, 56, 763.

[56] A. Proschak, Q. Zhou, T. Schöner, A. Thanwisai, D. Kresovic, A. Dowling, R. Ffrench-Constant, E. Proschak, H. B. Bode, Chembiochem : a European journal of chemical biology 2014, 15, 369.

[57] B. Gulcu, S. Hazir, H. K. Kaya, Journal of invertebrate pathology 2012, 110, 326.

[58] B. V. Mclnerney, W. C. Taylor, M. J. Lacey, R. J. Akhurst, R. P. Gregson, J. Nat. Prod. 1991, 54, 785.

[59] X. Yang, D. Qiu, H. Yang, Z. Liu, H. Zeng, J. Yuan, World J Microbiol Biotechnol 2011, 27, 523.

[60] S. W. Fuchs, F. Grundmann, M. Kurz, M. Kaiser, H. B. Bode, Chembiochem : a European journal of chemical biology 2014, 15.

[61] J. Li, G. Chen, J. M. Webster, Canadian journal of microbiology 1997, 43, 770.

[62] L. Zhao, R. M. Awori, M. Kaiser, J. Groß, T. Opatz, H. B. Bode, Journal of natural products 2019, 82, 3499.

[63] L. Sundar, F. N. Chang, Antimicrobial agents and chemotherapy 1992, 36, 2645.

[64] J. Li, G. Chen, H. Wu, J. M. Webster, Applied and environmental microbiology 1995, 61, 4329.

[65] Kaiji Hu, Jianxiong Li, John M. Webster, Nematology 1999, 1, 457.

[66] R.-U. Ehlers, R. C. Han, Nematol 1998, 44, 425.

[67] O. Strauch, R.-U. Ehlers, Applied Microbiology and Biotechnology 1998, 50, 369. 
[68] D. J. Bowen, J. C. Ensign, Applied and environmental microbiology 2001, 67, 4834.

[69] S. B. Bintrim, J. C. Ensign, Journal of bacteriology 1998, 180, 1261.

[70] M. Goetsch, H. Owen, B. Goldman, S. Forst, Journal of bacteriology 2006, 188, 2706.

[71] G. L. Challis, J. H. Naismith, Current opinion in structural biology 2004, 14, 748.

[72] C. Hertweck, Angewandte Chemie (International ed. in English) 2009, 48, 4688.

[73] J. Beld, E. C. Sonnenschein, C. R. Vickery, J. P. Noel, M. D. Burkart, Natural product reports 2014, 31, 61.

[74] R. H. Lambalot, A. M. Gehring, R. S. Flugel, P. Zuber, M. LaCelle, M. A. Marahiel, R. Reid, C. Khosla, C. T. Walsh 1996.

[75] A. O. Brachmann, S. A. Joyce, H. Jenke-Kodama, G. Schwär, D. J. Clarke, H. B. Bode, Chembiochem : a European journal of chemical biology 2007, 8, 1721.

[76] N. J. Tobias, A. K. Heinrich, H. Eresmann, P. R. Wright, N. Neubacher, R. Backofen, H. B. Bode, Environmental microbiology 2017, 19, 119.

[77] C. Rivière, A. D. Pawlus, J.-M. Mérillon, Natural product reports 2012, 29, 1317.

[78] W H Richardson, T M Schmidt, K H Nealson, Appl. Environ. Microbiol. 1988, 54, 1602.

[79] F. Lieutier, D. Sauvard, F. Brignolas, V. Picron, A. Yart, C. Bastien, C. JayAllemand, Forest Pathol 1996, 26, 145.

[80] T. Suga, S. Ohta, K. Munesada, N. Ide, M. Kurokawa, M. Shimizu, E. Ohta, Phytochemistry 1993, 33, 1395.

[81] V. L. Challinor, H. B. Bode, Annals of the New York Academy of Sciences 2015, 1354, 82.

[82] J. Peppers, A. S. Paller, T. Maeda-Chubachi, S. Wu, K. Robbins, K. Gallagher, J. E. Kraus, Journal of the American Academy of Dermatology 2019, 80, 89-98.e3. 
[83] J. S. Williams, M. Thomas, D. J. Clarke, Microbiology (Reading, England) 2005, 151, 2543.

[84] S. W. Fuchs, K. A. J. Bozhüyük, D. Kresovic, F. Grundmann, V. Dill, A. O. Brachmann, N. R. Waterfield, H. B. Bode, Angewandte Chemie (International ed. in English) 2013, 52, 4108.

[85] T. A. Schöner, D. Kresovic, H. B. Bode, Applied Microbiology and Biotechnology 2015, 99, 8323.

[86] Hyun Bong Park, Parthasarathy Sampathkumar, Corey E. Perez, Joon Ha Lee, Jeannie Tran, Jeffrey B. Bonanno, Elissa A. Hallem, Steven C. Almo, Jason M. Crawford, J. Biol. Chem. 2017, 292, 6680.

[87] R. Kontnik, J. M. Crawford, J. Clardy, ACS chemical biology 2010, 5, 659.

[88] K. Willecke, A. B. Pardee, The Journal of biological chemistry 1971, 246, 5264.

[89] G. F. Wang, T. Kuriki, K. L. Roy, T. Kaneda, European journal of biochemistry 1993, 213, 1091.

[90] J. D. Nickels, S. Chatterjee, B. Mostofian, C. B. Stanley, M. Ohl, P. Zolnierczuk, R. Schulz, D. A. A. Myles, R. F. Standaert, J. G. Elkins et al., The journal of physical chemistry letters 2017, 8, 4214.

[91] K. Zhu, D. O. Bayles, A. Xiong, R. K. Jayaswal, B. J. Wilkinson, Microbiology (Reading, England) 2005, 151, 615.

[92] V. McCully, G. Burns, J. R. Sokatch, Biochemical Journal 1986, 233, 737.

[93] D. F. Silbert, R. C. Ladenson, J. L. Honegger, Biochimica et Biophysica Acta (BBA) - Biomembranes 1973, 311, 349.

[94] M. Suutari, S. Laakso, Biochimica et Biophysica Acta (BBA) - Lipids and Lipid Metabolism 1992, 1126, 119.

[95] D. H. Yi, G. Sathiyanarayanan, H. M. Seo, J. H. Kim, S. K. Bhatia, Y. G. Kim, S. H. Park, J. Y. Jung, Y. K. Lee, Y. H. Yang, Bioprocess and biosystems engineering 2016, 39.

[96] L. Marchese, J. d. F. Nascimento, F. S. Damasceno, F. Bringaud, P. A. M. Michels, A. M. Silber, Pathogens (Basel, Switzerland) 2018, 7. 
[97] R. Max Wynn, J. R. Davie, J.-L. Song, J. L. Chuang, D. T. Chuang in Methods in Enzymology : Branched-Chain Amino Acids, Part B (Eds.: R. A. Harris, J. R. Sokatch), Academic Press, 2000, pp. 179-191.

[98] J. W. Hawes, Y. Zhao, k. M. Popov, y. shimomura, R. A. Harris in Methods in Enzymology : Branched-Chain Amino Acids, Part B (Eds.: R. A. Harris, J. R. Sokatch), Academic Press, 2000, pp. 200-207.

[99] J. L. Chuang, J. R. Davie, R. Max Wynn, D. T. Chuang in Methods in Enzymology : Branched-Chain Amino Acids, Part B (Eds.: R. A. Harris, J. R. Sokatch), Academic Press, 2000, pp. 192-200.

[100] A. O. Brachmann, D. Reimer, W. Lorenzen, E. Augusto Alonso, Y. Kopp, J. Piel, H. B. Bode, Angewandte Chemie (International ed. in English) 2012, 51, 12086.

[101] M. Debarbouille, R. Gardan, M. Arnaud, G. Rapoport, Journal of bacteriology 1999, 181, 2059.

[102] K. H. Choi, R. J. Heath, C. O. Rock, Journal of bacteriology 2000, 182, 365.

[103] F. I. Nollmann, A. K. Heinrich, A. O. Brachmann, C. Morisseau, K. Mukherjee, Á. M. Casanova-Torres, F. Strobl, D. Kleinhans, S. Kinski, K. Schultz et al., Chembiochem : a European journal of chemical biology 2015, 16, 766.

[104] A. O. Brachmann, S. Brameyer, D. Kresovic, I. Hitkova, Y. Kopp, C. Manske, K. Schubert, H. B. Bode, R. Heermann, Nature chemical biology 2013, 9, 573.

[105] M. Kniazeva, Q. T. Crawford, M. Seiber, C.-Y. Wang, M. Han, PLoS biology 2004, 2, E257.

[106] G. F. White, Science (Washington) 1927, 66.

[107] M. Fischer-Le Saux, V. Viallard, B. Brunel, P. Normand, N. E. Boemare, International journal of systematic bacteriology 1999, 49 Pt 4, 1645.

[108] S. Brameyer, R. Heermann, Current topics in microbiology and immunology 2017, 402, 103.

[109] C. Fu, W. P. Donovan, O. Shikapwashya-Hasser, X. Ye, R. H. Cole, PloS one 2014, 9, e115318. 
[110] H. B. Bode, M. W. Ring, G. Schwär, R. M. Kroppenstedt, D. Kaiser, R. Müller, Journal of bacteriology 2006, 188, 6524.

[111] S. E. Stein, J Am Soc Mass Spectrom 1999, 10, 770.

[112] A. Sündermann, L. F. Eggers, D. Schwudke in Encyclopedia of Lipidomics (Ed.: M. R. Wenk), Springer Netherlands; Imprint: Springer, Dordrecht, 2020, pp. 1-4.

[113] C. A. Easom, D. J. Clarke, BMC microbiology 2008, 8, 168.

[114] Jens Aumann, Ralf-Udo Ehlers, Nematology 2001, 3, 849.

[115] Alois Bräuer, Qiuqin Zhou, Gina L. C. Grammbitter, Maximilian Schmalhofer, Michael Rühl, Ville R. I. Kaila, Helge B. Bode, Michael Groll, Nat. Chem. 2020, 12, 755.

[116] T. Mori, T. Awakawa, K. Shimomura, Y. Saito, D. Yang, H. Morita, I. Abe, Cell chemical biology 2016, 23, 1468.

[117] H. B. Park, J. M. Crawford, Journal of natural products 2015, 78, 1437.

[118] A. Berg, A. de Kok, Biological chemistry 1997, 378, 617.

[119] A. de Kok, A. F. Hengeveld, A. Martin, A. H. Westphal, Biochimica et Biophysica Acta (BBA) - Protein Structure and Molecular Enzymology 1998, 1385, 353.

[120] H. B. Bode, M. W. Ring, G. Schwär, M. O. Altmeyer, C. Kegler, I. R. Jose, M. Singer, R. Müller, Chembiochem : a European journal of chemical biology 2009, 10, 128.

[121] H Oku, T Kaneda, J. Biol. Chem. 1988, 263, 18386.

[122] F. Kunst, N. Ogasawara, I. Moszer, A. M. Albertini, G. Alloni, V. Azevedo, M. G. Bertero, P. Bessières, A. Bolotin, S. Borchert et al., Nature 1997, 390, 249.

[123] U. Mäder, S. Hennig, M. Hecker, G. Homuth, Journal of bacteriology 2004, 186, 2240.

[124] M. Kniazeva, H. Shen, T. Euler, C. Wang, M. Han, Genes \& development 2012, 26, 554.

[125] T. Kaneda, E. J. Smith, Canadian journal of microbiology 1980, 26, 893.

[126] F. Jia, M. Cui, M. T. Than, M. Han, The Journal of biological chemistry 2016, 291, 2967. 
[127] M. Kniazeva, T. Euler, M. Han, Genes \& development 2008, 22, 2102.

[128] K. Hu, J. Li, B. Li, J. M. Webster, G. Chen, Bioorganic \& medicinal chemistry 2006, 14, 4677.

[129] J. M. Crawford, R. Kontnik, J. Clardy, Current biology : CB 2010, 20, 69.

[130] A. Krizsan, D. Volke, S. Weinert, N. Sträter, D. Knappe, R. Hoffmann, Angewandte Chemie (International ed. in English) 2014, 53, 12236.

[131] F. Oesch, Xenobiotica; the fate of foreign compounds in biological systems 1973, 3, 305.

[132] J. Casas, L. G. Harshman, B. D. Hammock, Insect Biochemistry 1991, 21, 17.

[133] H. Wojtasek, G. D. Prestwich, Biochemical and biophysical research communications 1996, 220, 323.

[134] J. R. Wiśniewski, M. Rudnicka, M. Kochman, Insect Biochemistry 1986, 16, 843.

[135] H. B. Park, T. N. Goddard, J. Oh, J. Patel, Z. Wei, C. E. Perez, B. Q. Mercado, R. Wang, T. P. Wyche, G. Piizzi et al., Angewandte Chemie (International ed. in English) 2020, 59, 7871.

[136] T. N. Goddard, J. Patel, H. B. Park, J. M. Crawford, Biochemistry 2020, 59, 1966.

[137] A.-C. Breuil, M. Adrian, N. Pirio, P. Meunier, R. Bessis, P. Jeandet, Tetrahedron Letters 1998, 39, 537.

[138] Philippe Jeandet, Bertrand Delaunois, Alexandra Conreux, David Donnez, Vitale Nuzzo, Sylvain Cordelier, Christophe Clément, Eric Courot, BioFactors 2010, 36, 331.

[139] E. Bode, A. K. Heinrich, M. Hirschmann, D. Abebew, Y.-N. Shi, T. D. Vo, F. Wesche, Y.-M. Shi, P. Grün, S. Simonyi et al., Angew. Chem. 2019, 131, 19133.

[140] R. M. Caprioli, Journal of the American Society for Mass Spectrometry 2015, 26, 850. 